\title{
Physical activity and oxidative stress in the elderly
}

Citation for published version (APA):

Meijer, E. P. (2001). Physical activity and oxidative stress in the elderly. [Doctoral Thesis, Maastricht University]. Datawyse / Universitaire Pers Maastricht. https://doi.org/10.26481/dis.20010705em

Document status and date:

Published: 01/01/2001

DOI:

10.26481/dis.20010705em

Document Version:

Publisher's PDF, also known as Version of record

\section{Please check the document version of this publication:}

- A submitted manuscript is the version of the article upon submission and before peer-review. There can be important differences between the submitted version and the official published version of record.

People interested in the research are advised to contact the author for the final version of the publication, or visit the DOI to the publisher's website.

- The final author version and the galley proof are versions of the publication after peer review.

- The final published version features the final layout of the paper including the volume, issue and page numbers.

Link to publication

\footnotetext{
General rights rights.

- You may freely distribute the URL identifying the publication in the public portal. please follow below link for the End User Agreement:

www.umlib.nl/taverne-license

Take down policy

If you believe that this document breaches copyright please contact us at:

repository@maastrichtuniversity.nl

providing details and we will investigate your claim.
}

Copyright and moral rights for the publications made accessible in the public portal are retained by the authors and/or other copyright owners and it is a condition of accessing publications that users recognise and abide by the legal requirements associated with these

- Users may download and print one copy of any publication from the public portal for the purpose of private study or research.

- You may not further distribute the material or use it for any profit-making activity or commercial gain

If the publication is distributed under the terms of Article $25 \mathrm{fa}$ of the Dutch Copyright Act, indicated by the "Taverne" license above, 


\section{Physical activity and oxidative stress in the elderly}

thesis 


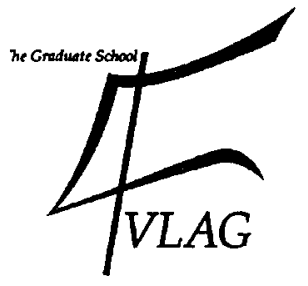

niutim
The study presented in this thesis was performed at the Nutrition and Toxicology Research Institute Maastricht (NUTRIM), which participates in the Graduate School VLAG (Food Technology, Agrobiotechnology, Nutrition and Health Sciences) accredited by the Royal Netherlands Academy of Arts and Sciences.

(c) Erwin Peke Meijer, Maastricht 2001

Physical activity and oxidative stress in the elderly Thesis Maastricht University - with a summary in Dutch ISBN: 90-5278-306-3

Cover design: Ineke Brummer

Lay-out: $\quad$ Erwin Meijer

Production: Datawyse, Universitaire Pers Maastricht 


\title{
Physical activity and oxidative stress in the elderly
}

\author{
PROEFSCHRIFT
}

ter verkrijging van de graad van doctor

aan de Universiteit Maastricht, op gezag van de Rector Magnificus, Prof.dr. A.C. Nieuwenhuijzen Kruseman, volgens het besluit van het College van Decanen, in het openbaar te verdedigen

op donderdag 5 Juli 2001 om 14.00 uur

door

Erwin Peke Meijer

geboren op 29 mei 1974 te Hoorn 


\section{Promotores}

Prof.dr. K.R. Westerterp

Prof.dr. A. Bast

\section{Beoordelingscommissie}

Prof.dr. H. Kuipers (voorzitter)

Prof.dr. J.C.S. Kleinjans

Prof.dr. J.F. Koster (Erasmus Universiteit Rotterdam)

Prof.dr. E. Ravussin (Pennington Biomedical Research Center, LA)

Prof.dr.ir. W.H.M. Saris

Financial support by the Netherlands Heart Foundation for the publication of this thesis is gratefully acknowledged.

Additional support granted by NOC*NSF Breedtesport, Nutricia Nederland B.V. and Philips Research is gratefully appreciated. 


\section{Contents}

\section{Chapter 1}

Introduction

Chapter 2

The effect of exercise training on total daily physical activity in elderly humans

Chapter 3

Effect of exercise training on physical activity and substrate utilization in the elderly

\section{Chapter 4}

Physical inactivity as a determinant of the physical activity level in the elderly

Chapter 5

Exercise-induced oxidative stress in older adults as measured by antipyrine oxidation

Chapter 6

Exercise training and oxidative stress in the elderly as measured by antipyrine hydroxylation products

\section{Chapter 7}

Antioxidant supplementation and exercise-induced oxidative stress in the 60-year-old as measured by antipyrine hydroxylates

\section{Chapter 8}

Exercise-induced oxidative stress in older adults as a function of the habitual activity level

Chapter 9

General discussion

Summary

Samenvatting

List of abbreviations

Dankwoord

List of publications 

Chapter 1

\section{Introduction}


In western societies aging of the population occurs rapidly. In $1999,10 \%, 7 \%$ and $6 \%$ of the Dutch population consisted of people in the age categories 55-64 y, 65-75 y and $75+y$, respectively. It has been estimated that in 2030 , the percentages for those age categories will increase to $13 \%, 11 \%$ and $10 \%$, respectively. Thus, in $203034 \%$ of the Dutch population will be older than $55 \mathrm{y}$, which is equivalent to approximately 6.100.000 people (CBS, 2000).

An increase in the age of the population also means an increase in the prevalence of age-related chronic diseases such as obesity, type 2 diabetes and coronary heart disease. Aging is associated with several changes including an increase in body weight and central adipose tissue, a decrease in muscle mass, bone density and strength. Additionally, aging is generally known to be associated with a decline in the daily physical activity level (15). Regular physical activity is thought to be an important determinant of health and an active lifestyle might delay the age-associated decline in body function and thus enhance the quality of life of older adults (34). Additionally, most prevalent chronic diseases, such as coronary heart disease, type 2 diabetes and obesity, have an association with physical inactivity. Higher levels of physical activity have been related with a lower cardiovascular disease profile and lower overall mortality (34).

An important modulator of the physical activity level might be the level of physical fitness (maximal oxygen uptake: $\mathrm{VO}_{2 \max }$ ) (19). Maximal oxygen uptake, an index of functional capacity of the cardiovascular system, decreases with advancing age. The rate of decline in $\mathrm{VO}_{2 \max }$ ranges from 10 to $13 \%$ per decade in males and from 7 to $11 \%$ per decade in females (45). This reduction results in a decrease in physiological functional capacity that would contribute to a loss of independence, increased incidence of disability, and reduced quality of life with age. Exercise training, however, improves $\mathrm{VO}_{2 \max }$ in elderly to the same relative extent as in younger adults (26). The degree to which $\mathrm{VO}_{2 \max }$ improves in older people with training is quite variable, with average improvements, depending on training intensity, ranging from 5 to $28 \%$. Although training cannot completely prevent the age-related reduction in $\mathrm{VO}_{2 \max }$, it might modulate the age-associated change in $\mathrm{VO}_{2 \max }$ (45). In addition, even small improvements in $\mathrm{VO}_{2 \max }$ are associated with a significantly lowered mortality $(6,37)$. Therefore, exercise programs for the elderly are promoted to improve or maintain maximal oxygen uptake.

On the other hand, however, there is increasing evidence indicating that exercise, especially when performed strenuously, is associated with an increased production of reactive oxygen species (ROS) such as superoxide, hydroxyl radical and singlet $\mathrm{O}_{2}$ (41). In skeletal muscle, mitochondria consume most of the oxygen and serve as the primary source of metabolic energy. This process, mitochondrial oxidative phosphorylation, couples respiration with generation of high-energy ATP. About 2-5\% of the oxygen consumed in the respiratory chain at rest has been estimated to escape as superoxide $(9,21)$. ROS generation may increase during exercise as a result of a higher mitochondrial oxygen consumption and electron transport flux (41). A state of 
increased levels of intracellular ROS production is referred to as oxidative stress. It has been shown that aging is associated with an increased susceptibility to oxidative stress (25). The relationship between oxidative stress and physical activity, however, is still poorly understood, particularly in advanced age, since there is a substantial lack of data regarding the effects of exercise and training on oxidative stress in the elderly. One of the reasons for the lack of data is the methodological aspect concerning the assessment of oxidative stress and the physical activity level.

\section{Energy expenditure and physical activity}

In general, total energy expenditure or average daily metabolic rate (ADMR) decreases with advancing age (15). The major components of ADMR are resting or basal metabolic rate (RMR, BMR), diet induced energy expenditure (DEE) and physical activity associated energy expenditure (AEE). In adults, BMR, DEE and AEE account for approximately $65-70 \%, 10-15 \%$ and $20-30 \%$ of ADMR, respectively (36). $\mathrm{AEE}$ is the most variable component of ADMR. AEE has been used as an estimate for the daily physical activity level. There is, however, no consensus on the way to normalize AEE for differences in body size (35). Therefore, in order to compare activity levels across individuals, a frequently used method to quantify physical activity is by expressing ADMR as a multiple of RMR or BMR (physical activity level, $\mathrm{PAL}=\mathrm{ADMR} / \mathrm{BMR}$ ). This method assumes that the variation in ADMR is due to body size and physical activity (16). Adjusting ADMR for RMR or BMR implies the use of metabolic body mass as the denominator or body mass to the exponent 0.66 to 0.75. In the general population PAL ranges between 1.2 and 2.2, where 2.2 represents a physically active lifestyle (5).

\section{Assessment of physical activity}

There is a large number of techniques for the assessment of physical activity, which can be grouped into five general categories: behavioral observation, questionnaires (including diaries, recall questionnaires and interviews), physiological markers like heart rate, calorimetry, and motion sensors (48). Currently, calorimetry, more specifically the doubly labeled water method, is generally accepted as the gold standard for physical activity assessment in free-living subjects. This technique, first conceived by Lifson et al. (30) in 1955 and later adapted for use in humans by Schoeller and van Santen (38), is based on the principle that the $\mathrm{O}_{2}$ of expired $\mathrm{CO}_{2}$ is in isotopic equilibrium with the $\mathrm{O}_{2}$ of body water. When a subject is loaded with ${ }^{2} \mathrm{H}_{2}{ }^{18} \mathrm{O}$, body water is enriched with the stable isotopes ${ }^{2} \mathrm{H}$ and ${ }^{18} \mathrm{O}$. The subsequent decrease in ${ }^{18} \mathrm{O}$ in the body water is a measure for ${ }^{2} \mathrm{H}_{2} \mathrm{O}$ plus $\mathrm{CO}_{2}$ outputs and the decrease in ${ }^{2} \mathrm{H}$ is a measure for $\mathrm{H}_{2} \mathrm{O}$ output alone. When the disappearance rate of both isotopes from the body fluid (e.g. blood, urine, saliva) is measured, the difference between the two disappearance rates is a measure for $\mathrm{CO}_{2}$ production (40). To convert the measured $\mathrm{CO}_{2}$ production to energy expenditure, the energy equivalent of $\mathrm{CO}_{2}$ is 
needed. Often, an assumed respiratory exchange ratio (RER) of 0.85 is used. Since in situations of energy balance, the food quotient (FQ) equals RER, the use of the FQ is more accurate for calculation of ADMR (51).

The doubly labeled water method, however, cannot be applied at population level, because ${ }^{18} \mathrm{O}$ is expensive and not readily available (39). Furthermore, this method can only be used to quantify the average level of physical activity over intervals of 1-3 weeks and does not provide information about the intensity, frequency, or duration of the physical activity. Assessment of physical activity patterns in subjects by using body-fixed accelerometers for movement registration is an appropriate alternative (8). Tri-axial accelerometers allow assessment of physical activity in large populations over periods that are long enough to be representative for normal daily life and with minimal discomfort for the subjects (7). Tri-axial accelerometers showed a close correlation with the doubly labeled water assessed PAL (7), as well as with ADMR adjusted for BMR (49). The standard error of estimate of ADMR in the latter study was $0.9 \mathrm{MJ} \cdot \mathrm{d}^{-1}$. Thus, tri-axial accelerometers are a reliable tool to assess the physical activity level in free-living subjects.

\section{Effects of exercise training on physical activity}

Westerterp (47) reviewed five well-controlled studies on the effect of imposed exercise training on ADMR and its components as measured with the doubly labeled water method (Table 1). One study was in children, three in young adults and one in the elderly. The energy expenditure associated with non-training physical activity was calculated from the difference between ADMR and RMR after adjusting for the thermic response to feeding and the energy cost of the exercise training. In children and young adults the size of the change in energy expenditure associated with physical activity was on average twice the energy cost of the exercise training intervention program. Exercise training did not affect non-training physical activity in the young adults. However, in elderly subjects (56-78 y) it was found that an 8-wk endurance training program did not change ADMR (18). Non-training AEE reduced from $2.39 \pm 1.62 \mathrm{MJ} \cdot \mathrm{d}^{-1}$ before the intervention to $1.42 \pm 1.89 \mathrm{MJ} \cdot \mathrm{d}^{-1}$ during the last 10 days of the training program. Here, it was suggested that the intensity of the training program $\left(3 \mathrm{~h} \cdot \mathrm{wk}^{-1}\right.$ at $85 \% \mathrm{VO}_{2 \max }$ ) was too high, and thus fatigued the elderly subjects during the remainder of the day, which resulted in a decline in non-training physical activity (18). However, further research is needed to examine if an exercise training program of moderate intensity can prevent the compensatory decline in non-training physical activity, and possibly increase the physical activity level in elderly humans. 
Table 1. Exercise training intervention studies measuring the effect of training on ADMR.

\begin{tabular}{llccc}
\hline reference & intervention & $\begin{array}{c}\text { subjects } \\
\text { (women/men) }\end{array}$ & $\begin{array}{c}\text { age } \\
(\mathrm{y})\end{array}$ & $\begin{array}{c}\Delta \text { ADMR } \\
(\%)\end{array}$ \\
\hline 4 & 4-wk five lh cycling sessions & $0 / 10$ & $10-11$ & $12 \pm 6$ \\
3 & 9-wk jogging up to $1 \mathrm{~h} \cdot \mathrm{d}^{-1}$ & $2 / 3$ & $24-33$ & $27 \pm 17$ \\
46 & 18-wk two weight training sessions & $0 / 12$ & $23-41$ & $9 \pm 8$ \\
50 & 40-wk jogging up to 50 $\mathrm{km} \cdot \mathrm{wk}^{-1}$ & $5 / 8$ & $28-41$ & $21 \pm 9$ \\
18 & 8-wk three cycling sessions & $5 / 6$ & $56-78$ & 3 \\
\hline
\end{tabular}

\section{Oxidative stress and aging}

Aging, an inevitable biological process, is characterized by a general decline in physiological function that leads to morbidity and mortality. In 1956, Harman (22) suggested that free radicals, any atomic or molecular species containing one or more unpaired electrons that are capable of independent existence (21), produced during aerobic respiration cause cumulative oxidative damage, resulting in aging and death. The free radical theory of aging is based on the fact that reactive oxygen species (ROS) are produced as a normal by-product of aerobic life. It has been estimated that under normal resting conditions $2-5 \%$ of the total electron flux leaks to form primary short-lived ROS, such as superoxide, hydrogen peroxide and hydroxyl radical (9). At least three lines of evidence support the theory. Firstly, aging has been shown to correlate with production of ROS and adequacy of cellular antioxidant defense systems $(42,52)$. Secondly, an increasing number of age-related and degenerative diseases have been found to have an etiological component associated with ROS generation (2). Thirdly, strategies that are effective to reduce oxidative stress are also found to affect aging. Clear examples are restriction of caloric intake and experimental elevation of enzymatic antioxidant defenses in rodents, which lowers steady-state levels of oxidative stress (44).

\section{Exercise-induced oxidative stress}

Regular physical activity and exercise are thought to be important determinants in the maintenance of optimal health and prevention of chronic disease (34). On the other hand, physical exercise markedly increases oxygen consumption, particularly in skeletal muscle (41). Increased oxygen consumption further increases the leaking of ROS, such as superoxide, hydroxyl radical and singlet $\mathrm{O}_{2}$, as products of oxidative phosphorylation, from the mitochondrial electron transport chain (21). The imbalance, in favor of the free radicals, between the increased ROS generation and the scavenging capacity is termed oxidative stress. Koren et al. (27) showed that production of ROS was significantly increased during maximal contraction of frog skeletal muscle by using electron spin resonance (ESR) spectroscopy. Recently, Ashton et al. (1) observed that exhaustive exercise significantly increased the normalized ESR signal 
intensity in human plasma. Although ESR is the most specific and direct method of measuring free radicals, available spin-traps are highly toxic and cannot be administered to humans. Furthermore, it has been shown that spin-traps of superoxide are still quite unstable and often decompose rapidly. Therefore, none of the spin-traps in use at present time seems to be ideal (24).

\section{Assessment of oxidative stress}

Monitoring the amount of oxidative stress is a major problem in free radical research (20). Most human studies investigating exercise-induced oxidative stress have relied on endogenous indices of free radical damage, such as plasma malondialdehyde (MDA) levels, conjugated dienes, and serum lipid peroxides. These studies showed an increase in post-exercise lipid peroxidation. The major disadvantage of using endogenous markers in vivo is the possibility that they are not only formed by free radicals but also by other pathways, for example, MDA could be formed by the enzymatic breakdown of prostaglandin endoperoxides (20). The studies described in this thesis used an exogenous marker, antipyrine (2,3-dimethyl-1-phenyl-3-pyrazolin5-one) for assessing oxidative stress. Antipyrine was first synthesized in Germany in 1884 and rapidly gained wide use due to its antipyretic and analgesic properties. The metabolic pathway of antipyrine has been extensively documented $(10,14,43)$. Antipyrine is metabolized in the hepatic smooth endoplasmic reticulum by at least three reactions (two hydroxylations and a $\mathrm{N}$-demethylation), resulting in the formation of four primary metabolites that are excreted in the urine, partly as conjugates: 4hydroxyantipyrine, norantipyrine, 3-hydroxymethyl-antipyrine and 3-carboxyantipyrine (Fig. 1). The half-life time of antipyrine is about $12 \mathrm{~h} \mathrm{(43).} \mathrm{The} \mathrm{properties}$ of antipyrine make it a very suitable marker for measuring oxidative stress in vivo. After oral ingestion antipyrine is completely absorbed and uniformly distributed in the total body water after approximately $1 \mathrm{~h}(14,43)$. Additionally, the pharmacokinetics of antipyrine is independent of blood flow to the liver (14), which is an advantage in clinical studies where blood flow is altered e.g. during exercise experiments. Moreover, the reaction rate constant of antipyrine with hydroxyl radicals is in the order of $10^{10} \mathrm{l} \cdot \mathrm{mol}^{-1} \cdot \mathrm{s}^{-1}(17)$. Exposure of an antipyrine solution in water to ${ }^{60} \mathrm{Co} \gamma-$ radiation leads to the formation of three phenolic antipyrine derivatives: parahydroxyantipyrine (p-APOH), ortho-hydroxyantipyrine (o-APOH) and metahydroxyantipyrine (m-APOH). The last two metabolites are not endogenously formed (Fig. 1) (12). Additionally, the free radical reaction products of antipyrine could be detected in human plasma that was spiked with a $1 \mathrm{mM}$ radiated antipyrine solution (13). A recently performed study in patients with claudicatio intermittens showed that 5-min exercise resulted in a significant increase in the plasma concentration of $p$ APOH and $0-\mathrm{APOH}$ (11). Therefore, the ratio of the hydroxylated products of antipyrine to the plasma concentration of antipyrine reflects the oxidative stress in vivo. Although elderly may be more susceptible to oxidative stress, the few studies that examined the exercise-induced oxidative stress in elderly subjects have only relied on 
endogenous markers $(28,31)$. Therefore, one might speculate if a submaximal bout of exercise would result in an increased oxidative stress in elderly humans.

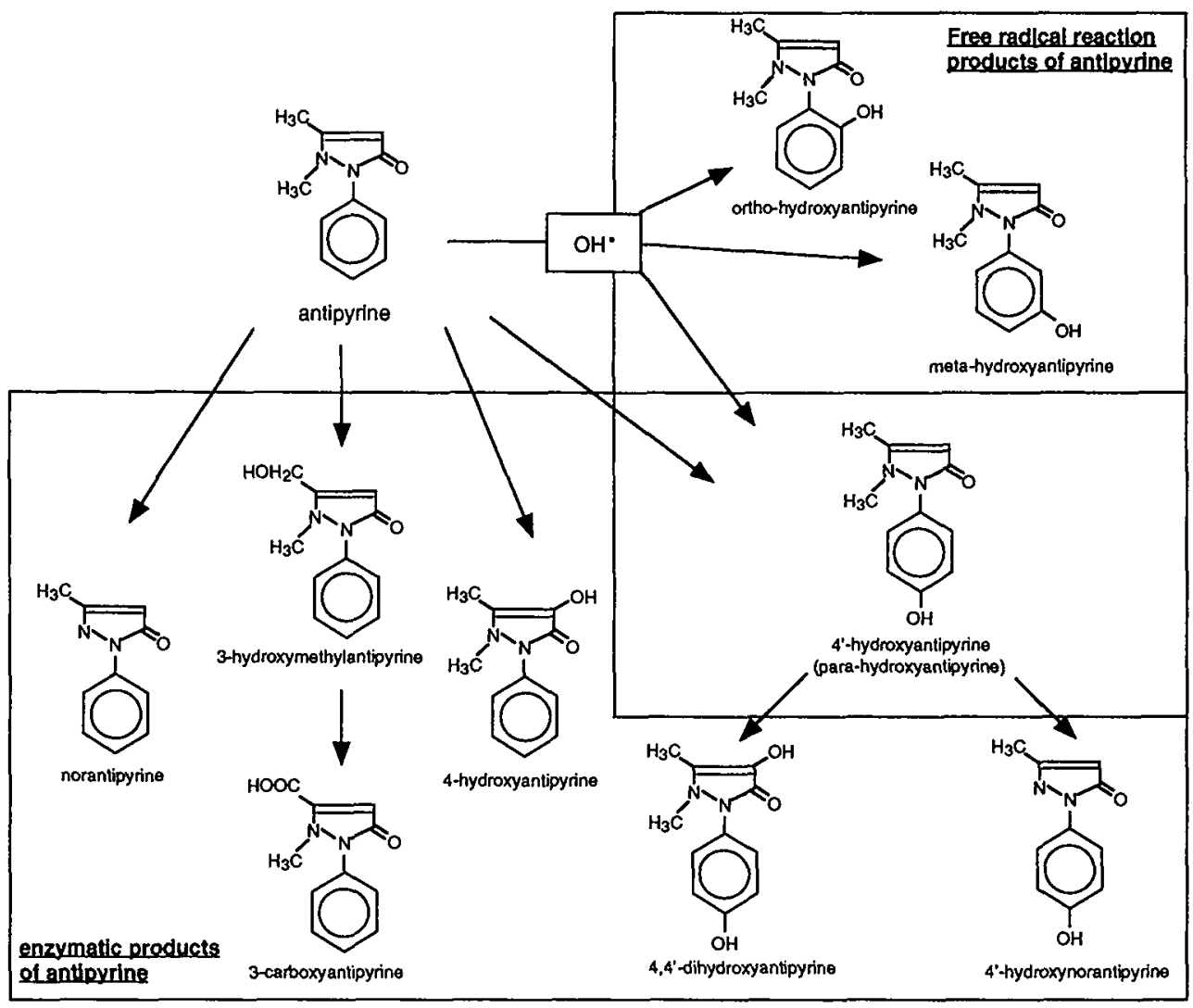

Figure 1. The enzymatic metabolism of antipyrine and its free radical reaction products.

\section{Antioxidants and training}

Biological antioxidants play an important role in protecting the cell against oxidative stress. The antioxidant defense system consists of an enzymatic and a non-enzymatic component. The enzymatic antioxidants include superoxide dismutases (SOD), catalase (CAT) and glutathione peroxidases (GPX). The non-enzymatic antioxidants include antioxidant vitamins ( $\alpha$-tocopherol, ascorbic acid, and $\beta$-carotene), thiols (mainly glutathione), and a variety of such low molecular weight compounds as lipoic acid and uric acid (23). Aging is associated with an increase in the tissue concentration of enzymatic antioxidants and a decrease in the plasma level of non-enzymatic 
antioxidants (33). The mechanism responsible for the age-associated change in the antioxidant system is still elusive, but it is clear that aging is related to an increased susceptibility to free radical damage $(25,42)$.

In view of the age related increase in the susceptibility to oxidative stress one might speculate if sedentary elderly would benefit from following an exercise training program. Leeuwenburgh et al. (29) showed that 10-wk endurance training increased GPX and SOD content in the deep vastus lateralis muscle of young rats, but had no effect on antioxidant enzyme content in old rats. They suggested that aged skeletal muscle had a limited capacity to increase its antioxidant potential. These findings were confirmed by Oh-ishi et al. (32), who reported that 6 -wk swimming training only increased GPX and SOD content in diaphragm muscle of young mice but not of old mice. So far, no studies have been conducted in healthy elderly subjects where oxidative stress was measured before and after a training period. It would be informative to know whether exercise training is effective in the induction of the antioxidant system, and whether elderly are able to cope with an increase in oxidative stress after following an exercise training program. Furthermore, it could be argued if an antioxidant supplementation intervention could be effective in elderly humans in reducing the exercise-induced oxidative stress. So far, only one study examined the effect of antioxidant supplementation on oxidative stress in elderly subjects (31). Meydani et al. (31) observed that the urinary level of MDA was lowered in the days after exercise when vitamin $E$ was supplemented when compared to the placebo group. These authors speculated that an antioxidant supplementation intervention might be particularly effective in exercising elderly. There is, however, a substantial lack of data regarding the relationship between oxidative stress, physical activity and antioxidant supplementation in an elderly population.

\section{Aim of the thesis}

This thesis intended to provide further insight in the effects of exercise training on the physical activity level and exercise-induced oxidative stress in the elderly. Therefore, the following objectives were addressed:

- To examine whether an exercise training program of moderate intensity affects the daily physical activity level and relative fat oxidation.

- To assess the determinants of physical inactivity in the elderly.

- To measure oxidative stress during exercise by using an exogenous marker for assessing oxidative stress.

- To examine whether a training program or an antioxidant supplementation intervention can alter the exercise-induced oxidative stress.

- To assess the relationship between the habitual activity level and exercise-induced oxidative stress. 


\section{Outline of the thesis}

The first studies described in this thesis were intended to obtain more information on the effects of exercise training on activity associated energy expenditure. Based on the observed compensatory decline in non-training physical activity in the elderly after high-intensity exercise, effects of a training program of moderate intensity were examined. Effects on the daily physical activity level were studied with tri-axial accelerometers (Chapter 2). In Chapter 3 the effect of this 12-wk training program on relative fat oxidation was investigated. Chapter 4 reports on the determinants of physical inactivity in an elderly population by using tri-axial accelerometers in combination with the doubly labeled water method. The subsequent studies were intended to obtain more information on exercise-induced oxidative stress in elderly subjects. In Chapter 5 exercise-induced oxidative stress in the elderly is described by using free radical reaction products of antipyrine. Chapter 6 examined if a 12-wk exercise-training program would be effective in the induction of the antioxidant defense system by lowering the exercise-induced oxidative stress. Chapter 7 describes the effects of 12-wk antioxidant vitamin supplementation on exercise-induced oxidative stress. Chapter 8 reports on the relationship between the habitual activity level and exercise-induced oxidative stress in elderly subjects. Finally, the results of the studies reported in this thesis and their consequences are discussed in Chapter 9. 


\section{References}

1. Ashton T, CC Rowlands, E Jones, IS Young, SK Jackson, B Davies, and JR Peters. Electron spin resonance spectroscopic detection of oxygen-centred radicals in human serum following exhaustive exercise. Eur. J. Appl. Physiol. 77: 498-502, 1998

2. Beckman KB, and BN Ames. The free radical theory of aging matures. Physiol. Rev. 78: 547581,1998

3. Bingham SA, GR Goldberg, WA Coward, AM Prentice, and JH Cummings. The effect of exercise and improved physical fitness on basal metabolic rate. Br. J. Nutr. 61: 155-173, 1989

4. Blaak EE, KR Westerterp, O Bar Or, LJ Wouters, and WHM Saris. Total energy expenditure and spontaneous activity in relation to training in obese boys. Am. J. Clin. Nutr. 55: 777-782, 1992

5. Black AE, WA Coward, TJ Cole, and AM Prentice. Human energy expenditure in affluent societies: an analysis of 574 doubly-labelled water measurements. Eur. J. Clin. Nutr. 50: 72-92, 1996

6. Blair SN, HW Kohl III, CE Barlow, RS Paffenberger, LW Gibbons, and CA Macera. Changes in physical fitness and all-cause mortality: a prospective study of healthy and unhealthy men. JAMA 273: 1093-1098, 1995

7. Bouten CVC, WPHG Verboeket van de Venne, KR Westerterp, M Verduin, and JD Janssen. Daily physical activity assessment: comparison between movement registration and doubly labeled water. J. Appl. Physiol. 81: 1019-1026, 1996

8. Bouten CVC, KR Westerterp, M Verduin, and JD Janssen. Assessment of energy expenditure for physical activity using a triaxial accelerometer. Med. Sci. Sports Exerc. 26: 1516-1523, 1994

9. Boveris A, and B Chance. The mitochondrial generation of hydrogen peroxide. General properties and effect of hyperbaric oxygen. Biochem. J. 134: 707-716, 1973

10. Brodie BB, and J Axelrod. The fate of antipyrine in man. J. Pharmacol. Exp. Ther. 98: 97-104, 1950

11. Coolen SAJ. Antipyrine hydroxylates as indicators for oxidative damage. Ph.D. thesis Eindhoven: Eindhoven University of Technology, 2000

12. Coolen SAJ, FM Everaerts, and FA Huf. Characterization of ${ }^{60} \mathrm{Co} \gamma$-radiation induced radical products of antipyrine by means of high-performance liquid chromatography, mass spectrometry, capillary zone electrophoresis, micellar electrokinetic capillary chromatography and nuclear magnetic resonance spectrometry. J. Chromatogr. A 788: 95-103, 1997

13. Coolen SAJ, $T$ Ligor, $M$ Van Lieshout, and FA Huf. Determination of phenolic derivatives of antipyrine in plasma with solid-phase extraction and high-performance liquid chromatographyatmospheric-pressure chemical ionization mass spectrometry. J. Chromatogr. B 732: 103-113, 1999

14. Danhof M, A van Zuilen, JK Boeijings, and DD Breimer. Studies of the different metabolic pathways of antipyrine in man. Oral versus i.v. administration and the influence of urinary collection time. Eur. J. Clin. Pharmacol. 21: 433-441, 1982

15. Elia M, P Ritz, and RJ Stubbs. Total energy expenditure in the elderly. Eur. J. Clin. Nutr. 54: S92-S103, 2000

16. FAO/WHO/UNU. Estimates of energy expenditure and protein requirements of adults and children. Report of a joint FAO/WHO/UNU expert consultation. Techn. Rep. Ser. 724: 71-112, 1985

17. Forni LG, VO Mora-Arellano, JE Packer, and RL Willson. Aminopyrine and antipyrine free radical-cations: pulse radiolysis studies of one-electron transfer reactions. J. Chem. Soc. Perkin Trans. II : 1579-1584, 1988 
18. Goran MI, and ET Poehlman. Endurance training does not enhance total energy expenditure in healthy elderly persons. Am. J. Physiol. 263: E950-957, 1992

19. Goran MI, and ET Poehlman. Total energy expenditure and energy requirements in healthy elderly persons. Metabolism 41: 744-753, 1992

20. Hageman JJ, A Bast, and NP Vermeulen. Monitoring of oxidative free radical damage in vivo: analytical aspects. Chem. Biol. Interact. 82: 243-293, 1992

21. Halliwell B, and JMC Gutteridge. Free radicals in biology and medicine. Oxford: Claredon Press, 1989

22. Harman D. Aging: a theory based on free radical and radiation chemistry. J. Gerontol. 11: 298300,1956

23. Ji LL, C Leeuwenburgh, S Leichtweis, M Gore, R Fiebig, J Hollander, and J Bejma. Oxidative stress and aging. Role of exercise and its influences on antioxidant systems. Ann. NY Acad. Sci. 854: 102-117, 1998

24. Kaur $\mathrm{H}$, and $\mathrm{B}$ Halliwell. Aromatic hydroxylation of phenylalanine as an assay for hydroxyl radicals. Measurement of hydroxyl radical formation from ozone and in blood from premature babies using improved HPLC methodology. Anal. Biochem. 220: 11-15, 1994

25. Khalil A, JR Wagner, G Lacombe, V Dangoisse, and T Fülöp Jr. Increased susceptibility of low-density lipoprotein (LDL) to oxidation by gamma-radiolysis with age. FEBS Lett. 392: 45 48, 1996

26. Kohrt WM, MT Malley, AR Coggan, RJ Spina, T Ogawa, AA Ehsani, RE Bourey, WHd Martin, and JO Holloszy. Effects of gender, age, and fitness level on response of VO2max to training in 60-71 yr olds. J. Appl. Physiol. 71: 2004-2011, 1991

27. Koren A, M Schara, and $M$ Sentjurc. EPR measurements of free radicals during tetanic contraction of frog muscle. Period. Biol. 82: 399-401, 1980

28. Leaf DA, MT Kleinman, M Hamilton, and RW Deitrick. The exercise-induced oxidative stress paradox: the effects of physical exercise training. Am. J. Med. Sci. 317: 295-300, 1999

29. Leeuwenburgh C, R Fiebig, R Chandwaney, and LL Ji. Aging and exercise training in skeletal muscle: responses of glutathione and antioxidant enzyme systems. Am. J. Physiol. 267: R439445,1994

30. Lifson N, GB Gordon, and R McClintock. Measurement of total carbon dioxide production by means of $\mathrm{D}_{2} \mathrm{O}^{18}$. J. Appl. Physiol. 7: 704-710, 1955

31. Meydani M, WJ Evans, G Handelman, L Biddle, RA Fielding, SN Meydani, J Burrill, MA Fiatarone, JB Blumberg, and JG Cannon. Protective effect of vitamin E on exercise-induced oxidative damage in young and older adults. Am. J. Physiol. 264: R992-998, 1993

32. Oh-ishi S, K Toshinai, T Kizaki, S Haga, K Fukuda, N Nagata, and H Ohno. Effects of aging and/or training on antioxidant enzyme system in diaphragm of mice. Respir. Physiol. 105: 195202, 1996

33. Pansarasa O, L Bertorelli, J Vecchiet, G Felzani, and F Marzatico. Age-dependent changes of antioxidant activities and markers of free radical damage in human skeletal muscle. Free Radic. Biol. Med. 27: 617-622, 1999

34. Pate RR, M Pratt, SN Blair, WL Haskell, CA Macera, C Bouchard, D Buchner, W Ettinger, GW Heath, AC King, A Kriska, AS Leon, BH Marcus, J Morris, RS Paffenberger, K Patrick, ML Pollock, JM Rippe, J sallis, and JH Wilmore. Physical activity and public health: a recommendation from the CDC and ACSM. JAMA 273: 402-407, 1995

35. Prentice AM, GR Goldberg, PR Murgatroyd, and TJ Cole. Physical activity and obesity: problems in correcting expenditure for body size. Int. J. Obes. 20: 688-691, 1996

36. Ravussin E, S Lillioja, TE Anderson, L Christin, and C Bogardus. Determinants of 24-hour energy expenditure in man. Methods and results using a respiratory chamber. J. Clin. Invest. 78: 1568-1578, 1986 
37. Sandvik L, J Erikssen, E Thaulow, G Erikssen, R Mundal, and K Rodahl. Physical fitness as a predictor of mortality among healthy, middle-aged Norwegian men. New Engl. J. Med. 328: 533-537, 1993

38. Schoeller DA, and $E$ van Santen. Measurement of energy expenditure in humans by doubly labeled water method. J. Appl. Physiol. 53: 955-959, 1982

39. Schoeller DA. The shortage of O-18 water. Obes. Res. 7: 519, 1999

40. Schoeller DA, E Ravussin, Y Schutz, KJ Acheson, P Baertschi, and E Jequier. Energy expenditure by doubly labeled water: validation in humans and proposed calculation. $\mathrm{Am}$. J. Physiol. 250: R823-830, 1986

41. Sen CK. Oxidants and antioxidants in exercise. J. Appl. Physiol. 79: 675-686, 1995

42. Shigenaga MK, TM Hagen, and BN Ames. Oxidative damage and mitochondrial decay in aging. Proc. Natl. Acad. Sci. USA 91: 10771-10778, 1994

43. Siri WE. The gross composition of the body. Adv. Biol. Med. Physiol. 4: 239-280, 1956

44. Sohal RS, and R Weindruch. Oxidative stress, caloric restriction, and aging. Science 273: 59-63, 1996

45. Toth MJ, AW Gardner, PA Ades, and ET Poehlman. Contribution of body composition and physical activity to age-related decline in peak VO2 in men and women. J. Appl. Physiol. 77: $647-652,1994$

46. Van Etten LMLA, KR Westerterp, FTJ Verstappen, BJB Boon, and WHM Saris. Effect of an 18-wk weight-training program on energy expenditure and physical activity. J. Appl. Physiol. 82: 298-304, 1997

47. Westerterp KR. Alterations in energy balance with exercise. Am. J. Clin. Nutr. 68: 970S-974S, 1998

48. Westerterp KR. Physical activity assessment with accelerometers. Int. J. Obes. 23: S45-S49, 1999

49. Westerterp KR, and CVC Bouten. Physical activity assessment: comparison between movement registration and doubly labeled water method. Z. Ernahrungswiss. 36: 263-267, 1997

50. Westerterp KR, GAL Meijer, EM Janssen, WHM Saris, and F Ten Hoor. Long-term effect of physical activity on energy balance and body composition. Br. J. Nutr. 68: 21-30, 1992

51. Westerterp KR, L Wouters, and WD van Marken Lichtenbelt. The Maastricht protocol for the measurement of body composition and energy expenditure with labeled water. Obes. Res. 1: 4957,1995

52. Yu BP. Cellular defences against damage from reactive oxygen species. Physiol. Rev. 74: 139$162,1994$. 


\title{
Chapter 2
}

\section{The effect of exercise training on total daily physical activity in elderly humans}

\author{
Erwin P. Meijer \\ Klaas R. Westerterp \\ Frans T.J. Verstappen
}

European Journal of Applied Physiology, 80(1): 16-21, 1999. 


\begin{abstract}
This study examined the effect of 12-wk of exercise training on daily physical activity in elderly humans. Training consisted of a weekly group session and an individual session with cardio- and weight-stack machines. A group of 15 subjects served as the exercise group (EXER; 59 $\pm 4 \mathrm{y}$ ) and 7 subjects served as the controls (CONT; $57 \pm 3 \mathrm{y}$ ). Physical activity and physical fitness were measured before the start of the training (T), at wk 6 and wk 12 (T0, T6, T12 respectively) in EXER, and at T0 and T12 in CONT. Physical activity over 14- $\mathrm{d}$ was measured using a tri-axial accelerometer and physical fitness was measured during an incremental exercise test. At T12, mean maximal power output had significantly increased in EXER compared to CONT ( $8 \pm 12$ vs. $-5 \pm 9 \mathrm{~W} ; \mathrm{P}<0.02)$ and mean submaximal heart rate $($ at $100 \mathrm{~W})$ had reduced $(-10 \pm 7$ vs. $-2 \pm 6 \mathrm{bts} \cdot \mathrm{min}^{-1} ; \mathrm{P}<0.05$ ). No differences or changes in physical activity were observed between EXER and CONT. At T6, physical activity on training days was significantly higher than on non-training days $(P<0.001)$. When the accelerometer output of the training session was subtracted from the accelerometer output on training days, at T12 non-training physical activity was significantly lower than on non-training days $(\mathrm{P}<0.004)$. Accelerometer output of the individual training session at T12 significantly increased compared to $\mathrm{T} 6(\mathrm{P}<0.05)$, whereas, accelerometer output of the group training session had remained unchanged. In conclusion, in elderly subjects an exercise training program of moderate intensity resulted in an improved physical fitness but had no effect on total daily physical activity. Training activity was compensated for by a decrease in non-training physical activity.
\end{abstract}




\section{Introduction}

Aging is frequently associated with a decrease in physical activity and consequently a decline in physical fitness, which may lead to a vicious circle of less and less physical activity and declining physical fitness. It has been suggested that the level of physical activity might, also, influence the decrease in fat-free mass with age $(9$, $14,19)$. Therefore, exercise programs for the elderly have been developed to improve or maintain their strength, muscle mass and physical fitness. Studies with young adults have shown that exercise intervention programs can influence body composition, energy metabolism and physical fitness in a beneficial way $(11,12,18)$.

Westerterp (24) reviewed five studies on the effect of a training program on average daily metabolic rate (ADMR) measured using the doubly labeled water method $(2,3,8,22,18)$, one of which was in children, three in young adults and one in the elderly. The energy expenditure associated with non-training physical activity was calculated from the difference between ADMR and resting metabolic rate after adjusting for the thermic response to feeding and the energy cost of the exercise training. In children and young adults the size of the change in energy expenditure associated with physical activity was on average twice the energy cost of the exercise training intervention program. However, in elderly subjects it was found that an endurance training program did not change total energy expenditure. Here, it was suggested that the intensity of the training program was too high, resulting in a decline in non-training physical activity (8).

The doubly labeled water method, however, can only be used to quantify the average level of physical activity over intervals of 1-3 weeks and does not provide information about patterns of physical activity related to time. Assessment of physical activity patterns in subjects by using body-fixed accelerometers seems to offer promising possibilities. Bouten et al. (5) developed a tri-axial accelerometer based on three separate uni-axial accelerometers. Comparison between physical activity generated accelerometer output and activity associated energy expenditure as measured with doubly labelled water in 30 free living subjects over 7-d intervals has shown a significant relationship ( $r=0.79$; ref. 4). Meijer et al. (10) and Van Etten et al. (18) have measured non-training physical activity with a tri-axial accelerometer before training, at 8 and 18-20 weeks of an exercise training program in young adults and found no change in non-training physical activity.

The purpose of this study was to investigate the effect of a 12-wk exercise training program of moderate intensity on the daily physical activity in elderly humans. Physical activity was registered by using a tri-axial accelerometer.

\section{Methods}

Subjects. The subjects were recruited from advertisements in the local media. Selection criteria were: age over $55 \mathrm{y}$, no health problems and no participation in sports during the previous year. Detailed information concerning the purpose and 
methods used in the study was provided, and written consent was obtained. The study was approved by the Ethics Committee of Maastricht University. A group of 15 subjects ( 8 women, 7 men) participated in the exercise-trained group (EXER), and 7 subjects (4 women, 3 men) served as non-trained controls (CONT). The variables comprising body composition, basal metabolic rate (BMR), daily physical activity and physical fitness were measured at training (T) week T0 (baseline), at T6 (6-wk of training) and T12 (12-wk of training) in EXER and at T0 and T12 in CONT.

Body composition. Physical characteristics are shown in Table 1. Anthropometric measurements were taken after an overnight stay at the laboratory. After voiding, body mass was measured on an electronic scale (Mettler, E1200). Body volume was determined by weighing underwater. Residual lung volume was simultaneously measured using the helium dilution technique (Volugraph 2000, Mijnhardt). Total body water (TBW) was determined using deuterium $\left({ }^{2} \mathrm{H}_{2} \mathrm{O}\right)$ dilution. Body composition was calculated from body mass, body volume and TBW using the threecompartment model of Siri (16).

Table 1. Characteristics of the exercise and control group. There were no differences between the groups (mean $\pm \mathrm{SD}$ ).

\begin{tabular}{lcc}
\hline & exercise group & control group \\
\hline number (men/women) & $15(7,8)$ & $7(3,4)$ \\
age, $y$ & $58.9 \pm 3.5$ & $57.4 \pm 2.6$ \\
body mass, $\mathrm{kg}$ & $71.4 \pm 10.1$ & $70.0 \pm 9.4$ \\
height, m & $1.67 \pm 0.07$ & $1.67 \pm 0.08$ \\
$\mathrm{BMI}, \mathrm{kg} \cdot \mathrm{m}^{-2}$ & $25.6 \pm 3.1$ & $25.1 \pm 1.1$ \\
fat, \% & $32.9 \pm 8.8$ & $33.3 \pm 6.9$ \\
$\mathrm{VO}_{2 \max }, 1 \cdot \mathrm{min}^{-1}$ & $2.03 \pm 0.5$ & $1.99 \pm 0.5$ \\
$\mathrm{~W}_{\max }, \mathrm{watt}$ & $145 \pm 40$ & $135 \pm 32$ \\
$\mathrm{HR}_{\max }, \mathrm{bts} \cdot \mathrm{min}^{-1}$ & $163 \pm 13$ & $159 \pm 18$ \\
\hline
\end{tabular}

Basal metabolic rate. After an overnight fast the basal metabolic rate (BMR) was measured for $30 \mathrm{~min}$ at $0700 \mathrm{~h}$. Oxygen consumption and carbon dioxide production were measured busing a computerized, open-circuit, ventilated hood system. Expired gases were analyzed using a paramagnetic oxygen analyzer (Servomex, The Netherlands) and an infrared carbon dioxide analyser (Servomex, The Netherlands). The system was similar to the analysis system for respiration chambers which has been described previously by Schoffelen et al. (15). Calculation of BMR was based upon the equation of Weir (21).

Daily physical activity. Physical activity over a $14-\mathrm{d}$ period was measured using a tri-axial accelerometer, consisting of three uni-axial piezo-electric accelerometers, attached to the lower back of the subjects by an elastic belt. It was a smaller version 
$(69 \times 28 \times 9 \mathrm{~mm}, 23 \mathrm{~g})$ of that used in previous studies $(5,18)$. The accelerometer calculated the sum of the rectified and integrated acceleration curves from the anteroposterior, medio-lateral and longitudinal axis of the trunk. The period for integration was set at $1 \mathrm{~min}$. The subjects were instructed to wear the accelerometer during waking hours, except during bathing and showering.

Physical fitness. To investigate the effect of the training program on aerobic power (maximal oxygen uptake, $\left.\mathrm{VO}_{2 \max }\right)$ and maximal power output $\left(\mathrm{W}_{\max }\right)$, the subjects exercised incrementally on an electromagnetically braked cycle ergometer (Lode Excalibur, Groningen, The Netherlands). They started to cycle for 3-min at $30 \mathrm{~W}$ at 60 $\mathrm{rev} \cdot \mathrm{min}^{-1}$ and the exercise intensity was increased every minute with $10 \mathrm{~W}$ until they were exhausted. Criteria for maximal performance were a forced ventilation, a leveling off of oxygen uptake or a respiratory quotient $(R)$ above 1.1. The oxygen uptake during the test was measured continuously, using a computerized open system (SensorMedics 2900 analyzer, Anaheim, Calif., USA). During the incremental exercise test heart rate was measured continuously (Polar Sport Tester, Kempele, Finland). To quantify the effect of the training program on heart function, heart rates were compared at a power output of $100 \mathrm{~W}$.

Training program. The subjects trained twice a week at a fitness club, once in a group session of 60-min with various aerobic exercises and once in an individual session of 90-min consisting of nine exercises using cardio- and weight-stack machines. Two sets of ten repetitions were performed in the following exercises: lat row, pec deck, leg extension, leg curl, biceps curl, triceps extension, shoulder press and sit-ups. In addition, each session included a 10-min of warming-up and cooling down with walking or cycling at a self selected intensity. A group session was chosen to improve compliance. The training sessions were supervised by a fitness instructor. The mean average training compliance was $85 \pm 9 \%$.

Statistics. Paired Student's t-tests were used to examine differences in EXER between baseline measurements and T6 and T12. Due to the small size of the group non-parametric Wilcoxon signed-rank tests were used to examine differences in CONT between baseline measurements and T12. An analysis of variance (ANOVA) for repeated measures within subjects was used to compare accelerometer output between T6 and T12. To compare differences between EXER and CONT, a nonparametric Mann-Whitney U-test was used. Statistical significance was set at $\mathrm{P}<0.05$.

\section{Results}

Body composition. In neither group, EXER or CONT, did the subjects show any change in body mass (Table 2). There were no changes in mean body composition in EXER (T0, T6 and T12: $33.0 \pm 8.0,32.5 \pm 7.6$ and $33.5 \pm 8.1 \%$ fat mass, respectively). 
Mean body composition in CONT, however, changed significantly (T0, T12: $32.8 \pm 5.9$ vs. $34.1 \pm 5.4 \%$ fat mass; $\mathrm{P}<0.05$ ).

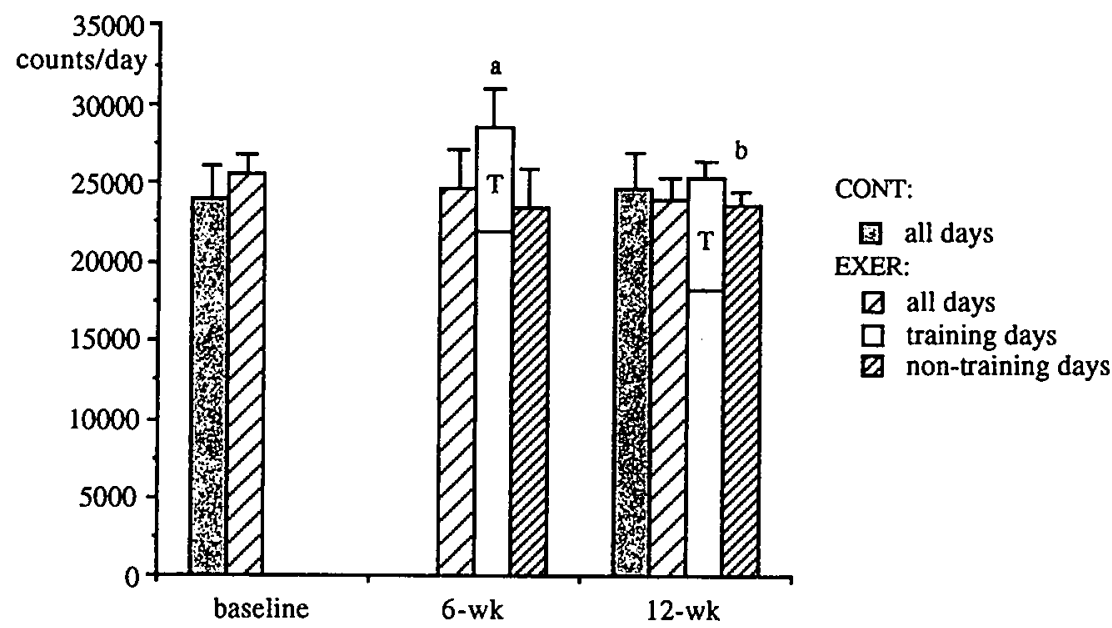

Figure 1. Accelerometer output counts (mean \pm SEM) during training days and non-training days. Accelerometer output did not differ between the exercise (EXER) and control (CONT) groups. T: Mean counts produced during a training session. Significantly different counts between training and non-training days ${ }^{\mathrm{a}} \mathrm{P}<0.001$. Significantly different counts between non-training days and training days minus training session ${ }^{\mathrm{b}} \mathrm{P}<0.01$.

Basal metabolic rate. There were no changes in mean BMR in either EXER (T0, T6 and T12: $4.7 \pm 0.5,4.7 \pm 0.5$ and $4.7 \pm 0.6 \mathrm{~kJ} \cdot \mathrm{min}^{-1}$, respectively) or CONT (T0, T12: $\left.4.6 \pm 0.6,4.7 \pm 0.4 \mathrm{~kJ} \cdot \mathrm{min}^{-1}\right)$.

Daily physical activity. As depicted in Fig. 1, average physical activity as measured with the tri-axial accelerometer over 2-wk intervals did not change between T0, T6 and T12 in EXER $\left(25572 \pm 5016,24697 \pm 9223,23935 \pm 5093\right.$ counts.day ${ }^{-1}$, respectively) or in CONT $\left(23990 \pm 5176,24568 \pm 6358\right.$ counts $\cdot$ day $^{-1}$, respectively). At T6 mean physical activity was significantly higher on training days than on non-training days ( $28477 \pm 9328$ vs. $23482 \pm 9251$ counts $\cdot$ day $^{-1} ; \mathrm{P}<0.001$ ), whereas, at $\mathrm{T} 12$ the difference between mean physical activity on training days and non-training days just failed to reach significance $\left(25234 \pm 4690\right.$ vs. $23575 \pm 5543$ counts $\cdot$ day $\left.^{-1} ; \mathrm{P}=0.06\right)$. The difference in mean physical activity between training days and non-training days was significantly larger at T6 than at T12 $\left(4996 \pm 4252\right.$ vs. $1659 \pm 3529$ counts day $\left.^{-1} ; \mathrm{P}<0.05\right)$.

A training session resulted in mean accelerometer outputs of $6064 \pm 1420$ counts at $\mathrm{T} 6$ and $6949 \pm 2146$ counts at $\mathrm{T} 12(\mathrm{P}=0.09)$. The mean accelerometer output of the individual training was significantly higher at T12 than at T6 $(6925 \pm 2110$ vs. $5521 \pm 1689$ counts; $P<0.05$; Fig. 2), whereas, the mean accelerometer output of the 
group training was not significantly different between T12 and T6 $(7389 \pm 2547$ vs. $6716 \pm 1675$ counts; Fig. 2). When the accelerometer output produced during a training was subtracted from total accelerometer output on training days, at T12 the mean physical activity on training days was significantly lower than on non-training days ( $18285 \pm 4568$ vs. $23575 \pm 5543$ counts $\cdot$ day $^{-1}$; $\mathrm{P}<0.01$; Fig. 1$)$. At T6 no difference was shown between mean non-training physical activity on training days when compared with that on non-training days $\left(22414 \pm 9095\right.$ vs. $23482 \pm 9251$ counts $\cdot$ day $\left.^{-1}\right)$.

Table 2. Changes in body composition, basal metabolic rate and physical fitness in the exercise and the control groups compared to baseline. T0 Baseline training, T6, T12 6 and 12 weeks of training.

\begin{tabular}{lccc}
\hline & exrecise group & & control group \\
& $\mathrm{T} 6$ & $\mathrm{~T} 12$ & $\mathrm{~T} 12$ \\
\hline body mass, $\mathrm{kg}$ & $0.0 \pm 0.3$ & $-0.2 \pm 0.3$ & $0.2 \pm 0.4$ \\
fat, \% & $-0.4 \pm 0.3$ & $0.5 \pm 0.4^{\ddagger}$ & $1.3 \pm 0.4^{*}$ \\
$\mathrm{BMR}, \mathrm{kJ} \cdot \mathrm{min}^{-1}$ & $0.0 \pm 0.1$ & $0.0 \pm 0.1$ & $0.0 \pm 0.2$ \\
$\mathrm{VO}_{2 \max }, \mathrm{l} \cdot \mathrm{min}^{-1}$ & $0.09 \pm 0.07$ & $0.10 \pm 0.06$ & $-0.17 \pm 0.09$ \\
$\mathrm{~W}_{\max }, \mathrm{watt}$ & $7 \pm 4^{*}$ & $8 \pm 3^{* *}$ & $-5 \pm 3^{\#}$ \\
$\mathrm{HR} 100 \mathrm{~W}, \mathrm{bts} \cdot \mathrm{min}^{-1}$ & $-8 \pm 1$ & $-10 \pm 2^{* *}$ & $-2 \pm 2^{\#}$ \\
\hline
\end{tabular}

Results are means \pm SEM. Significantly different from T0: ${ }^{*} \mathrm{P}<0.05,{ }^{* *} \mathrm{P}<0.001$. Significantly different from T6: $\ddagger P<0.01$. Significantly different between the groups: \# $P<0.05$.

Physical fitness. In Table 2 the differences in $\mathrm{W}_{\max }$ and $\mathrm{VO}_{2 \max }$ measured by the incremental exercise test are given for both groups. The $\mathrm{W}_{\max }$ at $\mathrm{T} 12$ had increased significantly in EXER, whereas the increase in $\mathrm{VO}_{2 \max }$ at $\mathrm{T} 12$ in EXER just failed to reach significance $(\mathrm{P}=0.06)$. In CONT no significant changes in $\mathrm{W}_{\max }$ and $\mathrm{VO}_{2 \max }$ were found. Heart rate at $100 \mathrm{~W}$ was significantly reduced in EXER at T6 and T12 when compared with T0 (130 \pm 19 and $128 \pm 22$ vs. $138 \pm 17$ bts $\left.\cdot \mathrm{min}^{-1} ; \mathrm{P}<0.001\right)$, whereas heart rate at $100 \mathrm{~W}$ in CONT remained unchanged between $\mathrm{T} 0$ an $\mathrm{T} 12$ (135 \pm 13 vs. $132 \pm 20$ ).

\section{Discussion}

The present study was undertaken to examine the effect of regular exercise training on daily physical activity in healthy elderly individuals. Daily physical activity was measured with a tri-axial accelerometer. The results showed that total physical activity over 14 days was not influenced by an exercise training program of moderate intensity, which is in contrast with the findings of Meijer et al. (10). They have shown, in young adults, an increase in total physical activity which was almost entirely due to the extra running activity of the exercise training program. In the present study, physical activity on training days was significantly higher than on non-training days, which was due to the imposed physical activity of the exercise training. After subtracting the physical activity of the session of exercise training, 
after 12-wk the subjects showed a significant decrease in non-training physical activity on training days (Fig. 1), a finding which agrees with those of Goran and Poehlman (8). They suggested that the level of exercise during the last week of their training program $\left(3 \mathrm{~h} \cdot \mathrm{wk}^{-1}\right.$ at $85 \%$ of $\left.\mathrm{VO}_{2 \max }\right)$ was too strenuous, and thus fatigued the elderly participants during the remainder of the day. They proposed that exercise training of lower intensity might influence the level of daily physical activity. Although a lower exercise intensity for training was used in the present study, nontraining physical activity on training days decline, which could probably be explained by the difference in exercise intensity on $\mathrm{T} 6$ and T12. At T6 the exercise training had no influence on non-training physical activity on training days (Fig. 1). At T12, when a higher exercise intensity was used, the elderly subjects showed a decline in non-training physical activity on training days. It would seem that elderly adults resist an increased exercise intensity.

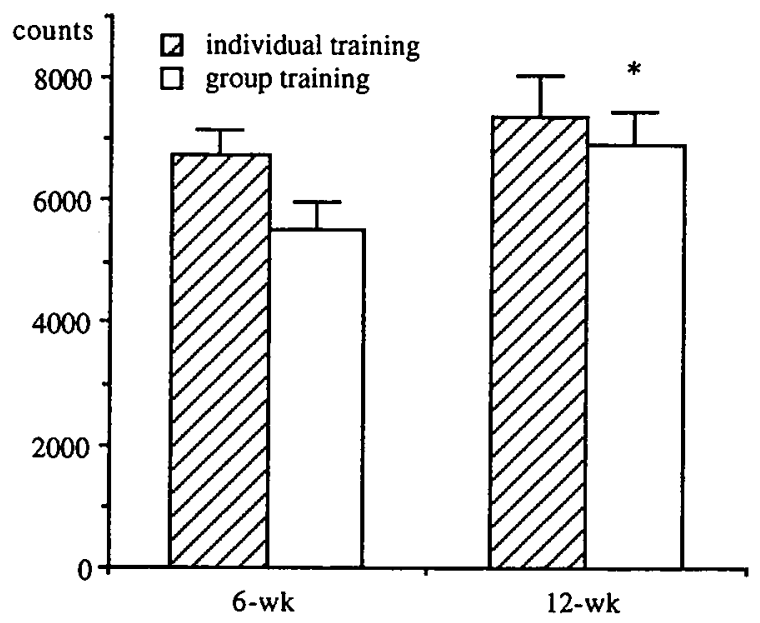

Figure 2. Accelerometer output counts (mean \pm SEM) during group and individual training sessions. Significantly different from week $6 * \mathrm{P}<0.05$.

The duration of the intervention might also partly explain the decline in non-training physical activity. Goran and Poehlman (8) reported a declined non-training physical activity after 8-wk of endurance training. The present study showed a decline in nontraining physical activity only after 12-wk of training. Probably, 6-wk of exercise training was too short to influence non-training physical activity.

The declined non-training physical activity at T12 could not be attributed to the fact that the exercise training program probably fatigued the elderly participants during the remainder of the day, because the training sessions were undertaken in the afternoon. It would seem that elderly subjects anticipate exercise training by 
reducing their physical activity before the training sessions, possibly by resting more to save energy. The results, therefore, cannot support the suggestion of Goran and Poehlman (8), that the elderly compensate for exercise training by reducing their physical activity afterwards. From a clinical perspective, our results would indicate that exercise prescribed to the elderly might reduce non-training physical activity.

The mean intensity of the individual training session, as measured with the triaxial accelerometer, was significantly higher at T12 when compared with T6 (Fig. 2). The group training sessions at $\mathrm{T} 12$, however, were not significantly different from group training sessions at T6. Thus, the mean increase in training intensity of both training sessions taken together just failed to reach significance $(\mathrm{P}=0.09)$. The difference between the individual and the group session might be due to the differences in training intensity of the individuals. During the individual sessions the load of the cardio- and weight-stack machines was determined from each individual s physical fitness at the onset of the training and was adjusted throughout the 12-wk program, whereas the various aerobic exercises of the group session were based on the mean level of physical fitness of the group.

Although the training program decreased non-training physical activity, a significant increase in $\mathrm{W}_{\max }$ was observed. The $\mathrm{VO}_{2 \max }$ tended to increase (Table 2); the $5 \%$ increase in mean $\mathrm{VO}_{2 \max }$, although not significant, after 12-wk exercise training $\left(2.03 \pm 0.5\right.$ vs. $\left.2.13 \pm 0.61 \cdot \mathrm{min}^{-1} ; \mathrm{P}=0.06\right)$ was similar to the results of previous studies $(8$, $13,17)$. Posner et al. (13) have reported a $8.5 \%$ increase in $\mathrm{VO}_{2 \max }$ after 16 -wk of exercise training of moderate intensity on a cycle ergometer. Goran and Poehlman (8) used a 8-wk exercise training program of high intensity and reported a significant $11 \%$ increase in $\mathrm{VO}_{2 \max }$, which agrees with the findings of Takeshima et al. (17), who have shown a $10 \%$ increase in $\mathrm{VO}_{2 \max }$ after 12-wk of endurance training at lactate threshold in elderly subjects. In elderly adults, however, it could be more important to detect improvements in the submaximal response to exercise training which have been shown to be related more to the accomplishment of daily activities (7).

In the present study, the reduced heart rate after 12-wk training program at a power output of $100 \mathrm{~W}$ was in agreement with findings of De Vito et al. (7). They used an exercise training program of low intensity with various aerobic exercises three times a week and demonstrated a significant reduction of $6 \mathrm{bts} \cdot \mathrm{min}^{-1}$ in the post-training heart rate when compared with the pre-training heart rate. Belman and Geasser (1) showed a training-induced reduction of $8 \mathrm{bts} \cdot \mathrm{min}^{-1}$ in heart rate at a submaximal power output after 8-wk of exercise training of low intensity (30 min walking at $50 \% \mathrm{VO}_{2 \max }$ four times a week). Thus, an exercise training program of moderate intensity twice a week as used in the present study would seem to improve physical fitness in healthy elderly adults.

The lack of change in body mass is in accordance with other exercise training intervention studies $(2,3,6,8,11,18)$. These studies, however, have shown a significant increase in fat-free mass and a decrease in fat mass. The present study started at the end of October (autumn) and was completed in February (winter). It has been suggested that body mass and body composition may show seasonal 
fluctuations, with an increase in body mass and fat mass in the winter and a decrease before summer (20). Fat mass increased significantly in CONT, whereas no significant changes in body composition in EXER were found (Table 2). Therefore, it can be argued that the exercise training program prevented the increase in fat mass due to seasonal changes.

The unchanged BMR in EXER, in the present study, was in accordance with other exercise training intervention studies $(2,3,11,18,25)$. These studies have shown that there is no clear long-term effect of exercise training on BMR. Two studies with elderly persons, however, have reported an increase in $\operatorname{BMR}(6,8)$. Campbell et al. (6) used a 12-wk resistance training program, whereas Goran and Poehlman (8) used an 8-wk endurance training program. Both studies measured BMR, as in the present study, at least $36 \mathrm{~h}$ after the last training session to prevent any carry-over effect from the last period of exercise and both studies reported an increased fat-free mass.

Although fat-free mass is an important determinant of BMR, most studies have shown an exercise-induced increase in fat-free mass without an increase in $\operatorname{BMR}(2,3,11,18,23)$. The longest training intervention study (40-wk of endurance training) showed the biggest absolute change in fat-free mass without an increase in BMR (23). In contrast, after 40-wk of endurance training BMR was slightly lower while fat-free mass was significantly increased with $5 \%$. It has been speculated that BMR may have changed as a defense mechanism of body mass maintenance, because body mass was significantly decreased by $1.0 \pm 1.7 \mathrm{~kg}$. The intensity of the training program used in this study and the fact that there were no significant changes in body mass and body composition might explain why BMR was unchanged after 12-wk of training.

In conclusion, in the elderly an exercise training program of moderate intensity resulted in an increase in physical activity, which was compensated for by a decrease in non-training physical activity. The exercise training program resulted in increased physical fitness. 


\section{References}

1. Belman MJ, and GA Geasser. Exercise training below and above the lactate threshold in the elderly. Med. Sci. Sports Exerc. 23(5): 562-568, 1991

2. Bingham SA, GR Goldberg, WA Coward, AM Prentice, and JH Cunnings. The effect of exercise and improved physical fitness on basal metabolic rate. Br. J. Nutr. 61: 155-173, 1989

3. Blaak EE, KR Westerterp, O Bar-Or, LJM Wouters, and WHM Saris. Effect of training on total energy expenditure and spontaneous activity in obese boys. Am. J. Clin. Nutr. 55: $777-782,1992$

4. Bouten CVC, WPHG Verboeket-Van de Venne, KR Westerterp, M Verduin, and JD Janssen. Daily physical activity assessment: comparison between movement registration and doubly labeled water. J. Appl. Physiol. 81: 1019-1026, 1996

5. Bouten CVC, KR Westerterp, M Verduin, and JD Janssen. Assessment of energy expenditure for physical activity using a triaxial accelerometer. Med. Sci. Sports Exerc. 26: 1516-1523, 1994

6. Campbell WW, MC Crim, VR Young, and WJ Evans. Increased energy requirements and changes in body composition with resistance training in older adults. Am. J. Clin. Nutr. 55: $802-810,1994$

7. De Vito G, R Hernandez, V Conzalez, F Felici, and F Figura. Low intensity physical training in older subjects. J. Sports Med. Phys. Fitness 37: 72-77, 1997

8. Goran MI, and ET Poehlman. Endurance training does not enhance total energy expenditure in healthy elderly persons. Am. J. Physiol. 263: E950-E957, 1992

9. Horber FF, SA Kohler, K Lippuner, and P Jaeger. Effect of regular physical training on ageassociated alteration of body composition in men. Eur. J. Clin. Invest. 26: 279-285, 1996

10. Meijer GAL, GME Janssen, KR Westerterp, F Verhoeven, and WHM Saris. The effect of a 5-month endurance-training programme on physical activity: evidence for a sex-difference in the metabolic response to exercise. Eur. J. Appl. Physiol. 62: 11-17, 1991a

11. Meijer GAL, KR Westerterp, GHP Seyts, GME Janssens, WHM Saris, F Ten Hoor. Body composition and sleeping metabolic rate in response to a 5-month endurance-training programme in adults. Eur. J. Appl. Physiol. 62: 18-21, 1991b

12. Poehlman ET, AW Gardner, PA Ades, SM Katzman-Rooks, SM Montgomery, OK Atlas, DL Ballor, and RS Tyzbir. Resting energy metabolism and cardiovascular disease risk in resistance-trained and aerobically trained males. Metabolism 41: 1351-1360, 1992

13. Posner JD, KM Gorman, L Windsor-Lansberg, J Larsen, M Bleiman, C Shaw, B Rosenberg, and $\mathrm{J}$ Knebl. Low to moderate intensity endurance training in healthy older adults: physiological responses after four months. J. Am. Geriatr. Soc. 40: 1-7, 1992

14. Rising R, IT Harper, AM Fontvielle, RT Ferraro, M Spraul, and E Ravussin. Determinants of total daily energy expenditure: variability in physical activity. Am. J. Clin. Nutr. 59: 800-804, 1994

15. Schoffelen PFM, KR Westerterp, WHM Saris, and F Ten Hoor. A dual-respiration chamber system with automated calibration. J. Appl. Physiol. 83(6): 2064-2072, 1997

16. Siri WE. The gross composition of the body. Adv. Biol. Med. Phys. 4: 239-203, 1956

17. Takeshima N, K Tanaka, F Kobayashi, $T$ Watanabe, and $T$ Kato. Effects of aerobic exercise conditioning at intensities corresponding to lactate threshold in the elderly. Eur. $J$. Appl. Physiol. 67(2): 138-143, 1993

18. Van Etten LMLA, KR Westerterp, FTJ Verstappen, BJB Boon, and WHM Saris. Effect of an 18-week weight-training program on energy expenditure and physical activity. J. Appl. Physiol. 82(1): 298-304, 1997 
19. Van Pelt RE, PP Jones, KP Davy, CA Desouza, H Tanaka, BM Davy, and DR Seals. Regular physical activity and the age-related decline in resting metabolic rate in women. $J$. Clin. Endocrinol. Metab. 82: 3208-3212, 1997

20. Van Staveren WA, P Deurenberg, J Burema, LC De Groot, and JG Hautvast. Seasonal variations in food intake, pattern of physical activity and changes in body weight in a group of young adult Dutch women consuming self selected diets. Int. J. Obes. 10(2): 133-145, 1986

21. Weir JB. New methods for calculating metabolic rate with special reference to predicting protein metabolism. J. Physiol. (Lond) 109: 1-9, 1949

22. Westerterp KR, GAL Meijer, EME Janssen, WHM Saris, and F Ten Hoor. Long term effect of physical activity on energy balance and body composition. Br. J. Nutr. 68: 21-30, 1992

23. Westerterp KR, GAL Meijer, P Schoffelen, and EME Janssen. Body mass, body composition and sleeping metabolic rate before, during and after endurance training. Eur. J. Appl. Physiol. 69: 203-208, 1994

24. Westerterp KR. Alterations in energy balance with exercise. Am. J. Clin. Nutr. 68 (suppl): 970S-974S, 1998

25. Wilmore JH, PR Stanforth, LA Hudspeth, J Gagnon, EW Daw, AS Leon, DC Rao, IS Skinner, and $C$ Bouchard. Alterations in resting metabolic rate as a consequence of 20 wk of endurance training: the HERITAGE Family study. Am. J. Clin. Nutr. 68: 66-71, 1998 
Chapter 3

\title{
Effect of exercise training on physical activity and substrate utilization in the elderly
}

\author{
Erwin P. Meijer \\ Klaas R. Westerterp \\ Frans T.J. Verstappen
}

International Journal of Sports Medicine,

21(7): 488-504, 2000. 


\section{Abstract}

This study examined the effect of training on physical activity and substrate utilization in the elderly. Before the start, in week 6 and week 12 (T0, T6 and T12) data on physical fitness, physical activity and substrate utilization, were collected in the exercise (11 males, 11 females; $63 \pm 8$ y) and control group ( 6 males, 5 females; $59 \pm 4$ y). Physical activity was registered with a tri-axial accelerometer and substrate utilization was calculated from resting respiratory exchange ratio (RER) by indirect calorimetry. At T6 physical activity on training days was significantly higher than on nontraining days $\left(33.4 \pm 10.3\right.$ vs. $26.5 \pm 7.8$ counts $\left.\cdot \mathrm{min}^{-1} ; \mathrm{P}<0.001\right)$. At T12, after adjusting for training activity, physical activity on training days was significantly lower than on non-training days $\left(23.7 \pm 8.4\right.$ vs. $28.2 \pm 9.3$ counts $\left.\mathrm{min}^{-1} ; \mathrm{P}<0.01\right)$. RER decreased significantly $(0.02 \pm 0.03 ; P<0.05)$, indicating a relatively larger fat oxidation. Changes in RER were negatively correlated with pre-training RER. In conclusion, in elderly an increase in structured training (exercise) is compensated for by a corresponding decrease in non-training physical activity. Training increased relative fat utilization in elderly with a high pre-training RER, whereas elderly with a low pre-training RER decreased their relative fat utilization. 


\section{Introduction}

Exercise programs for the elderly are promoted to improve or maintain physical fitness and health. It is generally believed that an improved physical fitness would increase the daily level of physical activity. Recently, however, three studies in the elderly reported a decrease in non-training physical activity as a consequence of participation in an exercise training program $(9,13,15)$. Morio et al. (15) measured the effect of training on non-training physical activity by using 7-d activity recordings. Non-training physical activity was calculated from the duration and unitary costs of the various recorded activities. Goran and Poehlman (9) calculated non-training physical activity from the difference between total energy expenditure and resting energy expenditure after adjusting for the thermic response to feeding and the energy cost of the exercise training. Meijer et al. (13), directly measured non-training physical activity with a tri-axial accelerometer.

Assessment of physical activity patterns in subjects by using body-fixed accelerometers seems to offer promising possibilities. Bouten et al. (5) developed a tri-axial accelerometer based on three separate uni-axial accelerometers. Comparison between physical activity generated accelerometer output and activity associated energy expenditure as measured with doubly labeled water in 30 free living subjects over $7-d$ intervals revealed a significant relationship (ref. $4 ; r=0.79$ ).

Aging is generally associated with an increase in adiposity and loss of fat-free mass, which could be partially explained by a decreased physical activity and declining resting metabolic rate $(1,7,10)$. It has also been suggested that elevated levels of body fat in the elderly may be due, at least partially, to a decrease in fat mobilization (11). Therefore, an exercise intervention to increase fat oxidation may be beneficial in reducing obesity in the elderly. Three studies examined the effect of exercise training on fat utilization in rest in the elderly $(16,19,22)$. These studies used respiratory exchange ratio (RER) as a marker for fat utilization. Two studies $(16,22)$ demonstrated an increase, and Sial et al. (19) reported no significant change in resting fat utilization. Treuth et al. (22) demonstrated an increased fat oxidation, as calculated from RER, after 16-wk strength training. Poehlman et al. (16), also, showed an increased fat oxidation during rest as measured with the $\left[{ }^{14} \mathrm{C}\right]$ palmitate infusion method, after 8-wk endurance training. Sial et al. (19), on the other hand, demonstrated only a training-induced increase in fat utilization during exercise as measured with stable isotope tracers. The differences between those three studies could partly be explained by differences in standardization.

Although it seems that training influences resting fat oxidation, Van Etten et al. (23) demonstrated in young adults that training induced changes in RER were negatively correlated with pre-training RER values. This suggests that training increases fat utilization in subjects with a high pre-training $R E R$, whereas fat utilization decreases in subjects displaying low pre-training RER.

The purpose of this study was to investigate the effect of a 12-wk exercise training program of moderate intensity on daily physical activity and substrate 
utilization in the elderly. Physical activity was registered by using a tri-axial accelerometer. RER was used as a measure for substrate utilization.

\section{Methods}

Subjects. Thirty-three healthy sedentary men and women, over $55 \mathrm{y}$ of age, were selected to participate in the study. Detailed information concerning the purpose and methods used in the study was provided, and written consent was obtained. Twenty-two subjects (11 women, 11 men) participated in the exercise group (EXER), and eleven subjects ( 5 women, 6 men) served as non-trained controls (CONT). The variables body composition, basal metabolic rate (BMR), daily physical activity and physical fitness were measured at T0 (baseline), at T6 (6-wk training) and T12 (12-wk training) in EXER and at T0 and T12 in CONT.

Table 1. Characteristics of the exercise and control group.

\begin{tabular}{lcc}
\hline & exercise group & control group \\
\hline Number (men/women) & $22(11 / 11)$ & $11(6 / 5)$ \\
Age, y & $63 \pm 8$ & $59 \pm 4$ \\
Height, m & $1.69 \pm 0.09$ & $1.70 \pm 0.10$ \\
Body mass, kg & $81.6 \pm 16.1$ & $75.1 \pm 13.3$ \\
BMI, kg.m ${ }^{-2}$ & $29 \pm 4$ & $26 \pm 3$ \\
Fat, \% & $37 \pm 7$ & $33 \pm 7$ \\
Fat mass, kg & $29.9 \pm 8.4$ & $24.6 \pm 6.9$ \\
Fat-free mass, kg & $51.6 \pm 11.2$ & $50.5 \pm 9.7$ \\
VO $_{2 \max }, \mathrm{l} \cdot \mathrm{min}^{-1}$ & $1.91 \pm 0.44$ & $2.02 \pm 0.36$ \\
$\mathrm{~W}_{\max }$, watt & $126 \pm 33$ & $144 \pm 28$ \\
$\mathrm{HR}_{\max }, \mathrm{bts} \cdot \mathrm{min}^{-1}$ & $141 \pm 18$ & $149 \pm 14$ \\
\hline
\end{tabular}

Results are means $\pm \mathrm{SD}$. Analysis revealed no differences between the groups.

Body composition. Physical characteristics are shown in Table 1. Anthropometric measurements were taken after an overnight stay at the laboratory. After voiding, body mass was measured on an electronic scale (Sauter, Type E1200, Albstadt 1, Ebingen, Germany). Body volume was determined with underwater weighing. Residual lung volume was simultaneously measured with the helium dilution technique (Volugraph 2000, Mijnhardt, Bunnik, The Netherlands). Total body water (TBW) was determined with deuterium $\left({ }^{2} \mathrm{H}_{2} \mathrm{O}\right)$ dilution (12). Body composition was calculated from body mass, body volume and TBW with the three-compartment model of Siri (20).

Basal metabolic rate. Basal metabolic rate (BMR) was measured after an overnight fast for 30-min at $7.00 \mathrm{~h}$ a.m. Due to limited use of the respiration chamber only fifteen subjects slept at the laboratory, the other 18 subjects were transported to the laboratory by car to reduce physical activity. Subjects driven to the laboratory at $\mathrm{T} 0$, 
were also driven to the laboratory at T6 and T12. BMR was measured for at least 15min under thermoneutral temperature conditions, after a period of 15 -min bed-rest. Oxygen consumption and carbon dioxide production were measured by means of a computerized, open-circuit, ventilated hood system. Gas analyses were performed using a paramagnetic oxygen analyzer (Servomex Type 500A, Crowborough Sussex, UK) and an infrared carbon dioxide analyzer (Servomex Type 12-X1). The system was similar to the analysis system for the respiration chambers described before (17). Calculation of BMR was based upon the Weir formula (25).

Sleeping metabolic rate. Sleeping metabolic rate (SMR) was measured during an overnight stay in a respiration chamber $(8.00$ p.m.: 7.00 a.m.) as described before (18). To minimize the residual effects of training on energy expenditure, subjects were measured 36 hours after the last training session. SMR was measured over a shiftable 3-h interval between 0.00-6.00 a.m. with the minimal activity level judged from Doppler radar observation. SMR was measured in 10 subjects randomly selected from the exercise group and 5 subjects randomly selected from the control group.

Daily physical activity. Physical activity over a 14-d interval was registered by using a tri-axial accelerometer, consisting of three uni-axial piezo-electric accelerometers, attached to the lower back of the subjects with an elastic belt. The tri-axial accelerometer was the same version $(69 \times 28 \times 9 \mathrm{~mm}, 30 \mathrm{~g})$ as described recently (13, 27). The accelerometer calculates the sum of the rectified and integrated acceleration curves from the antero-posterior, medio-lateral and longitudinal axis of the trunk. The time period for integration was set at 1-min. Subjects were instructed to wear the accelerometer during waking hours, except during bathing and showering.

Physical fitness. To investigate the effect of the training program on aerobic power (maximal oxygen uptake: $\left.\mathrm{VO}_{2 \max }\right)$ and maximal power output $\left(\mathrm{W}_{\max }\right)$, an incremental exercise test was performed on an electromagnetically braked cycle ergometer (Lode Excalibur, Groningen, The Netherlands). Subjects started to cycle 3-min at $30 \mathrm{~W}$ at 60 $\mathrm{rpm}$ and the workload was increased every minute with $10 \mathrm{~W}$ until exhaustion. Criteria for maximal aerobic performance were forced ventilation, leveling off of oxygen uptake or a respiratory exchange ratio (RER) above 1.1. The oxygen uptake during the test was measured continuously, using a computerized open system (SensorMedics 2900 analyzer, Anaheim, CA, USA). During the incremental exercise test heart rate was continuously measured (Polar Sport Tester, Kempele, Finland). To quantify the effect of the training program on the heart function, heart rate at a submaximal power output of $100 \mathrm{~W}$ and $70 \mathrm{~W}$ were compared before and after training.

Training program. The subjects trained twice a week at a fitness club, on one day a group session of 60-min with various aerobic exercises and another day an individual session of 90-min consisting of 9 exercises using cardio- and weight-stack machines 
(Sportesse, Germany). Two sets of 10 repetitions were performed of the following exercises: lat row (m. latissimus dorsi), pec deck (m. pectoralis major/minor), leg extension (quadriceps femoris), leg curl (hamstrings), biceps curl, triceps extension, shoulder press ( $\mathrm{m}$. deltoidius) and sit-ups (abdominal muscles). Additionally, each individual session included a 10-min warming-up and cooling down of walking or cycling on a self selected intensity. The group session consisted of 15-min warmingup with non-intensive aerobic running and stretching exercises, followed by 30-min step exercise. Each group session was concluded by 15 -min cooling down period during which low intensity aerobic and relaxation exercises were conducted. The group session was chosen to improve compliance. The intensity of both training sessions was approximately $50 \%$ of heart rate reserve as measured by heart rate (Polar Sport Tester, Kempele, Finland) and a slight progressive training design was used. Average training compliance was $86 \pm 8 \%$. A fitness instructor supervised the training sessions.

Table 2. Changes in body composition, basal metabolic rate and physical fitness in the exercise and in the control group.

\begin{tabular}{lccc}
\hline & exercise group & & control group \\
& $\mathrm{T} 6$ & $\mathrm{~T} 12$ & $\mathrm{~T} 12$ \\
\hline Body mass, $\mathrm{kg}$ & $-0.2 \pm 1.7$ & $-0.3 \pm 2.0$ & $0.6 \pm 0.9$ \\
Fat, \% & $-0.6 \pm 2.0$ & $-0.3 \pm 1.7$ & $-0.9 \pm 2.2$ \\
Fat-free mass, $\mathrm{kg}$ & $0.54 \pm 0.43$ & $0.14 \pm 1.60$ & $1.31 \pm 2.10$ \\
$\mathrm{BMR}, \mathrm{kJ} \cdot \mathrm{min}^{-1}$ & $-0.2 \pm 0.4^{*}$ & $-0.2 \pm 0.5^{*}$ & $-0.1 \pm 0.4$ \\
$\mathrm{VO}_{2 \max }, 1 \cdot \mathrm{min}^{-1}$ & $0.17 \pm 0.25^{*}$ & $0.16 \pm 0.34^{*}$ & $0.05 \pm 0.21$ \\
$\mathrm{~W}_{\max }$ watt & $6 \pm 17^{*}$ & $9 \pm 20^{*}$ & $0 \pm 10$ \\
$\mathrm{HR} 100 \mathrm{~W}, \mathrm{bts} \cdot \mathrm{min}^{-1}$ & $-8 \pm 11^{* *}$ & $-10 \pm 11^{* *}$ & $-1 \pm 6^{* * *}$ \\
$\mathrm{HR} 70 \mathrm{~W}, \mathrm{bts} \cdot \mathrm{min}^{-1}$ & $-6 \pm 11^{*}$ & $-9 \pm 11^{*}$ & $-1 \pm 9^{* * *}$ \\
\hline
\end{tabular}

Significantly different from T0: * $\mathrm{P}<0.05 ; * * \mathrm{P}<0.001$. Significantly different between the groups: *** $\mathrm{P}<0.001$

Statistics. The analysis of variance (ANOVA) for repeated measures within subjects was used to compare differences in EXER. Paired $t$-tests were used to analyze differences in CONT between baseline measurements and T12. To analyze differences between the exercise and control group regarding SMR and RER, the non-parametric Mann-Whitney $U$ test was used. Statistical significance was set at $\mathrm{P}<0.05$.

\section{Results}

Body composition. In both groups, EXER and CONT, subjects showed no change in body mass (Table 2). There were no changes in body composition in EXER (T0, T6 and T12: $37 \pm 7,36 \pm 7$ and $36 \pm 7 \%$ fat mass) and in CONT (TO and T12: $33 \pm 7$ and 
$32 \pm 7 \%$ fat mass). Gender had no significant effect on the explained variation of the effect of training on physical fitness, physical activity and substrate utilization.

Metabolic rate. BMR significantly decreased in EXER (T0 vs. T6 and T12: $4.9 \pm 1.1$ vs. $4.6 \pm 1.0$ and $4.7 \pm 0.9 \mathrm{~kJ} \cdot \mathrm{min}^{-1} ; \mathrm{P}<0.01$ and $\mathrm{P}<0.05$ ), whereas, there were no changes in BMR in CONT (T0 and T12: $4.8 \pm 0.6$ and $4.7 \pm 0.7 \mathrm{~kJ} \cdot \mathrm{min}^{-1}$ ). BMR adjusted for FFM, also, significantly decreased in EXER (TO vs. T6 and T12: $95 \pm 13$ vs. $90 \pm 13$ and $91 \pm 10$ $\mathrm{J} \cdot \mathrm{min}^{-1} \cdot \mathrm{kg}^{-1} ; \mathrm{P}<0.01$ and $\mathrm{P}<0.05$ ). No changes were shown in CONT (T0 vs. T12: $97 \pm 10$ vs. $\left.93 \pm 11 \mathrm{~J} \cdot \mathrm{min}^{-1} \cdot \mathrm{kg}^{-1}\right)$. SMR adjusted for FFM, measured in a subgroup of EXER $(n=10)$, significantly decreased (T0 vs. T6 and T12: $93 \pm 9$ vs. $84 \pm 8$ and $88 \pm 6$ $\mathrm{J} \cdot \mathrm{min}^{-1} \cdot \mathrm{kg}^{-1} ; \mathrm{P}<0.05$ and $\left.\mathrm{P}=0.06\right)$. No changes in SMR, measured in a subgroup of CONT $(\mathrm{n}=5)$, were shown (T0 and T12: $91 \pm 11$ and $90 \pm 11 \mathrm{~J} \cdot \mathrm{min}^{-1} \cdot \mathrm{kg}^{-1}$ ).

Substrate utilization. The decrease in $\mathrm{RER}_{\mathrm{SMR}}$ in EXER at $\mathrm{T} 12(0.80 \pm 0.03$ vs. $0.78 \pm 0.03 ; \mathrm{P}<0.05$ ) indicated an increased fat oxidation. However, $\mathrm{RER}_{\mathrm{BMR}}$ in EXER at $T 12$, remained unchanged. In CONT no changes in $R R_{S M R}$ or in $R E R_{B M R}$ were observed. Changes in $R R_{B M R}$ and RER $R_{S M R}$ at $T 12$ were negatively correlated with the pre-training RER ( $r=-0.62$ and $r=0.64 ; P<0.01$ and $P<0.05$, Fig. 1). No such relationship was observed in CONT.

Daily physical activity. As depicted in Fig. 2a, average daily physical activity as measured with the tri-axial accelerometer over two week intervals significantly increased in EXER (T6 and T12 vs. T0: $27.5 \pm 7.7$ and $28.0 \pm 8.9$ vs. $22.5 \pm 6.0$ counts $\min ^{-1} ; \mathrm{P}<0.05$ ). No change in physical activity was observed in CONT (T0 and T12: $28.5 \pm 9.2$ and $28.8 \pm 8.0$ counts $\left.\cdot \mathrm{min}^{-1}\right)$. At $\mathrm{T} 6$ physical activity was significantly higher on training days than on non-training days $(33.4 \pm 10.3$ vs. $26.5 \pm 7.8$ counts $\min ^{-1} ; \mathrm{p}<0.001$; Fig. $2 \mathrm{~b}$ ), whereas, at $\mathrm{T} 12$ there was no significant difference between physical activity on training and non-training days (30.1 \pm 8.8 vs. $28.2 \pm 9.3$ counts $\left.\cdot \mathrm{min}^{-1}\right)$. After subtracting the accelerometer output of the training sessions from total accelerometer output on training days and after adjusting for training time, at T12 physical activity on training days was significantly lower than on non-training days ( $23.7 \pm 8.4$ vs. $28.2 \pm 9.3$ counts $\cdot \mathrm{min}^{-1} ; \mathrm{P}<0.01$; Fig. 2 b). A training session resulted in an accelerometer output of $98 \pm 28$ counts $\cdot \mathrm{min}^{-1}$ at $\mathrm{T} 6$ and $109 \pm 17$ counts $\mathrm{min}^{-1}$ at $\mathrm{T} 12(\mathrm{P}<0.05)$. The time wearing the accelerometer did not change between $\mathrm{T} 0$, T6 and T12 in both groups (EXER: $865 \pm 61,870 \pm 63,881 \pm 58 \mathrm{~min} \cdot$ day $^{-1}$ and CONT: $870 \pm 69$, $861 \pm 81 \mathrm{~min} \cdot$ day $\left.^{-1}\right)$.

Physical fitness. In Table 2 the differences in $\mathrm{W}_{\max }$ and $\mathrm{VO}_{2 \max }$ measured at the incremental exercise test are presented for both groups. $\mathrm{W}_{\max }$ and $\mathrm{VO}_{2 \max }$ at $\mathrm{T} 12$ increased significantly in EXER. In CONT no significant changes in $\mathrm{W}_{\max }$ and $\mathrm{VO}_{2 \max }$ could be demonstrated. Heart rate at $100 \mathrm{~W}$ significantly reduced in EXER at T6 and T12 when compared with T0 $\left(113 \pm 17\right.$ and $111 \pm 18$ vs. $121 \pm 20$ bts $\left.\cdot \mathrm{min}^{-1} ; \mathrm{P}<0.01\right)$, whereas, heart rate at $100 \mathrm{~W}$ in CONT remained unchanged between $\mathrm{T} 0$ and $\mathrm{T} 12$ 
( $125 \pm 19$ vs. $124 \pm 21$ bts $\left.\mathrm{min}^{-1}\right)$. Heart rate at $70 \mathrm{~W}$, also, reduced in EXER and remained unchanged in CONT (Table 2).
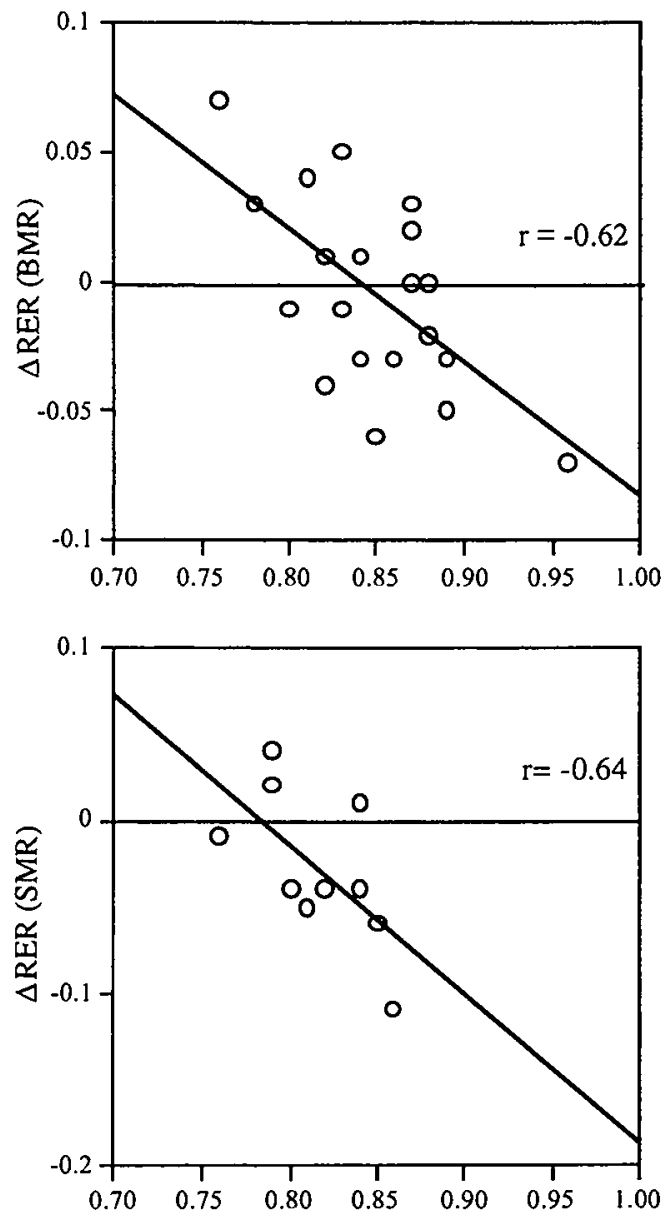

Figure 1. Relationship between respiratory exchange ratio $(\triangle \mathrm{RER})$ and pre-training RER measured during BMR $(\mathrm{P}<0.01)$ and SMR $(\mathrm{P}<0.05)$.

\section{Discussion}

The present study was performed to examine the effect of exercise training on daily physical activity in healthy older individuals. Daily physical activity was registered over a two week interval with a tri-axial accelerometer. Results show a significant increase in total physical activity, which is in accordance with findings of Meijer et al. (14) in young adults. They demonstrated that the increase in total physical activity was almost entirely the result of the added training for marathon running. 
Although the mode of exercise was different from the present study, the observed increase in total physical activity was similar. Overall physical activity on training days was significantly higher than on non-training days. After subtracting the physical activity of the training session, however, the remaining physical activity was lower than on non-training days (Fig. 2). The decline in non-training physical activity at T12 compared to T6 might be associated with an increased exercise intensity ( $109 \pm 17$ vs. $98 \pm 28$ counts $\cdot \mathrm{min}^{-1} ; \mathrm{P}<0.05$ ), since subjects were not suffering from any injuries. The decline in non-training physical activity agrees with previous findings $(9,13,15)$. Goran and Poehlman (9) suggested that in their study the exercise intensity during the last week of training $\left(3 \mathrm{~h} \cdot \mathrm{wk}^{-1}\right.$ at $85 \%$ of $\mathrm{VO}_{2 \text { max }}$ ) fatigued the elderly participants during the remaining of the day. Meijer et al. (13), however, used an exercise training program of moderate intensity, and exercise training sessions were performed in the late afternoon. The same protocol was used in the present study.

Possibly, the duration of the exercise intervention might explain the observed decline in non-training physical activity, because in the present study only after 12wk training a decline in non-training physical activity was observed. Goran and Poehlman (9) showed a decline after 8-wk endurance training. Probably, 6-wk exercise training of moderate intensity is too short to influence non-training physical activity. Because the exercise training sessions were performed during the late afternoon, the decline in non-training physical activity likely preceded the training sessions. Our results, therefore, suggest that the compensation in physical activity as a consequence of participation in an exercise training program seems to be an anticipatory mechanism, i.e. the elderly participants lowered their physical activity already before the exercise training sessions. Unfortunately, it is unknown at which time the training sessions were performed in the study of Goran and Poehlman (9). From a clinical perspective, our results indicate that exercise prescribed to elderly people might reduce non-training physical activity.

During sleep or rest RER showed a significant decrease after the training period. Assuming an unchanged contribution of protein oxidation, the decline in RER indicates approximately a $7 \%$ increase in the magnitude of the fat oxidation. Previous studies suggested that the training-induced increase in resting fat oxidation is attributed to an increased activity of the sympathetic nervous system $(16,19)$. Poehlman et al. (16) demonstrated that endurance training increased norepinephrine appearance rate by $35 \%$ and that approximately $50 \%$ of the variation of the increase in fat oxidation was explained by norepinephrine appearance rate $\left(\mathrm{r}^{2}=0.51, \mathrm{P}<0.01\right)$. In the present study, it was demonstrated that the change in RER was inversely correlated with pre-training RER (Fig. 1), which is in accordance with previous findings in young adults (23). Subjects with a low pre-training RER increased their RER, whereas subjects with a high pre-training RER showed a decrease. We, as Van Etten et al. (23), have yet no idea what biological mechanism might explain this finding. Change in eating habit is not likely since RER may change in both directions. Furthermore, the high correlation between pre-training RER and $\triangle \mathrm{RER}(\mathrm{P}<0.01)$ makes 
it less plausible that the change in RER was a consequence of regression to the mean.
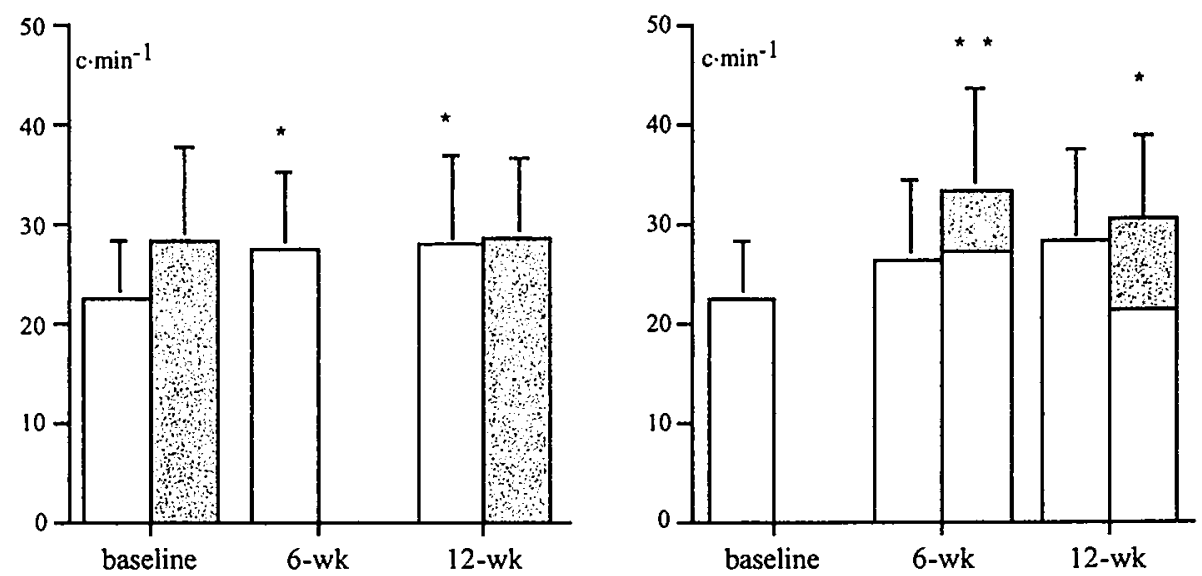

Figure 2. A: Daily accelerometer output (mean $\pm S D)$ in counts $\min ^{-1}$. Accelerometer output does not differ between the exercise group (EXER; open bars) and the control group (CONT; filled bars). Significantly different from T0 (* $\mathrm{P}<0.05)$. B: Accelerometer output (mean $\pm \mathrm{SD})$ on training and non-training days in counts $\mathrm{min}^{-1}$. Contribution accelerometer output of training session (filled squares). Significantly different between training and non-training days (** $P<0.001)$. Significantly different between non-training days and training days minus training session $\left({ }^{*} \mathrm{P}<0.01\right)$.

In the present study a significant increase in $\mathrm{W}_{\max }$ and $\mathrm{VO}_{2 \max }$ was observed (Table 2). The $8 \%$ increase in $\mathrm{VO}_{2 \max }$ after 12 -wk exercise training (1.91 \pm 0.44 vs. $2.07 \pm 0.59$ $\left.1 \cdot \mathrm{min}^{-1} ; \mathrm{P}<0.05\right)$ is similar to results of previous studies $(17,21)$. In elderly people, however, the accomplishment of daily activities corresponds better to submaximal responses to exercise training (8). In the present study, the reduction in heart rate at a submaximal power output of $100 \mathrm{~W}$ after 12-wk training is in agreement with findings of De Vito et al. (8). Thus, an exercise training program of moderate intensity twice a week as used in the present study improves physical fitness in healthy older adults.

The decreased SMR and BMR in EXER in the present study are in contrast with other exercise training intervention studies in the elderly $(6,9)$. Both studies demonstrated an increase in BMR. They measured BMR, as in the present study, at least $36 \mathrm{~h}$ after the last training session to prevent any carry-over effect from the prior exercise bout and both studies reported an increased fat-free mass. Although fat-free mass is an important determinant of BMR, most studies in young adults showed an exercise-induced increase in fat-free mass without an increase in BMR ( 2 , $3,24,26)$. The longest training intervention study (40-wk endurance training) showed the largest absolute increase (5\%) in fat-free mass with a slightly lower BMR (26). The authors speculated that BMR was decreased to prevent a further decline in body mass, because body mass was significantly decreased with $1.0 \pm 1.7 \mathrm{~kg}$. In the present 
study body mass and body composition did not change. We have no explanation for the observed decline in BMR and SMR. It does not seem likely that the decrease in BMR was due to methodological bias since the same subjects were driven to the laboratory prior to the BMR test at T0, T6 and T12.

The unchanged body mass is in accordance with other exercise training intervention studies $(2,3,6,9,24)$. However, these studies demonstrated a significant increase in fat-free mass and a decrease in fat mass without a change in body mass. Differences in training intervention (type of exercise) might explain the inconsistency in changes in body composition. In the present study two different training sessions were used, namely, a group session with various aerobic exercises and an individual resistance training session. In the other studies, however, only an endurance training protocol was used $(2,3,9)$ or a resistance training protocol was used $(6,24)$. Furthermore, all studies used a training program of high intensity, whereas, in the present study a training program of moderate intensity was used $(50 \%$ heart rate reserve).

In conclusion, in elderly an increase in structured training (exercise) is compensated for by a corresponding decrease in non-training physical activity. Furthermore, the exercise training program decreased SMR and BMR and increased relative fat utilization in elderly with a high pre-training RER, whereas relative fat utilization decreased in elderly with a low pre-training RER. 


\section{References}

1. Bemben MG, BH Massey, DA Bemben, RA Boileau, and JE Misner. Age-related patterns in body composition for men aged 20-79 yr. Med. Sci. Sports Exerc. 27(2): 264-269, 1995

2. Bingham SA, GR Goldberg, WA Coward, AM Prentice, and JH Cummings. The effect of exercise and improved physical fitness on basal metabolic rate. Br. J. Nutr. 61: 155-173, 1989

3. Blaak EE, KR Westerterp, O Bar-Or, LJM Wouters, and WHM Saris. Total energy expenditure and spontaneous activity in relation to training in obese boys. Am. J. Clin. Nutr. 55: 777-782, 1992

4. Bouten CVC, WPHG Verboeket-Van de Venne, KR Westerterp, M Verduin, and JD Janssen. Daily physical activity assessment: comparison between movement registration and doubly labeled water. J. Appl. Physiol. 81: 1019-1026, 1996

5. Bouten CVC, KR Westerterp, M Verduin, and JD Janssen. Assessment of energy expenditure for physical activity using a triaxial accelerometer. Med. Sci. Sports Exerc. 26: 1516-1523, 1994

6. Campbell WW, MC Crim, VR Young, and WJ Evans. Increased energy requirements and changes in body composition with resistance training in older adults. Am. J. Clin. Nutr. 60: 167-175, 1994

7. Davy KP, SL Evans, ET Stevenson, and DR Seals. Adiposity and regional body fat distribution in physically active young and middle-aged women. Int. J. Obes. 20: 777-783, 1996

8. De Vito G, R Hernandez, V Conzalez, F Felici, and F Figura. Low intensity physical training in older subjects. J. Sports Med. Phys. Fitness 37: 72-77, 1997

9. Goran MI, and ET Poehlman. Endurance training does not enhance total energy expenditure in healthy elderly persons. Am. J. Physiol. 263: E950-E957, 1992

10. Kohrt WM, MT Malley, GP Dalsky, and JO Holloszy. Body composition of healthy sedentary and trained, young and older men and women. Med. Sci. Sports Exerc. 24(7): $832-837,1992$

11. Lönnquist F, B Nyberg, $H$ Wahrenberg, and P Arner. Catecholamine-induced lipolysis in adipose tissue of the elderly. J. Clin. Invest. 85: 1614-1621, 1990

12. Marken Lichtenbelt WD, KR Westerterp, and L Wouters. Deuterium dilution as a method for determining total body water: effect of test protocol and sampling time. Br. J. Nutr. 72: 491-497, 1994

13. Meijer EP, KR Westerterp, and FTJ Verstappen. The effect of exercise training on total daily physical activity in the elderly. Eur. J. Appl. Physiol. 80(1): 16-21, 1999

14. Meijer GAL, GME Janssen, KR Westerterp, F Verhoeven, and WHM Saris. The effect of a 5-month endurance training programme on physical activity: evidence for a sex-difference in the metabolic response to exercise. Eur. J. Appl. Physiol. 62: 11-17, 1991

15. Morio B, C Montaurier, G Pickering, P Ritz, N Fellmann, J Coudert, B Beaufrere, and M Vermorel. Effects of 14 weeks of progressive endurance training on energy expenditure in elderly people. Br. J. Nutr. 80: 511-519, 1998

16. Poehlman ET, AW Gardner, PJ Arciero, MI Goran, and J Calles-Escadon. Effects of endurance training on total fat oxidation in elderly persons. J. Appl. Physiol. 76(6): 22812287, 1994

17. Posner JD, KM Gorman, L Windsor-Lansberg, J Larsen, M Bleiman, C Shaw, B Rosenberg, and $\mathrm{J}$ Knebl. Low to moderate intensity endurance training in healthy older adults: physiological responses after four months. J. Am. Geriatr. Soc. 40: 1-7, 1992 
18. Schoffelen PFM, KR Westerterp, WHM Saris, and F Ten Hoor. A dual-respiration chamber system with automated calibration. J. Appl. Physiol. 83(6): 2064-2072, 1997

19. Sial S, AR Coggan, RC Hickner, and S Klein. Training-induced alterations in fat and carbohydrate metabolism during exercise in elderly subjects. Am. J. Physiol. 274: E785E790, 1998

20. Siri WE. The gross composition of the body. Adv. Biol. Med. Phys. 4: 239-203, 1956

21. Takeshima N, K Tanaka, F Kobayashi, T Watanabe, and T Kato. Effects of aerobic exercise conditioning at intensities corresponding to lactate threshold in the elderly. Eur. $J$. Appl. Physiol. 67(2): 138-143, 1993

22. Treuth MS, GR Hunter, RL Weinsier, and SH Kell. Energy expenditure and substrate utilization in older women after strength training: 24-h calorimeter results. J. Appl. Physiol. 78(6): 2140-2146, 1995

23. Van Etten LMLA, KR Westerterp, and FTJ Verstappen. Effect of weight-training on energy expenditure and substrate utilization during sleep. Med. Sci. Sports Exerc. 27(2): $188-193,1995$

24. Van Etten LMLA, KR Westerterp, FTJ Verstappen, BJB Boon, and WHM Saris. Effect of an 18-week weight-training program on energy expenditure and physical activity. J. Appl. Physiol. 82(1): 298-304, 1997

25. Weir JB. New methods for calculating metabolic rate with special reference to predicting protein metabolism. J. Physiol. (Lond) 109: 1-9, 1949

26. Westerterp KR, GAL Meijer, $P$ Schoffelen, and EME Janssen. Body mass, body composition and sleeping metabolic rate before, during and after endurance training. Eur. $J$. Appl. Physiol. 1994; 69: 203-208, 1994

27. Westerterp KR. Physical activity assessment with accelerometers. Int. J. Obes. 23(Suppl 3): S45-S49, 1999 
Chapter 4

\section{Physical inactivity as a determinant of the physical activity level in the elderly}

Erwin P. Meijer Annelies H.C. Goris Loek Wouters

Klaas R. Westerterp

International Journal of Obesity, in press 


\section{Abstract}

We assessed the relationship between the mean physical activity level (PAL) and the time spent on activities of three different intensity levels in an elderly population. Data was compared with previously obtained data from a group of younger adults. Fourteen elderly women and 14 elderly men $\left(61 \pm 4 \mathrm{y} ; 27 \pm 5 \mathrm{~kg} \cdot \mathrm{m}^{-2} ; 33 \pm 7 \%\right.$ body fat $)$, and 14 young women and 16 young men $\left(27 \pm 5 \mathrm{y}, 24 \pm 2 \mathrm{~kg} \cdot \mathrm{m}^{-2}\right)$ participated in this study. PAL was determined as average daily metabolic rate (ADMR) combined with a measurement of basal metabolic rate (BMR): $P A L=A D M R / B M R$. ADMR was measured with the doubly labeled water method. BMR was measured with a ventilated hood system. Time spent on activity and activity intensity was measured by using a tri-axial accelerometer $(7 \times 2 \times 0.8 \mathrm{~cm}, 30 \mathrm{~g})$ over a 2-wk interval. Mean PAL was $1.65 \pm 0.14$. PAL was inversely related to the percentage of time spent on lowintensity activity (lying, sitting and standing), $1=0.43 ; \mathrm{P}<0.05$. Older subjects spent significantly more time at these activities than $20-35$ y old subjects $(82 \pm 7 \%$ vs. $65 \pm 7 \% ; \mathrm{P}<0.0001)$. Neither a significant relation was observed between PAL and the percentage of time spent on moderate (walking) or high (household activities, exercise and sports) intensity activity, or activity monitoring time $\left(14.4 \pm 1.2 \mathrm{~h} \cdot \mathrm{d}^{-1}\right)$. In conclusion, in the elderly, spending relatively more time on low-intensity activities affects the mean PAL negatively. To obtain a higher PAL does not necessarily imply high-intensity activities like sports. 


\section{Introduction}

Regular physical activity is an important contributor to a healthy lifestyle in the prevention of chronic disease (14). Aging, however, is associated with a decline in physical activity level $(1,19)$. Therefore, exercise programs for the elderly are promoted to improve or maintain physical fitness and health. Goran and Poehlman (8), however, showed that in elderly subjects training did not result in an increase in average daily metabolic rate (ADMR) as measured with the doubly labeled water method. The imposed training activity was compensated for by a corresponding decline in non-training physical activity. Goran and Poehlman (8) speculated that the level of exercise, $3 \mathrm{~h} \cdot \mathrm{wk}^{-1}$ at $85 \% \mathrm{VO}_{2 \max }$, was too vigorous and thus fatigued the elderly participants during the remainder of the day. Recently, however, we (11) showed the same compensatory effect of exercise training on non-training physical activity in elderly subjects, with a training program of only moderate intensity $(\sim 40 \%$ $\mathrm{VO}_{2 \max }$ ). It was shown that elderly subjects anticipate the training program by lowering their physical activity even before the exercise training session. Nontraining physical activity was measured directly by using tri-axial accelerometers.

Tri-axial accelerometers, as used in the previous study, are an objective and reliable tool to assess the physical activity level in free-living subjects (2). Additionally, accelerometers allow assessment of physical activity in large populations over periods that are long enough to be representative for normal daily life and with minimal discomfort for the subjects (20). Comparison between physical activity generated accelerometer output and activity associated energy expenditure as measured with doubly labeled water in 30 free-living subjects over 7-d intervals revealed a significant relationship $(r=0.80)(21)$. These tri-axial accelerometers are not only capable of measuring the physical activity pattern but also the intensity of movement.

The first purpose of the present study was to assess the relationship between the mean physical activity level and the time spent on activities of three different intensity levels (low-, moderate-, and high-intensity activities, respectively). Secondly, previously obtained data from a group of younger adults was used to examine possible age-associated differences in time spent on the three intensity levels. The physical activity level was assessed with the doubly labeled water method simultaneously with the use of tri-axial accelerometers.

\section{Methods}

Subjects. Twenty-eight healthy sedentary men and women participated in the study. Subjects were recruited from advertisements in the local media. Selection criteria were age over $55 \mathrm{y}$, no health problems, and no medication known to affect energy metabolism. Detailed information concerning the purpose and methods used in the study was provided, and written consent was obtained. The Ethics Committee of 
Maastricht University approved the study. Subject characteristics are shown in Table 1.

Table 1. Subject characteristics (mean \pm SD).

\begin{tabular}{lcc}
\hline & elderly & young adults \\
\hline Number (women/men) & $28(14 / 14)$ & $30(14 / 16)$ \\
Age, y & $61 \pm 4$ & $27 \pm 5$ \\
Body mass, $\mathrm{kg}$ & $77 \pm 12$ & $72 \pm 11$ \\
$\mathrm{BMI}, \mathrm{kg} \cdot \mathrm{m}^{-2}$ & $27 \pm 5$ & $24 \pm 2$ \\
Body fat, \% & $33 \pm 7$ & - \\
$\mathrm{VO}_{2 \max }, \mathrm{ml} \cdot \mathrm{kg}^{-1} \cdot \mathrm{min}^{-1}$ & $24 \pm 7$ & - \\
$\mathrm{W}_{\max }, \mathrm{W}$ & $148 \pm 47$ & - \\
\hline
\end{tabular}

BMI, body mass index; $\mathrm{VO}_{2 \max }$, maximal oxygen consumption; $\mathrm{W}_{\max }$, maximal workload capacity.

Study design. The study included a 2-wk observation period for the measurement of average daily metabolic rate (ADMR) and physical activity level (PAL).

Physical characteristics. Body mass was measured on an electronic scale (Sauter, Type E1200, Ebingen, Germany). Body composition was calculated from body mass, body volume and total body water (TBW) using Siri s three-compartment model (16). Body volume was determined by underwater weighing. Residual lung volume was measured simultaneously using the helium dilution technique (Volugraph 2000, Mijnhardt, Bunnik, The Netherlands). TBW was determined using deuterium $\left({ }^{2} \mathrm{H}_{2} \mathrm{O}\right)$ dilution. Maximal workload capacity $\left(\mathrm{W}_{\max }\right)$ and maximal oxygen uptake $\left(\mathrm{VO}_{2 \max }\right)$ were measured, on an electronically braked cycle ergometer (Lode Excalibur, Groningen, The Netherlands) during an incremental exercise test, as described before (11).

Energy expenditure. ADMR was measured with the doubly labeled water method according to the Maastricht protocol (22). Subjects were given, on the evening of day 0 after a background urine sample was collected, a weighed dose of a mixture of 99.9 atom $\%{ }^{2} \mathrm{H}_{2} \mathrm{O}$ in 10.0 atom $\% \mathrm{H}_{2}^{18} \mathrm{O}$, such that baseline levels were increased to $\geq 300 \mathrm{ppm}$ for ${ }^{2} \mathrm{H}$ and $\geq 2300 \mathrm{ppm}$ for ${ }^{18} \mathrm{O}$. Additionally, urine samples were collected on day 1 (from second void) on the evening of day 1 , evening of day 7 , morning day 8 (from second void), evening of day 14 , and morning of day 15 (from second void). Mean physical activity level was determined as ADMR combined with a measurement of basal metabolic rate (BMR): $\mathrm{PAL}=\mathrm{ADMR} / \mathrm{BMR}$.

Basal metabolic rate. BMR was measured after an overnight fast at $6.45 \mathrm{~h}$ a.m. After a period of 15 -min bed-rest under thermoneutral temperature conditions, BMR was measured for at least 15-min. Oxygen consumption and carbon dioxide production were measured by means of a computerized, open-circuit, ventilated hood system. Gas analyses were performed using a paramagnetic oxygen analyzer (Servomex Type 
500A, Crowborough Sussex, UK) and an infrared carbon dioxide analyzer (Servomex Type 12-X1). The system was similar to the analysis system for the respiration chambers described before (15). Calculation of BMR was based upon the Weir formula (18).

Daily physical activity. Physical activity over a 14-d interval was registered by using a tri-axial accelerometer, consisting of three uni-axial piezo-electric accelerometers, attached to the lower back of the subjects with an elastic belt. The tri-axial accelerometer was the same version $(7 \times 2 \times 0.8 \mathrm{~cm}, 30 \mathrm{~g})$ as described recently (20). The accelerometer calculates the sum of the rectified and integrated acceleration curves from the antero-posterior, medio-lateral and longitudinal axis of the trunk. The time period for integration was set at $1-\mathrm{min}$. Subjects were instructed to wear the accelerometer during waking hours, except during bathing and showering. Activities were defined in three intensity levels, as validated against indirect calorimetry (2). Low-intensity, associated with an accelerometer output $\leq 200$ counts $\min ^{-1}$, represents lying, sitting and standing ( $<3$ METs [work metabolic rate/resting metabolic rate]). Moderate-intensity, associated with an accelerometer output ranging from 200 to 500 counts. $\mathrm{min}^{-1}$, includes walking (3-6 METs). High-intensity, associated with an accelerometer output $\geq 500$ counts $\min ^{-1}$, includes household activities, exercise and sports ( $>6$ METs). The fraction of time spent on a certain intensity level was calculated as time spent on the intensity level divided by the total activity time.

Accelerometer data of the elderly subjects was compared with previously obtained accelerometer data of healthy non-obese younger adults (14 women and 16 men; $27 \mathrm{y}$ [range $20-35 \mathrm{y}$ ]; $24 \pm 2 \mathrm{~kg} \cdot \mathrm{m}^{-2}$ ), applying an earlier version of the accelerometer used in the present study (2). Definition of the three intensity levels was identical for the two studies, which allows direct comparison of the data. The absolute intensity cut-off points, however, were adjusted for difference in age, which was determined by using the same validation test for the elderly subjects as was done for the younger subjects (2).

Statistics. Data are presented as means $\pm S D$. Paired $t$-tests (two-tailed) with Bonferroni correction were used to evaluate differences within subjects, while differences between subjects were evaluated with unpaired $t$-tests with Bonferroni correction. Simple regression was used to examine the relationship between PAL and the three different activity intensities. Correlations are Pearson product-moment correlations. Statistical significance was accepted as $\mathrm{P}<0.05$. The StatView5.0 program (1992-98, SAS Institute Inc., Cary, NC, USA) was used as the statistical package.

\section{Results}

The mean PAL was $1.65 \pm 0.14$ (Table 2), and PAL was significantly correlated with accelerometer output (Fig. 1; $=0.78 ; \mathrm{P}<0.0001$ ). PAL was significantly associated 
with $\mathrm{VO}_{2 \max }$, adjusted for differences in fat-free mass $(\mathrm{r}=0.59 ; \mathrm{P}<0.0001)$. PAL was inversely related to the percentage of time spent on low-intensity activities $(r=0.43$; $\mathrm{P}<0.05$ ). No significant relationship was observed between PAL and the percentage of time spent on high-intensity activities $(r=0.38 ; \mathrm{P}=0.15)$. The relationship between PAL and the percentage of time spent on moderate activity intensities just failed to reach significance $(r=0.37 ; \mathrm{P}=0.07)$. Elderly subjects spent significantly more time on low-intensity activities than on moderate- or high-intensity activities $(\mathrm{P}<0.0001$; Fig. 2). Furthermore, elderly subjects spent significantly more time on low-intensity activities than younger adults ( $82 \pm 7 \%$ vs. $65 \pm 7 \%$; $\mathrm{P}<0.0001$; Fig. 2 ). The opposite was shown with moderate- and high-intensity activities, elderly spent significantly less of their time on moderate- and high-intensity activities than younger adults $(\mathrm{P}<0.0001)$. No significant differences were observed between elderly and younger adults in activity monitoring time or sleeping time (Table 2).

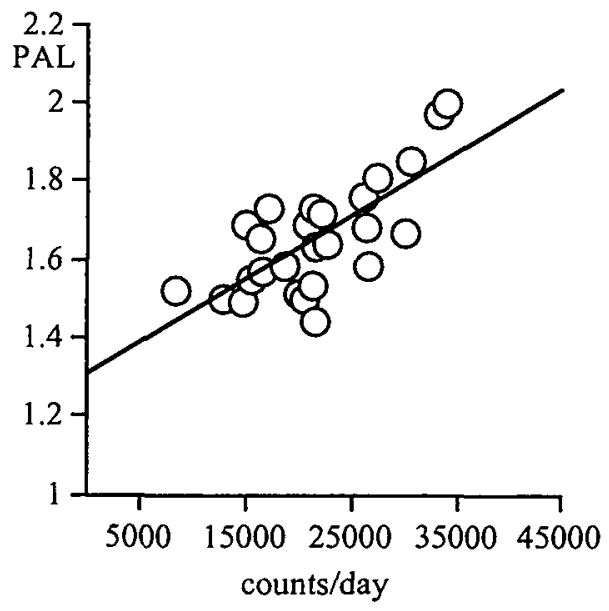

Figure 1. Physical activity level (PAL) as measured with the doubly labeled water method vs. accelerometer output in counts/day. PAL $=0.0002 \times$ accelerometer output $+1.30 ; \quad r=0.78$; $\mathrm{P}<0.0001$.

Table 2. Daily sleeping time, activity monitoring time, physical activity level (PAL), and the percentage of time spent on activities of low-, moderate-, and high-intensity. Data of younger adults obtained from Bouten et al. (2).

\begin{tabular}{lcccc}
\hline Variable (unit) & $\begin{array}{c}\text { elderly } \\
\text { mean }\end{array}$ & range & young adults \\
& 8.5 & $6.4-11.5$ & 8.3 & mean \\
\hline Sleeping time $\left(\mathrm{h} \cdot \mathrm{d}^{-1}\right)$ & 14.4 & $11.7-17.2$ & 13.7 & $10.7-10.5$ \\
Activity time $\left(\mathrm{h} \cdot \mathrm{d}^{-1}\right)$ & $1.65^{*}$ & $1.44-2.0$ & 1.77 & $1.51-2.04$ \\
PAL & $82^{* *}$ & $66-95$ & 65 & $52-82$ \\
Low activity (\%) & $15^{* *}$ & $3-22$ & 25 & $11-36$ \\
Moderate activity (\%) & $4^{* *}$ & $1-12$ & 9 & $3-15$ \\
\hline
\end{tabular}

${ }^{*} \mathrm{P}<0.01 ;{ }^{* *} \mathrm{P}<0.0001$ 


\section{Discussion}

The present study shows that, in an elderly population, spending relatively more time on low-intensity activities affects the mean PAL negatively. To obtain a higher PAL does not necessarily imply high-intensity activities like sports.

In this study PAL was inversely related to the time spent on low-intensity activities $(r=0.43, P<0.05)$. The relationship between time spent on moderateintensity activities and PAL just failed to reach significance $(\mathrm{r}=0.37 ; \mathrm{P}=0.07)$, which could be due to the small number of subjects in this study $(n=28)$. In addition, the study with the younger adults showed a strong correlation between PAL and time spent on low- or moderate-intensity activities $(r=0.67, P<0.0001 ; r=0.70, P<0.0001$, respectively). The results of both studies clearly indicate that spending relatively more time on low-intensity activities affect PAL negatively, whereas high-intensity activities does not have much impact on PAL. These findings suggest that reduction of physical inactivity does not necessarily imply high-intensity sports.

The results of this study support previous findings of training intervention studies in the elderly $(8,11,12)$. These studies demonstrated that exercise training in an elderly population results in a compensatory decline of non-training physical activity. Morio et al. (12) measured the effect of training on non-training physical activity by using 7-d activity recordings. Non-training physical activity was calculated from the duration and energy costs of the various recorded activities. Goran and Poehlman (8) calculated non-training physical activity from the difference between total energy expenditure and resting energy expenditure after adjusting for the thermic response to feeding and the energy cost of the exercise training. Meijer et al. (11) directly measured non-training physical activity with a tri-axial accelerometer.

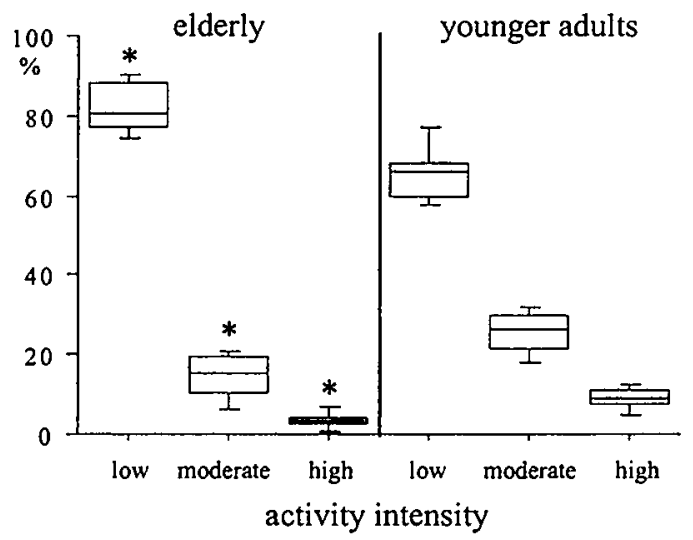

Figure 2. Box-and-whisker plots (median with quartiles and range) of the percentage of time spent on activities with low-, moderate-, and high-intensity of elderly (left side) and younger adults (right side). Significantly different between elderly and younger adults, ${ }^{*} \mathrm{P}<0.0001$. 
The proposed explanation that exercise training fatigues elderly subjects and thus reduces non-training physical activity afterwards, seems too simplistic. Recently, we (11) showed that elderly subjects anticipate a training program by lowering their physical activity even before the training session. The training program, two times one hour per week, was of moderate intensity $\left(-40 \% \mathrm{VO}_{2 \max }\right)$. Trying to obtain a higher PAL by exercise training counteracts its own effect by the compensatory increase of inactivity. Therefore, it could be argued that exercise training does not affect the mean PAL, at least in an elderly population. Although exercise training has no influence on PAL in an elderly population, it does not mean that exercise training should not be recommended to elderly humans. Following a training program has for example a considerable impact on skeletal muscle (9). Coggan et al. (5) demonstrated that exercise training improved maximal oxygen consumption, muscle fiber type composition, capillary density and oxidative capacity of skeletal muscle of 60-70-yold men and women. Furthermore, Kohrt et al. (10) showed that these changes, after following a training program, were similar to changes observed in young adults. It has to be mentioned, however, that training cannot completely prevent but only delay the age-related changes of these variables (4).

It remains speculative, however, why exercise training does not result in an increased PAL since a strong significant association is observed between $\mathrm{VO}_{2 \max }$ and PAL in this study $(r=0.59 ; \mathrm{P}<0.0001)$. Brochu et al. (3) recently showed in an elderly population that free-living physical activity associated energy expenditure was significantly related to the peak $\mathrm{VO}_{2 \max }(r=0.42 ; \mathrm{P}<0.0001)$. It could be argued that, although a strong positive correlation exists between these two variables, this relationship is not straightforward. To address this point, Dvorak et al. (6) reported that in an elderly population $(\mathrm{n}=117)$, high levels of $\mathrm{VO}_{2 \max }$, independent of physical activity levels, were associated with a more favorable cardiovascular disease risk profile. Additionally, Erikssen et al. (7) showed that even small improvements in $\mathrm{VO}_{2 \max }$ were associated with a lowered risk of death. Whereas, Pate et al. (14) showed that higher levels of PAL were associated with a lower cardiovascular disease profile and overall mortality. These studies support the idea that $\mathrm{VO}_{2 \max }$ and PAL may act in a unique and independent manner to improve cardiovascular and metabolic health in the elderly. A high PAL might be obtained, as shown by the results of the present study, by omitting physical inactivity instead of following an exercise training program.

It could be argued that our results are maybe not entirely generalizable to all older adults. The mean PAL in the present study $(1.65 \pm 0.14)$, however, is in accordance with previous findings $(1,17)$. Black et al. (1) reported for women a mean PAL of $1.69 \pm 23$ in the age group 40-64 y $(n=47)$ and a mean PAL of $1.62 \pm 0.25$ in the age group $65-74 \mathrm{y}(\mathrm{n}=24)$. For men mean PAL was $1.64 \pm 0.17$ and $1.61 \pm 0.28$ for the age groups $40-64$ y $(n=15)$ and $65-74$ y $(n=22)$, respectively. Starling et al. (17) reported a mean PAL of $1.68 \pm 0.28$ in 99 older men and women. The lower mean PAL $(1.58 \pm 0.21)$ observed in the study of Pannemans and Westerterp (13) compared to the PAL of present study, could partly be explained by the younger age of the subjects in our 
study (men $62 \pm 5 \mathrm{y}$ and women $59 \pm 3 \mathrm{y}$ vs. $71 \pm 5 \mathrm{y}$ and $68 \pm 4 \mathrm{y}$, respectively). In addition, not all subjects in the present study were retired, 9 subject had still a fulltime job (mean PAL 1.73 \pm 0.18 ). Furthermore, the lowest PAL observed in the present study was 1.44 , whereas the lowest PAL in the study of Pannemans and Westerterp (13) was 1.27. Therefore, one might assume that the measured PAL reflects the actual physical activity level of an elderly population.

PAL of the elderly was significantly lower than the PAL of the younger adults (Table 2). In another study, we (19) observed that the decline of $37 \%$ and $35 \%$ in ADMR for women and men, respectively, between the age groups $20-34$ y and $75+y$ was mainly a consequence of a substantial reduction in activity associated energy expenditure. In the present study it was shown that this reduction in activity associated energy expenditure could be explained by a shift from spending more time on low-intensity activities instead of moderate- and high-intensity activities (Figure 2). Elderly spent approximately $17 \%$ more of their time on low-intensity activities than younger adults. From a physiological perspective, elderly wanting to increase their activity level should be recommended to spent less time on low-intensity activities, sitting and standing, and more time on moderate-intensity activities like walking or cycling. This recommendation is in accordance with findings of Pate et al. (14), who recommended that regular moderate-intensity physical activity provides substantial health benefits.

In conclusion, the findings of this study show that, in the elderly, spending relatively more time on low-intensity activities affects the mean PAL negatively. To obtain a higher PAL does not necessarily imply high-intensity activities like sports. 


\section{References}

1. Black AE, WA Coward, TJ Cole, and AM Prentice. Human energy expenditure in affluent societies: an analysis of 574 doubly-labelled water measurements. Eur. J. Clin. Nutr. 50: 72 92, 1996

2. Bouten CVC, WP Verboeket-van de Venne, KR Westerterp, M Verduin, and JD Janssen. Daily physical activity assessment: comparison between movement registration and doubly labeled water. J. Appl. Physiol. 81: 1019-1026, 1996

3. Brochu M, RD Starling, PA Ades, and ET Poehlman. Are aerobically fit older individuals more physically active in their free-living time? A doubly labeled water approach. J. Clin. Endocrinol. Metab. 84: 3872-3876, 1999

4. Coggan AR, AM Abduljalil, SC Swanson, MS Earle, JW Farris, LA Mendenhall, and PM Robitaille. Muscle metabolism during exercise in young and older untrained and endurancetrained men. J. Appl. Physiol. 75: 2125-2133, 1993

5. Coggan AR, RJ Spina, DS King, MA Rogers, M Brown, PM Nemeth, and JO Holloszy. Skeletal muscle adaptations to endurance training in $60-$ to 70 -yr-old men and women. $J$. Appl. Physiol. 72: 1780-1786, 1992

6. Dvorak RV, A Tchernof, RD Starling, PA Ades, L DiPietro, and ET Poehlman. Respiratory fitness, free living physical activity, and cardiovascular disease risk in older individuals: a doubly labeled water study. J. Clin. Endocrinol. Metab. 85: 957-963, 2000

7. Erikssen G, K Liestøl, J Bjørnholt, E Thaulow, L Sandvik, and J Erikssen. Changes in physical fitness and changes in mortality. Lancet 352: 759-762, 1998

8. Goran MI, and ET Poehlman. Endurance training does not enhance total energy expenditure in healthy elderly persons. Am. J. Physiol. 263: E950-957, 1992

9. Kirkendall DT, and WE Garrett Jr. The effects of aging and training on skeletal muscle. Am. J. Sports Med. 26: 598-602, 1998

10. Kohrt WM, MT Malley, AR Coggan, RJ Spina, T Ogawa, AA Ehsani, RE Bourey, WHd Martin, and JO Holloszy. Effects of gender, age, and fitness level on response of VO2max to training in 60-71 yr olds. J. Appl. Physiol. 71: 2004-2011, 1991

11. Meijer EP, KR Westerterp, and FTJ Verstappen. Effect of exercise training on total daily physical activity in elderly humans. Eur. J. Appl. Physiol. 80: 16-21, 1999

12. Morio B, C Montaurier, G Pickering, P Ritz, N Fellmann, J Coudert, B Beaufrere, and M Vermorel. Effects of 14 weeks of progressive endurance training on energy expenditure in elderly people. Br. J. Nutr. 80: 511-519, 1998

13. Pannemans $\mathrm{DL}$, and $\mathrm{KR}$ Westerterp. Energy expenditure, physical activity and basal metabolic rate of elderly subjects. Br. J. Nutr. 73: 571-581, 1995

14. Pate RR, M Pratt, SN Blair, WL Haskell, CA Macera, C Bouchard, D Buchner, W Ettinger, GW Heath, AC King, A Kriska, AS Leon, BH Marcus, J Morris, RS Paffenberger, K Patrick, ML Pollock, JM Rippe, J Sallis, and JH Wilmore. Physical activity and public health: a recommendation from the CDC and ACSM. JAMA 273: 402-407, 1995

15. Schoffelen PF, KR Westerterp, WHM Saris, and F Ten Hoor. A dual-respiration chamber system with automated calibration. J. Appl. Physiol. 83: 2064-2072, 1997

16. Siri WE. The gross composition of the body. Adv. Biol. Med. Physiol. 4: 239-280, 1956

17. Starling RD, MJ Toth, WH Carpenter, DE Matthews, and ET Poehlman. Energy requirements and physical activity in free-living older women and men: a doubly labeled water study. J. Appl. Physiol. 85: 1063-1069, 1998

18. Weir JB. New methods for calculating metabolic rate with special reference to protein metabolism. J. Physiol. 109: 1-9, 1949 
19. Westerterp KR, and EP Meijer. Changes in physical activity patterns with age: a physiological perspective. J. Gerontol. in press

20. Westerterp KR. Physical activity assessment with accelerometers. Int. J. Obes. 23: S45S49, 1999

21. Westerterp KR, and CVC Bouten. Physical activity assessment: comparison between movement registration and doubly labeled water method. Z. Ernahrungswiss. 36: 263-267, 1997

22. Westerterp KR, L Wouters, and WD van Marken Lichtenbelt. The Maastricht protocol for the measurement of body composition and energy expenditure with labeled water. Obes. Res. 1: 49-57, 1995. 


\section{Chapter 5}

\section{Exercise-induced oxidative stress in older adults as measured by antipyrine oxidation}

Erwin P. Meijer

Stefan A.J. Coolen Aalt Bast

Klaas R. Westerterp

Metabolism, accepted for publication. 


\begin{abstract}
Aging is associated with increased susceptibility to free radical mediated tissue damage. Measuring exercise-induced oxidative stress, however, is a major problem in free radical research. We used an exogenous marker (antipyrine) to measure oxidative stress in older adults during submaximal exercise. Antipyrine pharmacokinetics is independent on blood flow to the liver. Furthermore, antipyrine reacts quickly with hydroxyl radicals $\left(10^{10}-10^{11} \mathrm{l} \cdot \mathrm{mol}^{-1} \cdot \mathrm{s}^{-1}\right)$ to form para- and ortho-hydroxyantipyrine. Ortho-hydroxyantipyrine is not formed in man through the mono-oxygenase pathway of cytochrome P450. Thirty-four subjects $(62 \pm 1 \mathrm{y})$ orally ingested $10-\mathrm{mg}$ antipyrine per $\mathrm{kg}$ body mass. One hour after ingestion subjects cycled $45-\mathrm{min}$ at $50 \%$ maximal power output. Exercise significantly increased the ratio of para-hydroxyantipyrine to native antipyrine in plasma $(0.0014 \pm 0.0001$ vs. $0.0021 \pm 0.0002 ; \mathrm{P}<0.0001)$. Also, the ratio of ortho-hydroxyantipyrine was significantly increased after exercise $(0.0014 \pm 0.0001$ vs. $0.0019 \pm 0.0002 ; \mathrm{P}<0.0001)$. Exercise significantly increased plasma levels of MDA $(0.55 \pm 0.07$ vs. $0.92 \pm 0.21 \mu \mathrm{M} ; \mathrm{P}<0.01)$. In conclusion, in older adults oxidative stress occurs during cycling at submaximal intensity as measured with free radical reaction products of antipyrine.
\end{abstract}




\section{Introduction}

Physical exercise markedly increases oxygen uptake particularly in skeletal muscle (25). Increased oxygen consumption further increases the leaking of reactive oxygen species (ROS), such as superoxide, hydroxyl radical $\left(\mathrm{OH}^{\circ}\right)$ and singlet oxygen, as products of oxidative phosphorylation, from the mitochondrial electron transport chain (12). The imbalance, in favor of the free radicals, between the increased ROS generation and the scavenging capacity is termed oxidative stress.

Aging is associated with an increased susceptibility to free radical mediated tissue damage $(2,15,21)$. Monitoring the amount of oxidative stress in vivo, however, is a major problem in free radical research (11). Most human studies investigating exercise-induced oxidative stress have relied on indirect endogenous indices of free radical damage, such as plasma malondialdehyde (MDA) levels (19), conjugated dienes (27), and serum lipid peroxides (1). Although these studies showed an increase in post-exercise lipid peroxidation, the major disadvantage of using endogenous markers in vivo is the possibility that they are not only formed by free radicals but also by other pathways, for example, MDA could be formed by the enzymatic breakdown of prostaglandin endoperoxides (11). A suitable approach to measure oxidative stress directly in vivo is aromatic hydroxylation by salicylic acid $(9,26)$ or phenylalanine $(14,24)$. These methods are based on the ability of $\mathrm{OH}^{*}$ to attack the benzene rings of aromatic molecules and to produce hydroxylated compounds that can be measured directly. Salicylic acid, however, has a high biological half-life of about $15-20 \mathrm{~min}$ and the metabolic breakdown depends on blood flow to the liver, which are disadvantages during endurance exercise experiments (4).

This study used antipyrine (2,3-dimethyl-1-phenyl-3-pyrazolin-5-one) as an aromatic probe for assessing oxidative stress. The properties of antipyrine make it a very suitable marker. Following oral ingestion antipyrine is uniformly distributed in the total body water after approximately $1 \mathrm{~h}$ (13). Antipyrine breakdown is independent of blood flow to the liver, which is important during exercise where blood flow is altered. Due to the reactive phenyl group, the reaction rate constant with $\mathrm{OH}^{*}$ is in the order of $10^{10}-10^{11} 1 \cdot \mathrm{mol}^{-1} \cdot \mathrm{s}^{-1}(10)$. Exposure of an antipyrine solution in water to ${ }^{60} \mathrm{Co} \gamma$-radiation leads to the formation of three phenolic antipyrine derivatives: para-hydroxyantipyrine ( $\mathrm{p}-\mathrm{APOH})$, ortho-hydroxyantipyrine (o-APOH) and meta-hydroxyantipyrine (m-APOH). The last two metabolites are not endogenously formed (6). The ratio of the hydroxylated products of antipyrine and the plasma concentration of antipyrine reflects the oxidative stress in vivo.

Although older people may be more susceptible to oxidative stress, so far studies have only measured exercise-induced oxidative stress in older adults by using endogenous markers. Therefore, the purpose of this study was to examine the effect of submaximal exercise on oxidative stress in older adults, by using free radical reaction products of antipyrine. 


\section{Methods}

Design. In this study, 34 older subjects $(62 \pm 1 \mathrm{y})$ subjects performed a maximal exercise test and at least $2 \mathrm{~h}$ thereafter a 45 -min cycling test at submaximal intensity. Exercise-induced oxidative stress was measured before and after the 45 -min cycling test by using free radical reaction products of antipyrine.

Subjects. The subjects were recruited from advertisements in the local media. Selection criteria were age over $55 \mathrm{y}$, no health problems and no participation in regular sports activities or exercise programs during the previous year. Physical characteristics of the subjects are shown in table 1. Detailed information concerning the purpose and methods used in the study was provided, and written consent was obtained. The local Ethical Committee approved the study.

Table 1. Subject characteristics (means \pm SEM).

\begin{tabular}{lc}
\hline number (men, women) & 21,13 \\
age, $\mathrm{y}$ & $62 \pm 1$ \\
body mass, $\mathrm{kg}$ & $75.1 \pm 2.4$ \\
height, $\mathrm{m}$ & $1.71 \pm 0.2$ \\
$\mathrm{BMI}, \mathrm{kg} \cdot \mathrm{m}^{-2}$ & $26 \pm 1$ \\
$\%$ fat mass & $32 \pm 2$ \\
$\mathrm{VO}_{2 \max }, \mathrm{l} \cdot \mathrm{min}^{-1}$ & $1.98 \pm 0.09$ \\
$\mathrm{~W}_{\max } \mathrm{W}$ & $130 \pm 7$ \\
$50 \% \mathrm{~W}_{\max }, \mathrm{W}$ & $65 \pm 3$ \\
\hline $\mathrm{BMI}$, body mass index; \% fat mass was determined by using \\
deuterium dilution combined with a measurement of \\
underwater weighing.
\end{tabular}

Protocol. After an overnight stay in the laboratory subjects first performed a maximal exercise test $(07.30 \mathrm{~h})$ of about $10-15 \mathrm{~min}$. Maximal power output $\left(\mathrm{W}_{\max }\right)$ and maximal $\mathrm{O}_{2}$ consumption $\left(\mathrm{VO}_{2 \max }\right)$ were determined on an electromagnetically braked cycle ergometer (Lode Excalibur, Groningen, The Netherlands), as described before (22). During the test $\mathrm{O}_{2}$ uptake was measured continuously, using a computerized open system (SensorMedics 2900 analyzer, Anaheim, CA). Additionally, heart rate was measured continuously (Polar Sport Tester, Kempele, Finland). At least $1 \mathrm{~h}$ after the exercise test a Teflon catheter (Baxter Quick Cath ${ }^{\circledR}$ II, Swinford, Ireland) was inserted into an antecubital vein, and a resting blood sample $(10 \mathrm{ml})$ was drawn. After that $(09.00 \mathrm{~h}$ ) subjects orally ingested $10 \mathrm{mg}$ antipyrine (Janssen, Geel, Belgium) per kg body mass. One hour after ingestion $(10.00 \mathrm{~h})$ they started to cycle for $45-\mathrm{min}$ at $50 \%$ $\mathrm{W}_{\max }$. Blood samples were drawn before the exercise protocol, 20-min during the exercise protocol and immediately after exercise. Blood was collected into EDTA (1.34 $\mathrm{mM})$ and $\mathrm{GSH}(0.65 \mathrm{mM})$ containing tubes and was centrifuged immediately (3000 rpm) 10 -min at $4{ }^{\circ} \mathrm{C}$. Aliquots of plasma were frozen immediately in liquid nitrogen 
and stored at $-20{ }^{\circ} \mathrm{C}$ until further analysis of MDA and of antipyrine and its phenolic derivatives.

Oxidative stress. Antipyrine and MDA were used as markers for oxidative stress. Antipyrine and its hydroxylated metabolites were measured in plasma by reversedphase HPLC-MS as described before (7). Briefly, a reversed-phase Supersphere RP18 Endcapped column (LC-Packings, Amsterdam, The Netherlands), $150 \times 1 \mathrm{~mm}$ I.D., $d_{p}=4$ $\mathrm{m}$ was attached to a LC system consisting of a LC-10AT pump (Shimadzu Ltd., Kyoto, Japan), and a Triathlon autosampler (Spark Holland, Emmen, The Netherlands). The HPLC was connected to an API-300 LC/MS/MS (Perkin Elmer Sciex Instruments, Thornhill, Canada) which operated in the multiple reaction mode and Turbo Ionspray ionization was used as interface between HPLC and MS. Sample pre-treatment consisted of $\mathrm{Cl} 8$ solid phase extraction (Sep-Pak ${ }^{\otimes} \mathrm{Cl} 8$ Cartridges, Waters, MA) in order to wash out salts and proteins. Cartridges were conditioned with methanol and $\mathrm{H}_{2} \mathrm{O}$. After that $450 \mu$ plasma was inserted in the cartridge, followed by $2 \mathrm{ml}$ ammonium-acetate buffer $(10 \mathrm{mM}, \mathrm{pH} 5)$. The cartridge was flushed with $1.5 \mathrm{ml}$ methanol to elute the target components. The samples were evaporated to dryness under nitrogen pressure and dissolved with $450 \mu 1 \mathrm{H}_{2} \mathrm{O}$ after which they stayed 30 -min in a waterbath $\left(30^{\circ} \mathrm{C}\right)$. Afterwards, treated samples were filtered by using Spartan 13/20 filters (Schleicher \& Schuell, Dassel, Germany).

Because, a competitive effect exists between antipyrine and other biomolecules for reaction with $\mathrm{OH}^{*}$, the formation of the free radical reaction products of antipyrine is dependent on the available concentration of antipyrine. Therefore, ratios of phenolic derivatives to native antipyrine are used, similar to the salicylic acid method (20).

MDA was measured in plasma using a fluorescent thiobarbituric acid (TBA) assay. TBA, $0.375 \mathrm{~g}$, (Sigma-Aldrich Chemie BV, Zwijndrecht, The Netherlands) was dissolved in $250 \mathrm{ml}^{2} \mathrm{H}_{2} \mathrm{O}$ and $2.5 \mathrm{ml} 1 \mathrm{M} \mathrm{HCl} .111 \mu \mathrm{l}$ plasma and $1000 \mu \mathrm{l}$ TBA solution were mixed and vortexed in an Eppendorf cup after which it was placed in a waterbath $\left(95^{\circ} \mathrm{C}\right.$ ) for $1 \mathrm{~h}$. Samples were cooled down to room temperature and the absorption was measured spectrophotometrically at $532 \mathrm{~nm}$ (Spectronic 1001, Meyvis, Bergen op Zoom, The Netherlands).

Statistics. All data are means \pm SEM. Statistical analysis of the data was done using a non-parametric Wilcoxon signed-ranked test, because the data was not normally distributed and to minimize for big inter-individual differences. Statistical significance was set at $\mathrm{P}<0.05$. The StatView5.0 program (SAS Institute Inc., Cary, NC) was used as the statistical package.

\section{Results}

Forty-five minutes of cycling at a submaximal intensity significantly increased the ratio of p-APOH to native antipyrine when compared with the ratio before exercise 
$(0.0014 \pm 0.0001$ vs. $0.0021 \pm 0.0002 ; \mathrm{P}<0.0001$; Fig. 1a). Additionally, the ratio of o$\mathrm{APOH}$ to native antipyrine was significantly increased after exercise when compared with the ratio before exercise $(0.0014 \pm 0.0001$ vs. $0.0019 \pm 0.0002 ; \mathrm{P}<0.0001$; Fig. 1b). The increase in both ratios was due to an increased concentration of p-APOH and oAPOH after exercise and not to changes in antipyrine concentration $(158.5 \pm 9.8 \mu \mathrm{M}$ and 155.6 $\pm 9.4 \mu \mathrm{M}$ before and after exercise, respectively). MDA levels in plasma were significantly increased immediately after exercise $(0.55 \pm 0.07$ vs. $0.92 \pm 0.21 \mu \mathrm{M}$; $\mathrm{P}<0.01$; Fig. 2). Also after 20 -min cycling MDA levels were significantly increased when compared with pre-exercise levels $(0.55 \pm 0.07$ vs. $0.71 \pm 0.13 \mu \mathrm{M} ; \mathrm{P}<0.05)$.
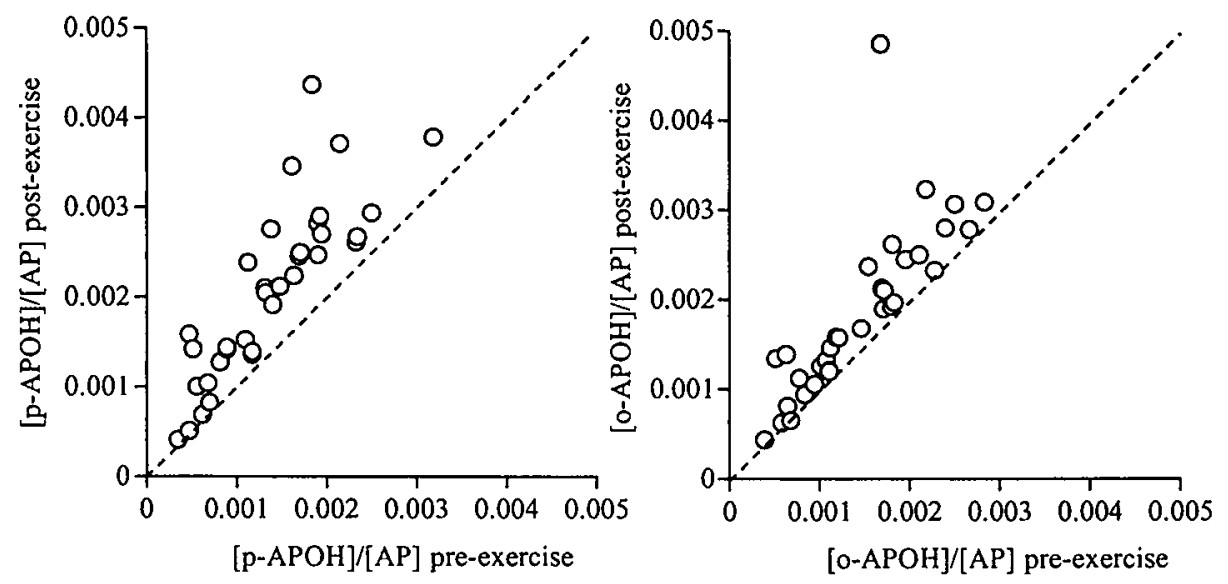

Figure 1. A) Ratio of para-hydroxyantipyrine (p-APOH) to native antipyrine (AP) in plasma of all subjects before ( $x$-axis) and immediately after exercise ( $y$-axis). If there was no difference between the ratio before and after exercise the line of identity (dotted line) would have been found. $\mathrm{P}<0.0001$. B) Ratio of ortho-hydroxyantipyrine $(0-A P O H)$ to native antipyrine (AP) in plasma of all subjects before ( $x$-axis) and immediately after exercise ( $y$-axis). If there was no difference between the ratio before and after exercise the line of identity (dotted line) would have been found. $\mathrm{P}<0.0001$.

\section{Discussion}

So far studies in the elderly that examined exercise-induced oxidative stress have relied on endogenous markers. This study investigated exercise-induced oxidative stress in older adults by using antipyrine as an exogenous marker. Results showed that the ratios of phenolic derivatives to native antipyrine were significantly increased after a 45 -min exercise at a submaximal intensity. Thus, in older adults submaximal exercise increased oxidative stress, which is in accordance to previous studies that have relied on endogenous markers $(17,23)$. Meydani et al. (23) observed a steady increase in the urinary TBA level after 45-min running down on an inclined treadmill in 55-74 y old subjects. Leaf et al. (17) observed a significant increase in the post-exercise levels of expired ethane and pentane in $4477 \mathrm{y}$ old 
cardiac patients. However, endogenous markers have several methodological disadvantages (11).

An appropriate approach to measure oxidative stress directly in vivo is aromatic hydroxylation by using salicylic acid $(9,26)$ or phenylalanine $(14,24)$. A disadvantage of salicylic acid, however, is that the metabolic breakdown is dependent on blood flow to the liver, which makes it less suitable during exercise experiments where liver blood flow will be altered. Additionally, the biological halflife is about $15-20 \mathrm{~min}$, resulting in a high metabolic breakdown (14). A serious disadvantage of phenylalanine is its relatively low rate constant for reaction with $\mathrm{OH}^{\cdot}$, at $1.9^{9} 1 \cdot \mathrm{mol}^{-1} \cdot \mathrm{s}^{-1}(14)$.

The novel antipyrine method used in this study has some advantages over the existing methods. Firstly, the reaction rate constant with $\mathrm{OH}^{*}$ is in the order of $10^{10}-10^{11} 1 \cdot \mathrm{mol}^{-1} \cdot \mathrm{s}^{-1}$, which is higher than the reaction rate of salicylic acid and phenylalanine with $\mathrm{OH}^{*}(10)$. Reaction with $\mathrm{OH}^{*}$ results in the formation of two in plasma measurable hydroxylated metabolites, of which at least one (o-APOH) is not known to be formed by the human mono-oxygenase pathway of cytochrome P450 (6). Secondly, metabolic breakdown of antipyrine is independent on blood flow to the liver, which is important during exercise where blood flow is altered (13). The biological half-life of antipyrine is about $12 \mathrm{~h}$, and antipyrine can be ingested in a relatively high dose. After oral ingestion antipyrine is uniformly distributed over the total body water, and not only the extracellular water compartment like salicylic acid (13). Coolen et al. (8) furthermore showed that the sensitivity of the HPLC to separate antipyrine and its phenolic derivatives increased by a factor 100-1000 when MS was used as a detector instead of the commonly used UV-spectrophotometer. The recently developed method (7) used in this study is highly selective in measuring the expected low concentrations of antipyrine and its phenolic derivatives in plasma. Therefore, this method should have been sensitive and selective to measure the potentially small changes in plasma concentrations of antipyrine and its free radical reaction products in exercising older human subjects.

Interestingly, Coolen (5) observed no significant increase in the free radical products of antipyrine in young adults after exercise. Those 19 young male adults $\left(23 \pm 1 \mathrm{y} ; 22 \pm 1 \mathrm{~kg} \cdot \mathrm{m}^{-2}\right)$ cycled for $2 \mathrm{~h}$ at the same relative submaximal intensity $(50 \%$ $\mathrm{W}_{\max } ; 154 \pm 7 \mathrm{~W}$ ) as the older adults in this study. The exercise-induced oxidative stress of the young adults was compared with a $2 \mathrm{~h}$ resting condition. No significant changes in the ratios of $\mathrm{p}-\mathrm{APOH}$ and $\mathrm{o}-\mathrm{APOH}$ to antipyrine could be observed. Additionally, no significant difference in the level of MDA before and after $2 \mathrm{~h}$ exercise was observed. Coolen (5) proposed that the training status of the subjects $\left(\mathrm{VO}_{2 \max }: 4.1 \pm 0.11 \cdot \mathrm{min}^{-1}\right)$ was too high to observe an effect on exercise-induced oxidative stress at such a moderate intensity, which is similar to a previous finding (27). It has to be mentioned, however, that food intake was not measured in both younger and older adults. Therefore, we cannot exclude that part of the differences found can be attributed to differences in food intake. In the present study the level of MDA significantly increased during and after exercise (Fig. 2). Although the older 
subjects in this study were relatively unfit (Table 1), which makes comparison of the data with young adults rather difficult, it could be argued that the increased levels of MDA and free radical reaction products of antipyrine might indicate a clear exerciseinduced oxidative stress. In Fig. 1 it is clearly shown that exercise results in an increase in the ratio of the hydroxylated metabolites to the plasma antipyrine concentration in almost every subject.

It could be argued, however, that subjects performed the maximal exercise test and the submaximal exercise trial on one day, which could have influenced the measured exercise-induced oxidative stress. To minimize the effect of the maximal exercise test, the time between the two cycling test was at least $2 \mathrm{~h}$. Recently, Leaf et al. (16) observed in seven healthy men and women that the expired ethane and pentane levels (markers of lipid peroxidation) were already declining 5-min after performing a maximal exercise test. This suggests that the residual effect of the time frame used on the measured oxidative stress is probably negligible. Additionally, all the subjects were able to perform the 45-min cycling test without physical complaints.

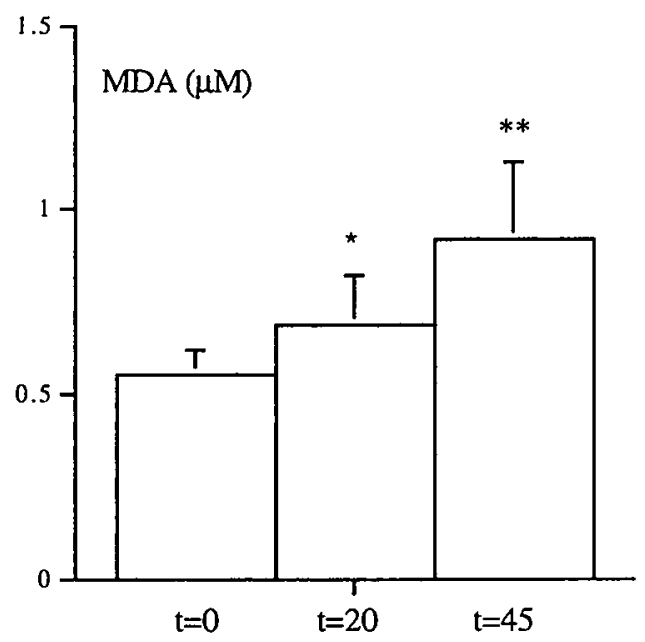

Figure 2. Plasma concentration of MDA $\pm \operatorname{SEM}(\mu \mathrm{M})$, before $(t=0), 20-\min \quad(t=20)$ and immediately after exercise at $50 \% \mathrm{~W}_{\max }(\mathrm{t}=45)$. Statistical difference when compared with $\mathrm{t}=0$, * $\mathrm{P}<0.05 ; * * \mathrm{P}<0.01$.

It has to be mentioned, however, that the lack of a resting control group is a limitation of this study. It could be argued that the increase in p-APOH and o-APOH was due to the fact that under normal resting conditions $2-5 \%$ of the total electron flux leaks to form primary short-lived ROS, such as superoxide, hydrogen peroxide and $\mathrm{OH}^{\circ}$ (3). (26). This explanation seems unlikely, because an increase in the ratios of $\mathrm{p}-\mathrm{APOH}$ and $\mathrm{o}-\mathrm{APOH}$ to native antipyrine was observed between the pre- and post-exercise condition. In addition, the increase in these ratios was highly significant $(\mathrm{P}<0.0001)$. Furthermore, the plasma MDA levels were increased with 
almost $70 \%$ after exercise (Fig. 2). Although the TBA assay lacks specificity when applied to human plasma (12), it seems that in the elderly submaximal exercise results in an increased oxidative stress.

In view of the age related increase in the susceptibility to oxidative stress one might speculate if untrained elderly would benefit from following an exercise training program. Leeuwenburgh et al. (18) showed that 10-wk endurance training increased GSH peroxidase and superoxide dismutase content in the deep vastus lateralis muscle of young rats, but had no effect on antioxidant enzyme content in old rats. They suggested that aged skeletal muscle had a limited capacity to further increase its antioxidant potential. So far no studies have been conducted in healthy older adults where oxidative stress was measured before and after a training period. It would be informative to know whether training is effective in the induction of the antioxidant system, and whether older adults are able to cope with an increase in oxidative stress after following a training program.

In conclusion, the present study demonstrated that, in older adults, oxidative stress occurred during a single bout of submaximal endurance exercise as measured with free radical reaction products of antipyrine. 


\section{References}

1. Alessio HM, and AH Goldfarb. Lipid peroxidation and scavenger enzymes during exercise: adaptive response to training. J. Appl. Physiol. 64: 1333-1336, 1988

2. Bejma J, and LL Ji. Aging and acute exercise enhance free radical generation in rat skeletal muscle. J. Appl. Physiol. 87: 465-470, 1999

3. Boveris $\mathrm{A}$, and $\mathrm{B}$ Chance. The mitochondrial generation of hydrogen peroxide. General properties and effect of hyperbaric oxygen. Biochem. J. 134: 707-716, 1973

4. Coolen SAJ, FA Huf, and JC Reijenga. Determination of free radical reaction products and metabolites of salicylic acid using capillary electrophoresis and micellar electrokinetic chromatography. J. Chromatogr. B 717: 119-124, 1998

5. Coolen SAJ. Antipyrine hydroxylates as indicators for oxidative damage. Ph.D. thesis. Eindhoven: Eindhoven University of Technology, 2000

6. Coolen SAJ, FM Everaerts, and FA Huf. Characterization of ${ }^{60} \mathrm{Co} \gamma$-radiation induced radical products of antipyrine by means of high-performance liquid chromatography, mass spectrometry, capillary zone electrophoresis, micellar electrokinetic capillary chromatography and nuclear magnetic resonance spectrometry. J. Chromatogr. A 788: 95103, 1997

7. Coolen SAJ, M Van Lieshout, JC Reijenga, and FA Huf. Determination of phenolic derivatives of antipyrine in plasma with HPLC-Tandem MS using ESI and Turbo ionspray as interfaces. J. Microcolumn Sep. 11: 701-707, 1999

8. Coolen SAJ, T Ligor, M Van Lieshout, and FA Huf. Determination of phenolic derivatives of antipyrine in plasma with solid-phase extraction and high-performance liquid chromatography- atmospheric-pressure chemical ionization mass spectrometry. $J$. Chromatogr. B 732: 103-113, 1999

9. Coudray C, M Talla, S Martin, M Fatome, and A Favier. High-performance liquid chromatography-electrochemical determination of salicylate hydroxylation products as an in vivo marker of oxidative stress. Anal. Biochem. 227: 101-111, 1995

10. Forni LG, VO Mora-Arellano, JE Packer, and RL Willson. Aminopyrine and antipyrine free radical-cations: pulse radiolysis studies of one-electron transfer reactions. J. Chem. Soc. Perkin Trans. II : 1579-1584, 1988

11. Hageman JJ, A Bast, and NP Vermeulen. Monitoring of oxidative free radical damage in vivo: analytical aspects. Chem. Biol. Interact. 82: 243-293, 1992

12. Halliwell B, and JMC Gutteridge. Free radicals in biology and medicine. Oxford: Claredon Press, 1989

13. Hartleb M. Drugs and the liver. Part II. The role of the antipyrine test in drug metabolism studies. Biopharm. Drug Dispos. 12: 559-570, 1991

14. Kaur $\mathrm{H}$, and B Halliwell. Detection of hydroxyl radicals by aromatic hydroxylation. Methods Enzymol. 233: 67-82, 1994

15. Khalil A, JR Wagner, G Lacombe, V Dangoisse, and T Fülöp, Jr. Increased susceptibility of low-density lipoprotein (LDL) to oxidation by gamma-radiolysis with age. FEBS Lett. 392: $45-48,1996$

16. Leaf DA, MT Kleinman, M Hamilton, and TJ Barstow. The effect of exercise intensity on lipid peroxidation. Med. Sci. Sports Exerc. 29: 1036-1039, 1997

17. Leaf DA, MT Kleinman, $M$ Hamilton, and RW Deitrick. The exercise-induced oxidative stress paradox: the effects of physical exercise training. Am. J. Med. Sci. 317: 295-300, 1999 
18. Leeuwenburgh C, R Fiebig, R Chandwaney, and LL Ji. Aging and exercise training in skeletal muscle: responses of glutathione and antioxidant enzyme systems. Am. J. Physiol. 267: R439-445, 1994

19. Lovlin R, W Cottle, I Pyke, M Kavanagh, and AN Belcastro. Are indices of free radical damage related to exercise intensity. Eur. J. Appl. Physiol. 56: 313-316, 1987

20. McCabe DR, TJ Maher, and IA Acworth. Improved method for the estimation of hydroxyl free radical levels in vivo based on liquid chromatography with elecrtochemical detection. $J$. Chromatogr. B 691: 23-32, 1997

21. Mecocci P, G Fano, S Fulle, U MacGarvey, L Shinobu, MC Polidori, A Cherubini, J Vecchiet, U Senin, and MF Beal. Age-dependent increases in oxidative damage to DNA, lipids, and proteins in human skeletal muscle. Free Radic. Biol. Med. 26: 303-308, 1999

22. Meijer EP, KR Westerterp, and FTJ Verstappen. Effect of exercise training on total daily physical activity in elderly humans. Eur. J. Appl. Physiol. 80: 16-21, 1999

23. Meydani M, WJ Evans, G Handelman, L Biddle, RA Fielding, SN Meydani, J Burrill, MA Fiatarone, JB Blumberg, and JG Cannon. Protective effect of vitamin $\mathrm{E}$ on exercise-induced oxidative damage in young and older adults. Am. J. Physiol. 264: R992-998, 1993

24. O'Neill CA, CL Stebbins, S Bonigut, B Halliwell, and C Longhurst. Production of hydroxyl radicals in contracting skeletal muscle of cats. J. Appl. Physiol. 81: 1197-1206, 1996

25. Sen CK. Oxidants and antioxidants in exercise. J. Appl. Physiol. 79: 675-686, 1995

26. Tabatabaei AR, and FS Abbott. LC/MS analysis of hydroxylation products of salicylate as an indicator of in vivo oxidative stress. Free Radic. Biol. Med. 26: 1054-1058, 1999

27. Vasankari T, U Kujala, O Heinonen, J Kapanen, and $M$ Ahotupa. Measurement of serum lipid peroxidation during exercise using three different methods: diene conjugation, thiobarbituric acid reactive material and fluorescent chromolipids. Clin. Chim. Acta 234: 63-69, 1995. 


\title{
Chapter 6
}

\section{Exercise training and oxidative stress in the elderly as measured by antipyrine hydroxylation products}

\author{
Erwin P. Meijer \\ Stefan A.J. Coolen \\ Aalt Bast \\ Klaas R. Westerterp
}

Free Radical Research, in press. 


\begin{abstract}
Effects of 12-wk exercise training on oxidative stress were examined in elderly humans. We measured oxidative stress during a 45 -min cycling test by using antipyrine hydroxylation products. Antipyrine breakdown is independent of blood flow to the liver, which is important during exercise. Furthermore, antipyrine reacts quickly with hydroxyl radicals to form para- and ortho-hydroxyantipyrine. Orthohydroxyantipyrine is not formed in man through the mono-oxygenase pathway of cytochrome P450. Twenty subjects ( 9 women; $60 \pm 3$ y) participated in the training program. Thirteen subjects ( 5 women; $64 \pm 7 \mathrm{y}$ ) served as inactive controls. Subjects trained, twice a week for $1 \mathrm{~h}$, at a fitness center. After 12-wk, maximal oxygen uptake $(\mathrm{P}<0.005)$ and workload capacity $(\mathrm{P}<0.001)$ were only significantly elevated in the training group. After 12-wk, both groups observed no change in the ratios of antipyrine hydroxylates, para- and ortho-hydroxyantipyrine, to native antipyrine. Furthermore, no differences were observed within or between groups in the exerciseinduced increase in the plasma level of thiobarbituric acid reactive species. In conclusion, 12-wk training had no effect on exercise-induced oxidative stress in elderly humans as measured by free radical reaction products of antipyrine. Despite the fact that training in elderly humans improves functional capacity, it appears not to compromise antioxidant defense mechanisms.
\end{abstract}




\section{Introduction}

Recent animal studies support the contention that exercise training may result in upregulation of the antioxidant capacity to cope with increased oxidative stress $(1,7,15)$. Leeuwenburgh et al. (18), however, showed that 10-wk training increased glutathione (GSH) peroxidase and superoxide dismutase (SOD) content in the deep vastus lateralis muscle of young rats, but had no effect in old rats. They suggested that aged skeletal muscle has a limited capacity to further increase its antioxidant potential. This finding was confirmed by Oh-Ishi et al. (22), who showed that 6-wk swimming training improved the antioxidant enzyme system only in young mouse diaphragm and not in that of old mice. In humans, data on the effect of training on oxidative stress is scanty and controversial $(21,24,26,28)$. So far, no studies have been conducted in healthy elderly humans. Therefore, it would be informative to know whether elderly can cope better with exercise-induced oxidative stress after a training program.

Studies in humans have relied on endogenous markers for measuring exerciseinduced oxidative stress. We used antipyrine (2,3-dimethyl-1-phenyl-3-pyrazolin-5one), an exogenous marker, for assessing oxidative stress. The metabolic pathway of antipyrine has been extensively documented $(2,8,13,27)$. Antipyrine is metabolized in the hepatic smooth endoplasmic reticulum by at least three reactions (two hydroxylations and a $\mathrm{N}$-demethylation), resulting in the formation of four primary metabolites: 4-hydroxyantipyrine, norantipyrine, 3-hydroxymethyl-antipyrine and 3carboxy-antipyrine (Fig. 1). After oral ingestion about $90 \%$ is excreted in the urine as unchanged antipyrine (3\%), 4-hydroxyantipyrine (29\%), norantipyrine (17\%), 3hydroxymethylantipyrine $(35 \%)$, and as 3-carboxyantipyrine $(3 \%)(9)$. The properties of antipyrine make it a very suitable marker for measuring oxidative stress. After oral ingestion, antipyrine is completely absorbed and uniformly distributed in the total body water after approximately $1 \mathrm{~h}(8,13,27)$. Antipyrine breakdown is independent of blood flow to the liver, which is important during exercise where blood flow is altered. The half-life time of antipyrine is about $12 \mathrm{~h}(8,13)$. Furthermore, the reaction constant of antipyrine with hydroxyl radicals is in the order of $10^{10} 1 \cdot \mathrm{mol}^{-1} \cdot \mathrm{s}^{-1}(10)$. Exposure of an antipyrine solution in water to ${ }^{60} \mathrm{Co} \gamma$-radiation leads to the formation of three phenolic antipyrine derivatives: para-hydroxyantipyrine ( $\mathrm{p}-\mathrm{APOH}$ ), orthohydroxyantipyrine (o-APOH) and meta-hydroxyantipyrine (m-APOH). The last two metabolites are not endogenously formed (Fig. 1) (4). Moreover, the free radical products of antipyrine could be detected in human plasma that was spiked with a 1 $\mathrm{mM}$ radiated antipyrine solution (6). A recently performed study in 16 patients with claudicatio intermittens, an early manifestation of atherosclerosis in the leg which is characterized by a low-grade repetitive ischemia-reperfusion during physical exercise, showed that 5 -min of walking exercise $\left(3 \mathrm{~km} \cdot \mathrm{h}^{-1}, 8^{\circ}\right.$ inclination) resulted in a significantly increased plasma concentration of p-APOH and o-APOH (Fig. 2) (3). The ratio of $0-A P O H$ to native antipyrine increased significantly from $1.26 \times 10^{-3} \pm 0.14 \times 10^{-3}$ before exercise to $1.47 \times 10^{-3} \pm 0.18 \times 10^{-3} 5$-min after exercise. 
Thus, the ratio of the hydroxylated products of antipyrine and the plasma concentration of antipyrine reflects the oxidative stress in vivo.

This study was designed to determine whether 12-wk exercise training would affect oxidative stress in exercising elderly. Antipyrine was used as an exogenous marker for measuring oxidative stress. Ratios of hydroxylates to native antipyrine were used to adjust for interindividual differences in biological availability, distribution and metabolism of antipyrine, similar to the salicylic acid method (19).

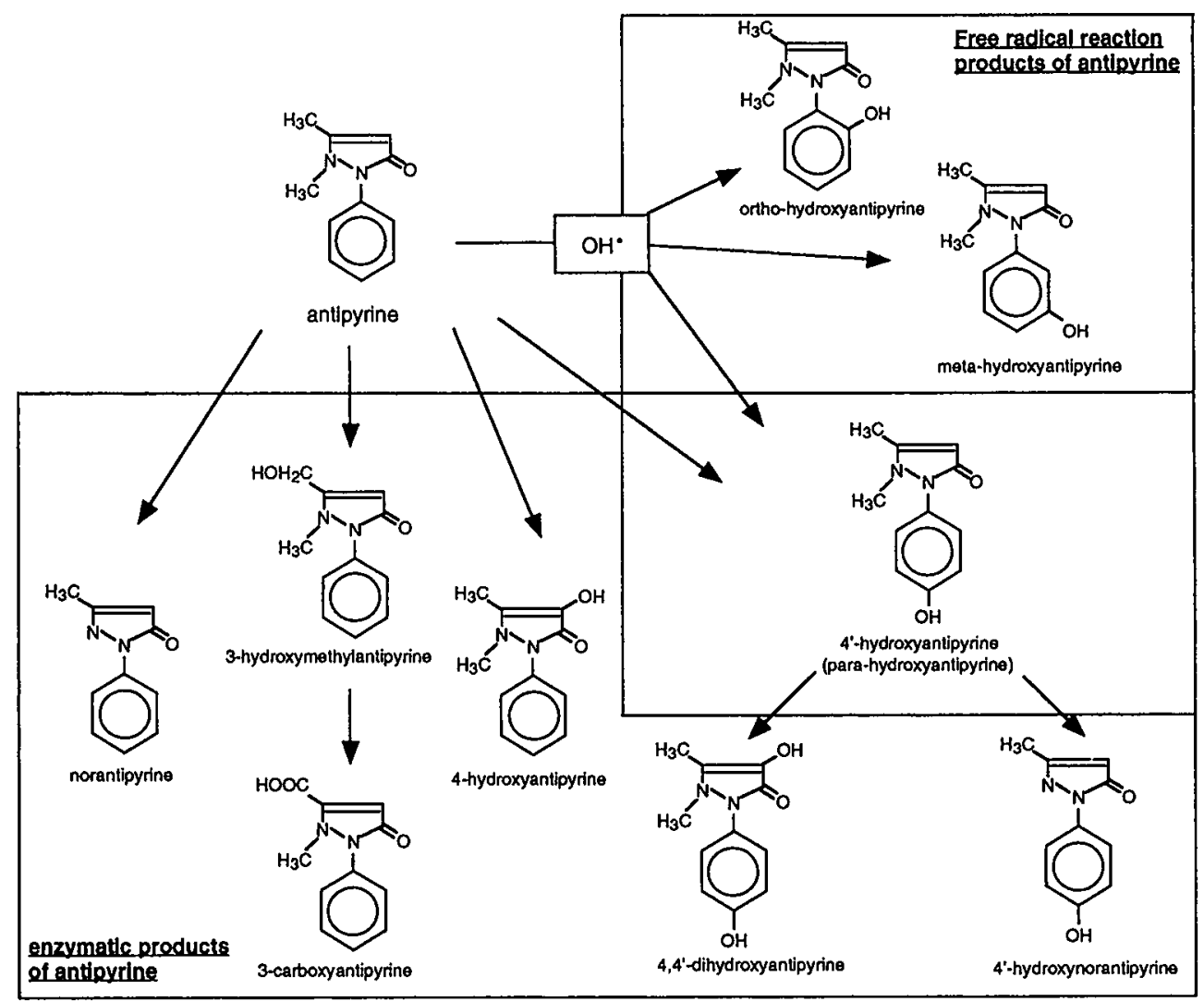

Figure 1. Metabolic pathway of antipyrine and its free radical reaction products.

\section{Methods}

Subjects. Thirty-three subjects were recruited with advertisements in the local media. Selection criteria were age over $55 \mathrm{y}$, no health problems and no participation in sports during the previous year. After detailed information concerning the purpose and methods used in the study was provided and written consent was obtained, 20 subjects 
( 9 women) participated in the exercise-trained group (EXER), and 13 subjects ( 5 women) served as non-trained controls (CONT). Physical characteristics are shown in Table 1. The local Ethical Committee approved the study.

Study design. Exercise-induced increase in oxidative stress was measured in elderly humans, before and after a 12 -wk training program, with a 45 -min cycling test at submaximal intensity. Oxidative stress was measured by free radical products of antipyrine.

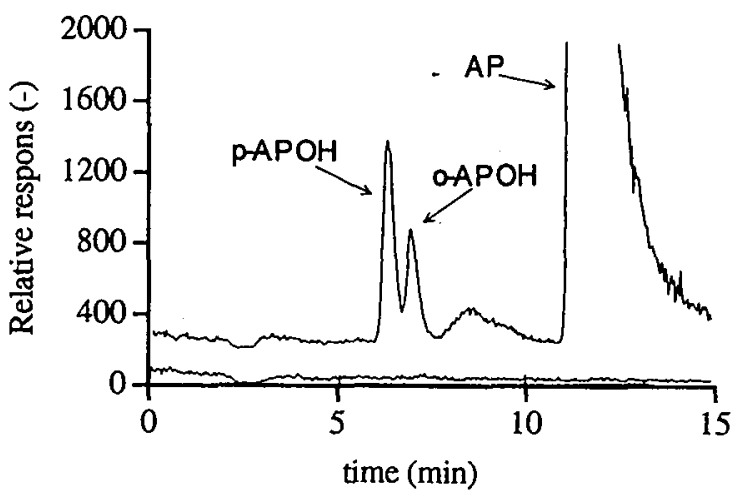

Figure 2. Typical chromatogram of the formation of para- (p-APOH) and ortho-hydroxyantipyrine (oAPOH) in plasma immediately after 5 -min exercise in a patient with claudicatio intermittens (AP: antipyrine).

Study protocol. After an overnight stay at the laboratory, maximal workload capacity $\left(\mathrm{W}_{\max }\right)$ and maximal $\mathrm{O}_{2}$ consumption $\left(\mathrm{VO}_{2 \max }\right)$ were determined, at baseline (T0) and after 12-wk (T12). Subjects exercised incrementally on an electromagnetically braked cycle ergometer (Lode Excalibur, Groningen, The Netherlands), as described recently (20). $\mathrm{O}_{2}$ uptake during the test was measured continuously, using a computerized open system (SensorMedics 2900 analyzer, Anaheim CA, USA). During the incremental exercise test heart rate was measured continuously (Polar Sport Tester, Kempele, Finland).

One hour thereafter a Teflon catheter (Quick Cath ${ }^{\mathbb{D}}$ II, Baxter Healthcare S.A., Swinford, Ireland) was placed into an antecubital vein and a resting blood sample (10 $\mathrm{ml}$ ) was drawn. Subjects then orally ingested $10 \mathrm{mg}$ antipyrine (Janssen Chimica, Geel, Belgium) per $\mathrm{kg}$ body mass. One hour after ingestion subjects cycled for 45 -min at $50 \% \mathrm{~W}_{\max }$. Blood samples were drawn before exercise and immediately after exercise. Blood was collected into EDTA $(1.34 \mathrm{mM})$ and GSH $(0.65 \mathrm{mM})$ containing tubes and was centrifuged immediately $\left(3000 \mathrm{rpm}, 10\right.$-min at $\left.4{ }^{\circ} \mathrm{C}\right)$. Aliquots of plasma were frozen in liquid nitrogen and stored at $-20{ }^{\circ} \mathrm{C}$ until further analysis of antipyrine and its hydroxylates. 
Table 1. Characteristics of the exercise training and control group. There were no differences between the two groups. Data are expressed as mean \pm SEM.

\begin{tabular}{lcc}
\hline & exercise training & control group \\
\hline Number (women, men) & $20(9,11)$ & $13(5,8)$ \\
Age, $\mathrm{y}$ & $60 \pm 1$ & $64 \pm 2$ \\
Height, cm & $171 \pm 2$ & $171 \pm 3$ \\
Body mass, kg & $78.6 \pm 3.2$ & $69.5 \pm 3.2$ \\
$\mathrm{BMI}, \mathrm{kg} \cdot \mathrm{m}^{-2}$ & $27 \pm 1$ & $24 \pm 1$ \\
$\mathrm{VO}_{2 \max }, 1 \cdot \mathrm{min}^{-2}$ & $2.02 \pm 0.13$ & $1.92 \pm 0.14$ \\
$\mathrm{~W}_{\max }, \mathrm{W}$ & $134 \pm 9$ & $124 \pm 10$ \\
\hline
\end{tabular}

Training program. Subjects trained twice a week, for one hour, on non-consecutive days for 12-wk. All training sessions were performed at a fitness center and supervised by a fitness instructor. The sessions consisted of 10 exercises using weight stack machines (Sportesse, Essen, Germany) and 1 dynamic exercise (120 sec cycling). All exercises were performed in cyclic order. The resistance exercises were performed for about $45 \mathrm{sec}$ (10-15 repetitions) and existed of the following exercises: chest press, triceps press, crunch, biceps curl, abduction, adduction, leg extension, leg curl, seated row and lat-pull. After each exercise subjects could rest for about $85 \mathrm{sec}$, to standardize the training protocol as much as possible, before the next exercise started. Each training session included a 15-min warming-up and a 10-min cooling-down. The warming-up existed of aerobic exercises and the cooling down existed of stretch- and relaxing movements. The intensity of the training program was approximately $50 \%$ of heart rate reserve (HRR).

Sample Analysis. Antipyrine and its hydroxylates were measured with reversed phase HPLC combined with mass spectrometry (HPLC-MS) (5). A reversed-phase Supersphere RP18 Endcapped column (LC-Packings, Amsterdam, The Netherlands), $150 \times 1 \mathrm{~mm}$ I.D., $d_{p}=4 \mu \mathrm{m}$ was attached to a $\mathrm{LC}$ system consisting of a LC-10AT pump (Shimadzu Ltd., Kyoto, Japan), and a Triathlon autosampler (Spark Holland, Emmen, The Netherlands). The HPLC was connected to an API-300 LC/MS/MS (Perkin Elmer Sciex Instruments, Thornhill, Canada) which operated in the multiple reaction mode and Turbo Ionspray ionization was used as interface. Final data processing was done using an integration program (TurboQuan 1.0, Perkin Elmer Sciex Instruments, Thornhill, Canada). Sample pre-treatment consisted of $\mathrm{C} 18$ solid phase extraction (Sep-Pak ${ }^{\otimes}$ C18 Cartridges, Waters, USA) in order to wash out salts and proteins. Cartridges were conditioned with $5 \mathrm{ml}$ methanol and $5 \mathrm{ml} \mathrm{H}{ }_{2} \mathrm{O}$. After that $450 \mu \mathrm{l}$ plasma was inserted in the cartridge, followed by $2 \mathrm{ml}$ ammonium-acetate buffer ( 10 $\mathrm{mM}, \mathrm{pH}$ adjusted with acetic acid to 5). The cartridge was flushed with $1.5 \mathrm{ml}$ methanol to elute the target components. Samples were evaporated to dryness under nitrogen pressure (QBT4 Grant Instruments Ltd., Cambridge, UK), dissolved in $450 \mu \mathrm{l}$ 
$\mathrm{H}_{2} \mathrm{O}$, and placed in a waterbath $\left(30^{\circ} \mathrm{C}\right)$ for 30 -min. Afterwards, treated samples were filtered by using Spartan 13/20 filters (Schleicher \& Schuell, Dassel, Germany).

Thiobarbituric acid-reactive substances (TBARS) were measured in plasma using a fluorescent thiobarbituric acid (TBA) assay. TBA, $0.375 \mathrm{~g}$, (Sigma-AIdrich Chemie BV, Zwijndrecht, The Netherlands) was dissolved in $250 \mathrm{ml}$ demineralized $\mathrm{H}_{2} \mathrm{O}$ and $2.5 \mathrm{ml} 1 \mathrm{M} \mathrm{HCl} .111 \mu \mathrm{l}$ plasma and $1000 \mu \mathrm{l}$ TBA solution were mixed and vortexed in an Eppendorf cup after which it was placed in a waterbath $\left(95^{\circ} \mathrm{C}\right)$ for $1 \mathrm{~h}$. Samples were cooled down to room temperature and the absorption was measured spectrophotometrically at $532 \mathrm{~nm}$ (Spectronic 1001, Meyvis, Bergen op Zoom, The Netherlands). Results were expressed as micromoles of MDA.

Statistics. All data are presented as means \pm SEM. To compare differences within the two groups the non-parametric Wilcoxon signed-ranked test was used. To compare differences between the two groups the non-parametric Mann-Whitney $U$ test was used. Statistical significance was set at $\mathrm{P}<0.05$. The StatView5.0 program (SAS Institute Inc., Cary, NC) was used as the statistical package.

\section{Results}

Twelve weeks of exercise training significantly elevated $\mathrm{VO}_{2 \max }$ in EXER $(25.8 \pm 6.4$ vs. $28.1 \pm 5.4 \mathrm{ml} \cdot \mathrm{kg}^{-1} \cdot \mathrm{min}^{-1} ; \mathrm{P}<0.01$ ), whereas $\mathrm{VO}_{2 \max }$ in CONT remained unchanged $\left(27.5 \pm 4.6\right.$ vs. $\left.27.6 \pm 5.6 \mathrm{ml} \cdot \mathrm{kg}^{-1} \cdot \mathrm{min}^{-1}\right)$. Training significantly elevated $\mathrm{W}_{\max }$ with approximately $8 \%(134 \pm 9$ vs. $145 \pm 8 \mathrm{~W} ; \mathrm{P}<0.001)$, no change in $\mathrm{W}_{\max }$ was observed in CONT (124 \pm 10 vs. $125 \pm 11 \mathrm{~W})$. Therefore, at T12 EXER cycled at a significantly higher absolute intensity of $50 \% \mathrm{~W}_{\max }$ when compared with $\mathrm{T} 0$, whereas CONT cycled at the same absolute intensity of $50 \% \mathrm{~W}_{\max }$ at both $\mathrm{T} 0$ and $\mathrm{T} 12$.

In EXER, the exercise-induced increase in the ratio of p-APOH to native antipyrine was not significantly different after 12 -wk training (T0 and $\mathrm{T} 12$ : $5.7 \times 10^{-4} \pm 0.9 \times 10^{-4}$ and $7.1 \times 10^{-4} \pm 1.0 \times 10^{-4}$; Fig. 3a). Additionally, the exercise-induced increase in the ratio of o-APOH to antipyrine was not significantly different after 12wk of training (T0 and T12: $2.8 \times 10^{-4} \pm 0.8 \times 10^{-4}$ and $3.9 \times 10^{-4} \pm 0.9 \times 10^{-4}$; Fig. $3 \mathrm{~b}$ ). Additionally, in CONT no differences in the ratios of hydroxylates to antipyrine could be observed. At T0 and T12 the ratios of $\mathrm{p}$-APOH were $8.7 \times 10^{-4} \pm 1.5 \times 10^{-4}$ and $6.7 \times 10^{-4} \pm 1.5 \times 10^{-4}$, respectively (Fig. 3a). At T0 and T12 the ratios of $0-\mathrm{APOH}$ were $5.5 \times 10^{-4} \pm 1.5 \times 10^{-4}$ and $4.0 \times 10^{-4} \pm 0.9 \times 10^{-4}$, respectively (Fig. 3b). Furthermore, no differences were observed within or between groups in the exercise-induced increase in the plasma level of TBARS. Differences between the level of TBARS pre- and postexercise at $\mathrm{T} 0$ and $\mathrm{T} 12$ were $0.33 \pm 0.32 \mu \mathrm{M}$ and $0.14 \pm 0.13 \mu \mathrm{M}(\mathrm{P}=0.31)$ in EXER, and $0.14 \pm 0.26 \mu \mathrm{M}$ and $0.13 \pm 0.06 \mu \mathrm{M}(\mathrm{P}=0.47)$ in CONT, respectively. 

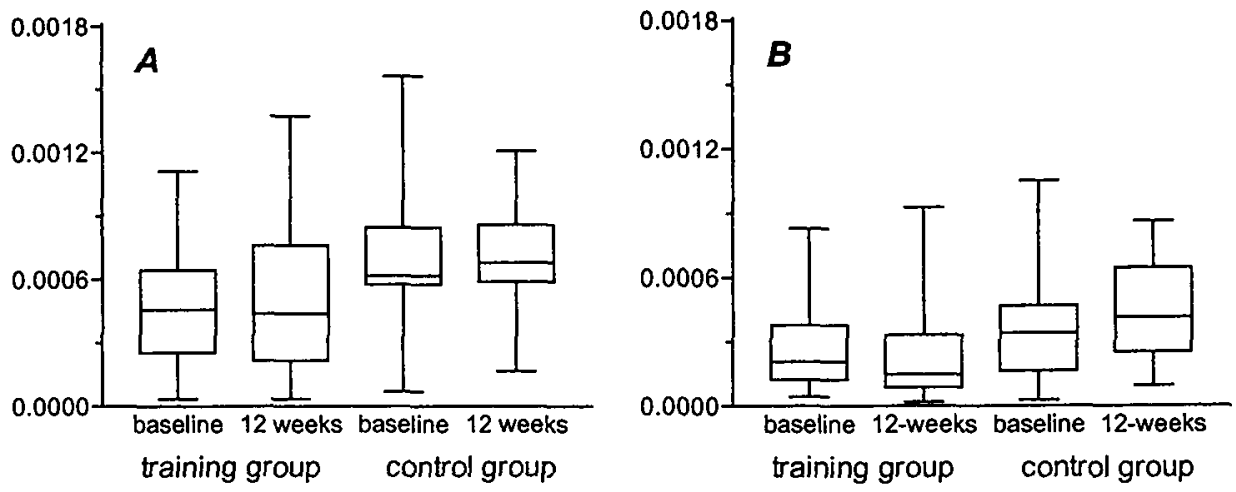

Figure 3. Box-and-whisker plots (median with quartiles and range) of the exercise-induced increase in the ratio of para-hydroxyantipyrine (A) and ortho-hydroxyantipyrine (B) to native antipyrine during 45-min cycling at baseline and after 12-wk in the exercise and control group. No statistical differences were observed between or within the groups.

\section{Discussion}

This study was undertaken to examine the effect of a 12-wk training program on exercise-induced oxidative stress in the elderly. Antipyrine was used as an exogenous marker for measuring oxidative stress. Results showed that in elderly humans training had no effect on the exercise-induced increase in the ratios of free radical reaction products of antipyrine and the concentration of antipyrine in plasma during $45-\mathrm{min}$ cycling.

This study used a newly developed technique to assess oxidative stress. The metabolic pathway of antipyrine has been extensively documented $(2,8,13,27)$. Recently, it was shown in vitro that exposure of an antipyrine solution in water to ${ }^{60} \mathrm{Co}$ $\gamma$-radiation leads to the formation of three phenolic antipyrine derivatives: parahydroxyantipyrine, ortho-hydroxyantipyrine and meta-hydroxyantipyrine (Fig. 1) (4). In case that an antioxidant is added to an antipyrine solution in water, the conversion of antipyrine after exposure to ${ }^{60} \mathrm{Co} \gamma$-radiation can be used as indicator for the free radical scavenging capacity of a potential antioxidant (3). For example, ascorbic acid significantly reduced the conversion of antipyrine, depending on the added concentration of ascorbic acid. The results of the antipyrine method were linearly correlated $\left(r^{2}=0.99\right)$ with the results of the commonly used deoxyribose assay.

However, the properties of antipyrine make it also a suitable marker for measuring oxidative stress in vivo. Antipyrine can be safely ingested in a relatively high dose, usually $10 \mathrm{mg}$ per $\mathrm{kg}$ body mass, with a maximum of $4 \mathrm{~g} \cdot \mathrm{day}^{-1}$. After oral ingestion, antipyrine is completely absorbed and uniformly distributed in the total body water after approximately $I \mathrm{~h}(8,13,27)$. The half-life time of antipyrine is about 
$12 \mathrm{~h}(8,13)$. Furthermore, antipyrine breakdown is independent of blood flow to the liver, which is important in clinical studies where the blood flow is altered e.g. exercise experiments (13). Moreover, antipyrine reacts quickly with hydroxyl radicals (reaction rate constant $10^{10} \mathrm{l} \cdot \mathrm{mol}^{-1} \cdot \mathrm{s}^{-1}$ ) to form two in plasma measurable hydroxylated metabolites, of which at least one (o-APOH) is not known to be formed by the human mono-oxygenase pathway of cytochrome P450 (Fig. 1) (4). Thus, the ratio of the hydroxylated products of antipyrine to plasma concentration of antipyrine can be used as a marker for oxidative stress.

Due to its high reactivity, the hydroxyl radical has a very short half-life and is therefore present only transiently in extremely low concentration (12). It is therefore necessary that the aromatic probe produce concentrations in body fluids sufficient to scavenge hydroxyl radicals in order to compete with other scavenger molecules. Consequently, the concentration of the hydroxylated products in plasma is extremely low. Recently, Coolen et al. (6) showed that the sensitivity of HPLC to separate antipyrine and its free radical reaction products increased by a factor 100-1000 when MS was used as a detector instead of the commonly used UV-spectrophotometer. In this study, the free radical products of antipyrine could be detected in human plasma that was spiked with a $1 \mathrm{mM}$ radiated antipyrine solution (6). Coolen et al. (5), furthermore, demonstrated that HPLC-MS with Turbo Ionspray as interface improved the signal to noise ratio when compared with electrospray ionization or atmospheric pressure chemical ionization as interfaces. The detection limit for antipyrine with Turbo Ionspray as interface, since no standards of the phenolic derivatives are available, was $1.3 \mathrm{pg}$. in $20 \mu \mathrm{l}$ water, which makes this technique highly sensitive and selective for determination of the phenolic derivatives of antipyrine in plasma. Therefore, the method used in this study should have been sensitive and selective to measure the potentially small changes in plasma concentrations of antipyrine and its hydroxylates in exercising elderly humans.

Recently, a study in 16 patients with claudicatio intermittens (51-74 y) showed that 5-min walking exercise resulted in a significantly increase in the plasma concentration of the free radical reaction products of antipyrine (Fig. 2) (3). Claudicatio intermittens is caused by narrowing or obstruction of arteries in the aortoiliacal region or in peripheral arteries, and it is characterized by a chronic ischemiareperfusion injury during physical exercise, which results in an increased oxidative stress. The claudicants, seven patients were claudicants in one leg and nine in both legs, orally ingested $15-\mathrm{mg}$ antipyrine per kg body mass. One hour after ingestion, similar to the protocol used in the present study, the claudicants started with the 5-min walking exercise $\left(3 \mathrm{~km} \cdot \mathrm{h}^{-1}, 8^{\circ}\right.$ inclination). The exercise resulted in a significant increase $(\mathrm{P}=0.002)$ in the serum lactate concentration $(1.59 \pm 0.21$ and $2.99 \pm 0.6$ $\mathrm{mmol} \cdot \mathrm{l}^{-1}$ before and after exercise, respectively). Interestingly, the exercise-induced increase in the ratio o-APOH to antipyrine was similar in claudicants performing 5min walking exercise $\left(\Delta 2.1 \times 10^{-4}\right)$ compared to elderly cycling for $45-\mathrm{min}$ at submaximal intensity $\left(\Delta 2.8 \times 10^{-4}\right)$, which confirms that the increased hydroxyl radical 
formation in the exercising elderly subjects could be detected by the antipyrine method.

Because the plasma level of p-APOH and o-APOH depends on that of antipyrine, and because the latter could vary among individuals ingesting the same dose of antipyrine, ratios of the hydroxylated products of antipyrine and the plasma concentration of antipyrine were used similar to the salicylic acid method (19). Additionally, there was no difference in concentration of antipyrine between pre- and post-exercise conditions (158.5 $\pm 9.8 \mu \mathrm{M}$ and $155.6 \pm 9.4 \mu \mathrm{M}$ pre- and post-exercise, respectively). Therefore, the exercise-induced increase in both ratios was due to an increased concentration of $\mathrm{p}-\mathrm{APOH}$ and $\mathrm{o}-\mathrm{APOH}$ after exercise and not to changes in antipyrine concentration. This study clearly showed no differences in the exerciseinduced increase in the ratios of the hydroxylated products of antipyrine and the plasma concentration of antipyrine after 12-wk training (Fig. 3). The fact that no differences were observed within or between groups in the exercise-induced increase in the level of TBARS in plasma furthermore suggests that training had no effect on exercise-induced oxidative stress in elderly humans.

The implications of this study are in accordance with findings of Leaf et al. (17), who showed that after 12-wk training in elderly cardiac patients the expired levels of ethane and pentane were unchanged. However, some limitations have to be considered when ethane and pentane, end products of lipid peroxidation, are used as indirect markers of oxidative stress $(11,12)$. Firstly, blood flow could influence the level of expired ethane and pentane. During exercise, blood flow increases in muscle tissue, thus liberating alkanes that are stored in membranes. Therefore, increase of pentane exhalation does not necessarily reflect an increase in oxidative stress. Secondly, one must realize that those alkanes, once formed in vivo, are susceptible to metabolism. Thirdly, expired alkanes can arise from other sources, e.g. inhaled air or gut bacteria. Furthermore, Leaf et al. (17) showed that the serum level of MDA was significantly decreased after training, which is in contrast with findings of the present study. It has to be mentioned, however, that the TBA assay used to measure MDA lacks specificity when applied to human plasma $(11,12)$. Therefore, the results of Leaf et al. (17) should be interpreted with some caution.

Recently, Leeuwenburgh et al. (18) showed that exercise training significantly increased GSH peroxidase and SOD content in the deep vastus lateralis muscle in young, but not in old rats. Additionally, Oh-Ishi et al. (22) showed that training only improved the antioxidant enzyme system in young mouse diaphragm. Both studies suggested that aged skeletal muscle had a limited capacity to increase its antioxidant potential. Although in the present study antioxidant capacity or enzyme activity was not determined, the fact that aging muscle has a limited capacity to increase its antioxidant enzyme system might explain why we were unable to observe any effect of training on oxidative stress in exercising elderly humans.

Additionally, it could be argued that the intensity of the training program ( $\sim 50 \%$ HRR), was too low to pose a challenge for adaptive responses to the antioxidant defense systems. Powers et al. (25) showed in rats that high intensity 
training was superior to low-intensity exercise training in the up-regulation of skeletal muscle SOD activity. Nevertheless, low-intensity exercise training resulted in a significant up-regulation of rat skeletal muscle SOD activity. In addition, $\mathrm{VO}_{2 \max }$ was significantly increased by approximately $9 \%$ in EXER, indicating that the intensity of the training program should have been high enough to induce changes in the antioxidant enzyme system. However, it may be possible that greater elevations of $\mathrm{VO}_{2 \max }$ or a longer training period may be necessary before any significant changes in oxidative stress during exercise would occur.

Powers et al. (25) used an entirely aerobic training program, whereas in the present study the training program consisted of a combination of strength and endurance training. Powers et al. (25) also showed that the training-induced upregulation in the antioxidant enzyme system was limited to highly oxidative muscles (type I and IIa fibers). Furthermore, in a cross-sectional study, Jenkins et al. (16) reported higher antioxidant enzyme activities in muscle of males with a high $\mathrm{VO}_{2 \max }$ than in males with a low $\mathrm{VO}_{2 \max }$. In contrast to this finding, Hellsten et al. (14) showed that anaerobic training improved the level of antioxidant protection in human muscle. Additionally, Ørtenblad et al. (23) reported that the activities of antioxidant enzymes were markedly elevated in highly trained jumpers when compared with untrained subjects. Although the previous mentioned studies all used different types of training and different types of markers for assessing oxidative stress, which makes comparison extremely difficult, it could be argued that the type of training used in this study could have had the potential to up-regulate the antioxidant enzyme system, resulting in a lowered oxidative stress during exercise.

In conclusion, 12-wk of exercise training had no effect on exercise-induced increase in oxidative stress in elderly humans as measured by free radical products of antipyrine. Despite the fact that exercise training in elderly humans improves functional capacity, it appears not to compromise antioxidant defense mechanisms. 


\section{References}

1. Alessio HM, and AH Goldfarb. Lipid peroxidation and scavenger enzymes during exercise: adaptive response to training. J. Appl. Physiol. 64: 1333-1336, 1988

2. Brodie BB, and J Axelrod. The fate of antipyrine in man. J. Pharmacol. Exp. Ther. 98: 97-104, 1950

3. Coolen SAJ. Antipyrine hydroxylates as indicators for oxidative damage. Ph.D. thesis. Eindhoven: Eindhoven University of Technology, 2000

4. Coolen SAJ, FM Everaerts, and FA Huf. Characterization of ${ }^{60} \mathrm{Co}_{0} \gamma$-radiation induced radical products of antipyrine by means of high-performance liquid chromatography, mass spectrometry, capillary zone electrophoresis, micellar electrokinetic capillary chromatography and nuclear magnetic resonance spectrometry. J. Chromatogr. A 788: 95-103, 1997

5. Coolen SAJ, M Van Lieshout, JC Reijenga, and FA Huf. Determination of phenolic derivatives of antipyrine in plasma with HPLC-Tandem MS using ESI and Turbo ionspray as interfaces. $J$. Microcolumn Sep. 11: 701-707, 1999

6. Coolen SAJ, T Ligor, M Van Lieshout, and FA Huf. Determination of phenolic derivatives of antipyrine in plasma with solid-phase extraction and high-performance liquid chromatographyatmospheric-pressure chemical ionization mass spectrometry. J. Chromatogr. B 732: 103-113, 1999

7. Criswell D, S Powers, S Dodd, J Lawler, W Edwards, K Renshler, and S Grinton. High intensity training-induced changes in skeletal muscle antioxidant enzyme activity. Med. Sci. Sports Exerc. 25: 1135-1140, 1993

8. Danhof M, A van Zuilen, JK Boeijings, and DD Breimer. Studies of the different metabolic pathways of antipyrine in man. Oral versus i.v. administration and the influence of urinary collection time. Eur. J. Clin. Pharmacol. 21: 433-441, 1982

9. Danhof $\mathrm{M}$, and DD Breimer. Studies on the different metabolic pathways of antipyrine in man I. Oral administration of 250,500 and $1000 \mathrm{mg}$ to healthy volunteers. Br. J. Clin. Pharmacol. 8: 529-537, 1979

10. Forni LG, VO Mora-Arellano, JE Packer, and RL Willson. Aminopyrine and antipyrine free radical-cations: pulse radiolysis studies of one-electron transfer reactions. J. Chem. Soc. Perkin Trans. II : 1579-1584, 1988

11. Hageman JJ, A Bast, and NP Vermeulen. Monitoring of oxidative free radical damage in vivo: analytical aspects. Chem. Biol. Interact. 82: 243-293, 1992

12. Halliwell B, and JMC Gutteridge. Free radicals in biology and medicine. Oxford: Claredon Press, 1989

13. Hartleb M. Drugs and the liver. Part II. The role of the antipyrine test in drug metabolism studies. Biopharm. Drug Dispos. 12: 559-570, 1991

14. Hellsten Y, FS Apple, and B Sjodin. Effect of sprint cycle training on activities of antioxidant enzymes in human skeletal muscle. J. Appl. Physiol. 81: 1484-1487, 1996

15. Itoh H, T Ohkuwa, T Yamamoto, Y Sato, M Miyamura, and M Naoi. Effects of endurance physical training on hydroxyl radical generation in rat tissues. Life Sci. 63: 1921-1929, 1998

16. Jenkins RR, R Friedland, and H Howald. The relationship of oxygen uptake to superoxide dismutase and catalase activity in human skeletal muscle. Int. J. Sports Med. 5: 11-14, 1984

17. Leaf DA, MT Kleinman, M Hamilton, and RW Deitrick. The exercise-induced oxidative stress paradox: the effects of physical exercise training. Am. J. Med. Sci. 317: 295-300, 1999

18. Leeuwenburgh C, R Fiebig, R Chandwaney, and LL Ji. Aging and exercise training in skeletal muscle: responses of glutathione and antioxidant enzyme systems. Am. J. Physiol. 267: R439445,1994 
19. McCabe DR, TJ Maher, and IA Acworth. Improved method for the estimation of hydroxyl free radical levels in vivo based on liquid chromatography with elecrtochemical detection. $J$. Chromatogr. B 691: 23-32, 1997

20. Meijer EP, KR Westerterp, and FTJ Verstappen. Effect of exercise training on total daily physical activity in elderly humans. Eur. J. Appl. Physiol. 80: 16-21, 1999

21. Mena P, M Maynar, JM Gutierrez, J Maynar, J Timon, and JE Campillo. Erythrocyte free radical scavenger enzymes in bicycle professional racers. Adaptation to training. Int. J. Sports Med. 12: 563-566, 1991

22. Oh-ishi S, K Toshinai, T Kizaki, S Haga, K Fukuda, N Nagata, and H Ohno. Effects of aging and/or training on antioxidant enzyme system in diaphragm of mice. Respir. Physiol. 105: 195202, 1996

23. Ørtenblad N, K Madsen, and MS Djurhuus. Antioxidant status and lipid peroxidation after short-term maximal exercise in trained and untrained humans. Am. J. Physiol. 272: R12581263, 1997

24. Pilger A, D Germadnik, D Formanek, H Zwick, N Winkler, and HW Rudiger. Habitual longdistance running does not enhance urinary excretion of 8 -hydroxydeoxyguanosine. Eur. J. Appl. Physiol. 75: 467-469, 1997

25. Powers SK, D Criswell, J Lawler, LL Ji, D Martin, RA Herb, and G Dudley. Influence of exercise and fiber type on antioxidant enzyme activity in rat skeletal muscle. Am. J. Physiol. 266: R375-380, 1994

26. Robertson JD, RJ Maughan, GG Duthie, and PC Morrice. Increased blood antioxidant systems of runners in response to training load. Clin. Sci. Colch. 80: 611-618, 1991

27. Siri WE. The gross composition of the body. Adv. Biol. Med. Physiol. 4: 239-280, 1956

28. Tiidus PM, J Pushkarenko, and ME Houston. Lack of antioxidant adaptation to short-term aerobic training in human muscle. Am. J. Physiol. 271: R832-836, 1996. 
32 


\title{
Chapter 7
}

\section{Antioxidant supplementation and exercise-induced oxidative stress in the 60-year-old as measured by antipyrine hydroxylates}

\author{
Erwin P. Meijer \\ Annelies H.C. Goris \\ Joan Senden \\ Joost L.J. van Dongen \\ Aalt Bast \\ Klaas R. Westerterp
}

British Journal of Nutrition, accepted for publication. 


\begin{abstract}
The effects of 12-wk antioxidant supplementation on exercise-induced oxidative stress were investigated in older humans $\left(60 \pm 1 \mathrm{y}\right.$; body mass index $\left.26 \pm 1 \mathrm{~kg} \cdot \mathrm{m}^{-2}\right)$. Subjects were randomly divided in two groups: supplementation $(\mathrm{n}=11)$ with $100-\mathrm{mg}$ $\mathrm{dl}-\alpha$-tocopheryl acetate, $200-\mathrm{mg}$ ascorbic acid, and 2-mg $\beta$-carotene, and placebo $(n=9)$. Before and after 12-wk supplementation, subjects cycled for 45-min at submaximal intensity ( $50 \%$ maximal workload capacity). Antipyrine was used as marker for oxidative stress. Antipyrine reacts quickly with hydroxyl radicals to form para- and ortho-hydroxyantipyrine. The latter metabolite is not formed in man through the mono-oxygenase pathway of cytochrome P450. Daily supplementation significantly increased plasma concentrations of $\alpha$-tocopherol and $\beta$-carotene in the supplemented group $\left(\Delta 14.4 \pm 3.2\right.$ and $0.4 \pm 0.1 \mu \mathrm{mol}^{-1} \mathrm{l}^{-1} ; \mathrm{P}<0.001$ and $\left.\mathrm{P}<0.01\right)$. No significant differences, within and between groups, were observed in the exerciseinduced increase in the ratios para- and ortho-hydroxyantipyrine to antipyrine. Additionally, supplementation did not affect the exercise-induced increase in thiobarbituric acid reactive species in plasma. In conclusion, in 60-year-old subjects antioxidant supplementation had no effect on the exercise-induced increase in oxidative stress as measured by free radical products of antipyrine.
\end{abstract}




\section{Introduction}

It has been hypothesized that aging is associated with deleterious effects of reactive oxygen species (ROS) taking place throughout the life span. There is strong evidence that ROS play an important role in many degenerative diseases like cancer, atherosclerosis and diabetes (3). The effects of ROS are scavenged by antioxidant enzymes, as well as with low molecular-weight non-enzymatic antioxidant vitamins. In cell membranes the most important is $\alpha$-tocopherol, the major member of the vitamin $\mathrm{E}$ family. This molecule acts as a chain-breaking antioxidant, intercepting lipid peroxyl radicals and so terminating lipid peroxidation (4). Other lipid-soluble compounds that can act as an antioxidant are the carotenoids, like $\beta$-carotene (2). The major watersoluble free radical scavenger is ascorbic acid (vitamin C) which also plays a role in sparing vitamin $E$, by regenerating $\alpha$-tocopherol from the oxidized tocopheroxyl radical $(29,35)$. Several studies in older human subjects showed that antioxidant supplementation resulted in an improved immune function and a decreased oxidative damage $(16,27,30)$.

Besides antioxidant supplementation, also exercise is often prescribed to elderly individuals to achieve optimal health. It is, however, generally known that exercise increases ROS generation and results in an induction of the antioxidant defense system $(9,19,32)$. Recently, Coolen (6) observed no increase in oxidative stress in young adults, who cycled for $2 \mathrm{~h}$ at $50 \%$ of their maximal workload capacity $\left(\mathrm{W}_{\max }\right)$. It was proposed that the training status of the subjects was too high to observe an effect on exercise-induced oxidative stress at such a moderate intensity. In elderly subjects, however, we observed that submaximal exercise resulted in a significant increased oxidative stress (25). Furthermore, we showed that training did not affect the exercise-induced increase in oxidative stress. Because aging is associated with an increased susceptibility to free radical damage, it would be informative to know whether physically active older humans would benefit from an antioxidant vitamin supplementation intervention.

To measure oxidative stress in vivo, antipyrine (2,3-dimethyl-1-phenyl-3pyrazolin-5-one), an exogenous marker, was used. The properties of antipyrine make it a suitable marker for measuring oxidative stress in vivo. Following oral ingestion antipyrine is completely absorbed and uniformly distributed in the total body water after approximately $1 \mathrm{~h}(36)$. Additionally, antipyrine is independent of blood flow to the liver, which is an advantage in clinical studies where blood flow is altered e.g. exercise experiments (13). Moreover, the reaction rate constant of antipyrine with hydroxyl radicals, the most aggressive free radicals that exist, is in the order of $10^{10}$ $1 \cdot \mathrm{mol}^{-1} \cdot \mathrm{s}^{-1}(10)$. Exposure of an antipyrine solution in water to ${ }^{60} \mathrm{Co} \gamma$-radiation, leads to the formation of three phenolic antipyrine derivatives: para-hydroxyantipyrine, orthohydroxyantipyrine and meta-hydroxyantipyrine. The last two metabolites are not endogenously formed (7). Recently, we showed in elderly subjects that a submaximal bout of cycling exercise resulted in a significant increase in the plasma levels of paraand ortho-hydroxyantipyrine (25). 
So far, studies in older adults that examined the effect of an antioxidant vitamin supplementation intervention on exercise-induced oxidative stress have only relied on endogenous markers. Therefore, the purpose of this study was to investigate the effects of 12-wk antioxidant supplementation on exercise-induced oxidative stress in 60-year-old human subjects by using antipyrine as an exogenous marker.

\section{Methods}

Study design. The study was designed as a placebo-controlled, double-blind, randomized, parallel group trial. Before and after the 12-wk supplementation period, subjects performed a maximal exercise test and a $45-\mathrm{min}$ cycling test at submaximal intensity. Exercise-induced oxidative stress was measured during the second cycling test by using antipyrine.

Subjects. Twenty-two healthy men and women aged $\geq 55 \mathrm{y}$, with no known medical illness and receiving no prescription medication, participated in the study. Subjects were recruited from advertisements in the local media, and were randomly divided over two groups: 11 subjects in the supplementation group, and 11 subjects in the control placebo group. Two subjects dropped out of the study due to personal reasons. Final data processing was done with 9 subjects in the placebo group. Subject characteristics are shown in Table 1. Detailed information concerning the purpose and methods used in the study was provided before informed consent was obtained. The local Ethical Committee approved the study.

Table 1. Subject characteristics

\begin{tabular}{|c|c|c|c|c|c|c|}
\hline & \multicolumn{3}{|c|}{ Supplemented group $(n=11)^{a}$} & \multicolumn{3}{|c|}{ Placebo group $(n=9)^{b}$} \\
\hline & mean & $\mathrm{SE}$ & range & mean & $\mathrm{SE}$ & range \\
\hline Age, $y$ & 60 & 1 & $55-66$ & 59 & 1 & $55-65$ \\
\hline Body mass, $\mathrm{kg}$ & 79.9 & 3.1 & $55.9-99.6$ & 68.0 & 2.2 & $57.7-86.9$ \\
\hline $\mathrm{BMI}\left(\mathrm{kg} \cdot \mathrm{m}^{-2}\right.$ & 27 & 27 & $21-34$ & 24 & 1 & $19-29$ \\
\hline$\%$ body fat & 31 & 3 & $17-48$ & 30 & 2 & $19-41$ \\
\hline $\mathrm{VO}_{2 \max }, \mathrm{ml} \cdot \mathrm{min}^{-1} \cdot \mathrm{kg}^{-1} \mathrm{FFM}$ & 36 & 2.6 & $21-51$ & 37 & 3 & $26-51$ \\
\hline$W_{\max }, W$ & 146 & 19 & $70-270$ & 139 & 13 & $85-230$ \\
\hline
\end{tabular}

${ }^{a}$ five women and six men; ${ }^{b}$ five women and four men. BMI, body mass index; $\mathrm{VO}_{2 \max }$, maximal $\mathrm{O}_{2}$ uptake; $\mathrm{W}_{\max }$, maximal workload capacity; FFM, fat-free mass. No significant differences were observed between the two groups.

Protocol. After an overnight stay at the laboratory, $\mathrm{W}_{\max }$ and maximal $\mathrm{O}_{2}$ uptake $\left(\mathrm{VO}_{2 \max }\right)$ were measured, on an electronically braked cycle ergometer (Lode Excalibur, Groningen, The Netherlands) during an incremental exercise test, as described before (26). One hour thereafter a Teflon catheter (Quick Cath ${ }^{\otimes} I I$, Baxter Healthcare S.A., Swinford, Ireland) was placed into an antecubital vein, and a resting blood sample (15 
$\mathrm{ml}$ ) was drawn. Immediately thereafter, subjects orally ingested antipyrine (10-mg per $\mathrm{kg}$ body mass; Janssen Chimica, Geel, Belgium). One hour after ingestion subjects cycled for $45-\min$ at $50 \% \mathrm{~W}_{\max }$ (determined during the first cycling trial). Blood samples $(10 \mathrm{ml})$ were drawn before and immediately after exercise. Blood was collected into EDTA $(1.34 \mathrm{mM})$ and GSH $(0.65 \mathrm{mM})$ containing tubes and was centrifuged immediately $\left(3000 \mathrm{rpm}, 10-\mathrm{min}\right.$ at $\left.4^{\circ} \mathrm{C}\right)$. Aliquots of plasma were frozen in liquid nitrogen and stored at $-20^{\circ} \mathrm{C}$ until further analysis. Resting blood samples (5 $\mathrm{ml}$ ) for determination of antioxidant status and cholesterol levels were collected into EDTA-containing tubes.

Supplementation. Subject were either supplemented for 12-wk with one capsule a day containing placebo (microcrystallin cellulose) or with a capsule containing 100 mg dl- $\alpha$-tocopheryl acetate, 200-mg ascorbic acid (10\% CWS), and 2-mg $\beta$-carotene (Roche Vitamins Benelux, Deinze, Belgium). Dutch Biofarmaceutics BV (DBF, Helmond, The Netherlands) produced the capsules.

Oxidative stress. Antipyrine and thiobarbituric acid-reactive substances (TBARS) were used as markers for oxidative stress. Antipyrine and its hydroxylates were measured in plasma by reversed-phase HPLC-MS as described before (8). Briefly, a reversed-phase Supersphere RP18 Endcapped column (LC-Packings, Amsterdam, The Netherlands) was attached to a $\mathrm{LC}$ system consisting of a LC-10AT pump (Shimadzu Ltd., Kyoto, Japan), and a Triathlon autosampler (Spark Holland, Emmen, The Netherlands). The HPLC was connected to an API-300 LC/MS/MS (Perkin Elmer Sciex Instruments, Thornhill, Canada) which operated in the multiple reaction mode with Turbo ionspray as interface. Sample pre-treatment consisted of $\mathrm{C} 18$ solid phase extraction (Sep-Pak ${ }^{\otimes} \mathrm{C} 18$ Cartridges, Waters, Milford, MA) in order to wash out salts and proteins. Cartridges were conditioned with methanol and $\mathrm{H}_{2} \mathrm{O}$, after that $450 \mu \mathrm{I}$ plasma was inserted in the cartridge, followed by $2 \mathrm{ml} 10 \mathrm{mM}$ ammonium-acetate buffer. The cartridge was flushed with $1.5 \mathrm{ml}$ methanol to elute the target components. Samples were evaporated to dryness under nitrogen pressure and dissolved with $450 \mu 1 \mathrm{H}_{2} \mathrm{O}$ after which they stayed 30-min in an ultrasonic waterbath $\left(30^{\circ} \mathrm{C}\right.$ ). Afterwards, samples were filtered by using Spartan 13/20 filters (Schleicher \& Schuell, Dassel, Germany).

Because, a competitive effect exists between antipyrine and other biomolecules for reaction with hydroxyl radicals, the formation of antipyrine hydroxylates is dependent on the available concentration of antipyrine. Therefore, ratios of phenolic derivatives to native antipyrine are used, similar to the salicylic acid method (23).

TBARS were measured in plasma using a fluorescent thiobarbituric acid (TBA) assay. TBA (Sigma-Aldrich Chemie BV, Zwijndrecht, The Netherlands), 0.375 $\mathrm{g}$, was dissolved in $250 \mathrm{ml} \mathrm{H}_{2} \mathrm{O}$ and $2.5 \mathrm{ml} 1 \mathrm{M} \mathrm{HCl} .111 \mu \mathrm{l}$ plasma and $1000 \mu \mathrm{l} \mathrm{TBA}$ solution were mixed and vortexed in an Eppendorf cup after which it was placed in a waterbath $\left(95^{\circ} \mathrm{C}\right)$ for $1 \mathrm{~h}$. Samples were cooled down to room temperature and the 
absorption was measured spectrophotometrically at $532 \mathrm{~nm}$ (Spectronic 1001, Meyvis, Bergen op Zoom, The Netherlands). Results were expressed as micromoles of malondialdehyde (MDA).

Antioxidant status. Antioxidant intake was derived from total food intake measured with a 7-d dietary record (12). Subjects received instructions from a dietitian on how to keep a food record and were asked not to change their habitual food intake. From the data of food records antioxidant intake was calculated by a computer program based on food tables (Becel Nutritional Program, 1988; Nederlandse Unilever bedrijven BV, Rotterdam, The Netherlands). Additionally, plasma was analyzed for the $\alpha$-tocopherol and $\beta$-carotene content by HPLC (15) on an Inertsil ODS-2, C-18 reversed-phase column (GL Sciences Inc., Tokyo, Japan). Fluorescence detection was used for the determination of $\alpha$-tocopherol. Simultaneously, $\beta$-carotene was detected by arbsorbance. Chromatogram peak areas were calculated with Gynkosoft Chromatography Data System (Gynkotek GmbH, Germering, Germany), and calibrated against a mixture of various standard substances dissolved in ethanol/dioxane/acetonitrile (1:1:3). To adjust $\alpha$-tocopherol levels for the total cholesterol concentration in plasma, total cholesterol was determined enzymatically (CHOD-PAP method; Monotest cholesterol, Boehringer, Mannheim, Germany) with a COBAS FARA semiautomatic analyzer (Hoffman-La Roche, Basel, Switzerland).

Statistics. Data are presented as means \pm SE. The non-parametric Mann-Whitney Utest was used to evaluate differences between groups, while the non-parametric Wilcoxon signed-rank test was used to evaluate differences within groups. Statistical significance was accepted as $\mathrm{P}<0.05$. The StatView5.0 program (SAS Institute Inc., Cary, NC) was used as the statistical package.

\section{Results}

Effect of antioxidant supplementation. 12-wk antioxidant vitamins supplementation resulted in a significant increase in the plasma concentrations of $\alpha$-tocopherol ( $\Delta$

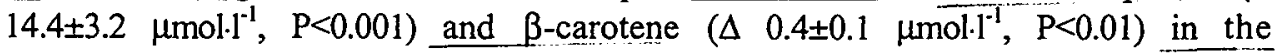
supplemented group. No significant changes in plasma concentrations of $\alpha$ tocopherol $\left(\Delta 5.6 \pm 2.1 \mu \mathrm{mol} \cdot \mathrm{l}^{-1}\right)$ and $\beta$-carotene $\left(\Delta 0.1 \pm 0.2 \mu \mathrm{mol} \cdot \mathrm{l}^{-1}\right)$ were observed in the placebo group. In the supplemented group, $\alpha$-tocopherol levels in plasma were also significantly increased after adjusting for the plasma cholesterol level $(\Delta 2.5 \pm 0.5$ $\left.\mathrm{mmol} \cdot \mathrm{mol}^{-1}, \mathrm{P}<0.001\right)$. As a consequence of the supplementation, daily intake of ascorbic acid and $\beta$-carotene was significantly increased (Table 2). 


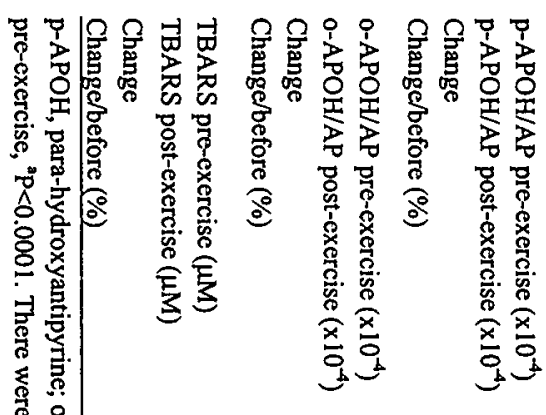

弯

$\exists$

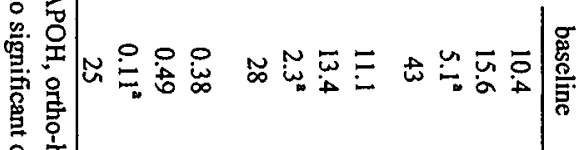

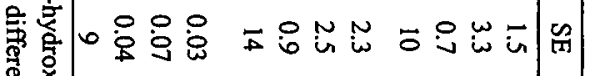
है

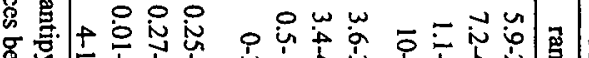

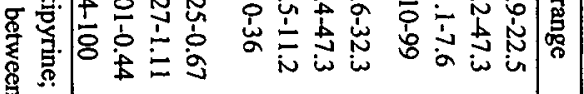

焉尊 콜.

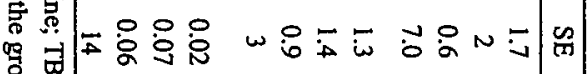
总存

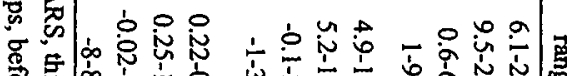

象

吉

券

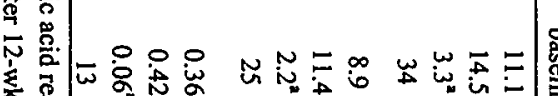

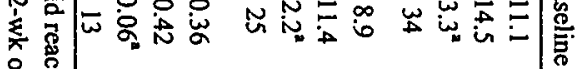

$\stackrel{\circ}{\circ}$

寻泀

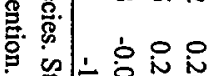

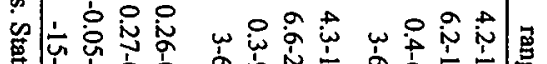

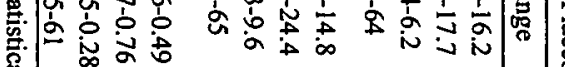

है। $\infty$ के

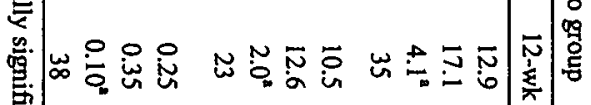

窟

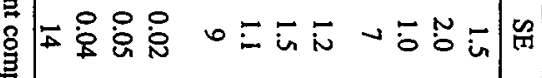

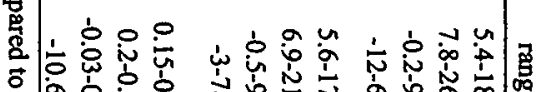

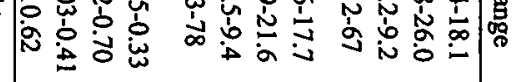

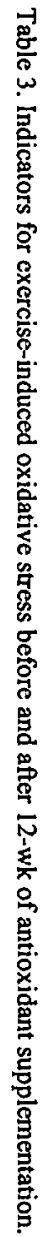

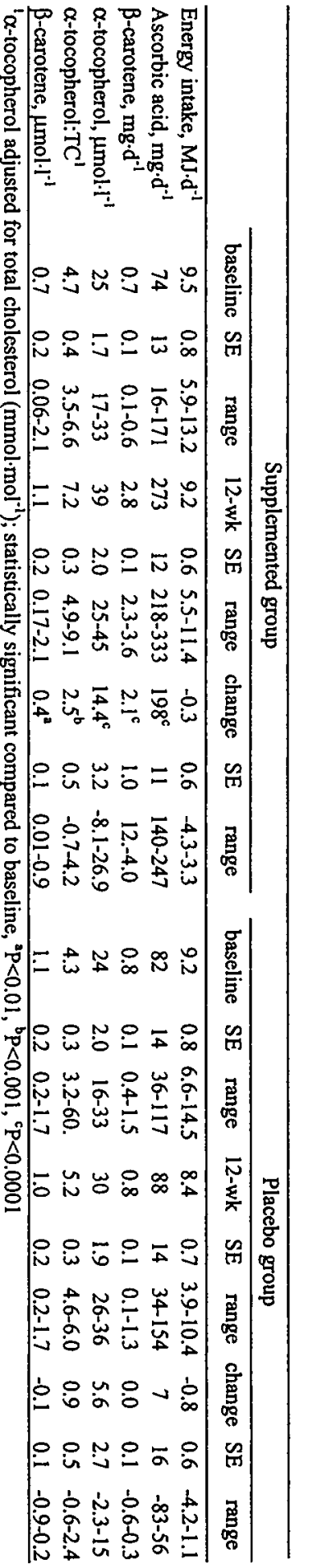


Exercise-induced oxidative stress. In both groups, the 45 -min cycling test resulted in significant $(\mathrm{P}<0.0001)$ increase in the plasma levels of TBARS $(\Delta 0.10 \pm 0.05$ and $\Delta$ $0.07 \pm 0.03 \mu \mathrm{M}$ for supplemented and placebo group, respectively). In addition, the ratios of para- and ortho-hydroxyantipyrine ( $\mathrm{p}-\mathrm{APOH}$ and $\mathrm{o}-\mathrm{APOH}$ ) to native antipyrine were significantly increased immediately after exercise. The increase in the ratios of $\mathrm{p}-\mathrm{APOH}$ and $\mathrm{o}-\mathrm{APOH}$ to antipyrine in the supplemented group was $5.1 \times 10^{-4} \pm 2.0 \times 10^{-4}$ and $2.3 \times 10^{-4} \pm 0.9 \times 10^{-4}$, respectively $(\mathrm{P}<0.0001)$. The increase in the ratios of $\mathrm{p}-\mathrm{APOH}$ and $\mathrm{o}-\mathrm{APOH}$ to antipyrine in the placebo group was $3.3 \times 10^{-4} \pm 0.5 \times 10^{-4}$ and $2.2 \times 10^{-4} \pm 1.0 \times 10^{-4}$, respectively $(\mathrm{P}<0.0001)$.

Effect of antioxidant supplementation. Although 12-wk supplementation significantly increased the plasma antioxidant level, no effect on the exercise-induced increase in the ratios of $\mathrm{p}-\mathrm{APOH}$ and $\mathrm{o}-\mathrm{APOH}$ to antipyrine was observed (Table 3). Additionally, no differences within and between both groups were observed in the exercise-induced increase of the plasma levels of TBARS before and after $\overline{12-w k}$ (Table 3).

\section{Discussion}

Recently, we showed in 60-year-old human subjects that a submaximal bout of exercise significantly increased the exercise-induced oxidative stress (25), whereas no significant increase was observed in a group of young adults, who exercised at the same relative intensity $\left(50 \% \mathrm{~W}_{\max }\right)$ (6). Therefore, it was hypothesized that supplementation with antioxidants could possibly reduce the increase in exerciseinduced oxidative stress in older subjects. The results of this study, however, showed that 12-wk of antioxidant vitamin supplementation in 60-year-old human subjects had no effect on the exercise-induced increase in oxidative stress, as measured by free radical reaction products of antipyrine. Additionally, no change was observed in the exercise-induced increase of TBARS. It has to be mentioned, however, that the TBA assay lacks specificity when applied to human plasma.

The finding that antioxidant supplementation had no effect on exerciseinduced oxidative stress is in accordance with previous studies that have relied on endogenous markers $(20,22,38)$. Witt et al. (38) was the first to study the influence of a combined antioxidant supplement. They used urinary output of 8hydroxyguanosine, a marker of RNA damage, as indicator for oxidative stress. Their subjects were moderately trained and cycled at $65 \% \mathrm{VO}_{2 \max }$ for $90-\mathrm{min}$ on 3 consecutive days. There was no evidence of exercise-induced damage in their control group, and subjects who took a combination of vitamin E, ascorbic acid and $\beta$-carotene for 1 month did not differ from controls. In addition, Maxwell et al. (22) reported, in 24 younger adults (17-22 y), that supplementation for 3-wk with either placebo, $400 \mathrm{mg}$ ascorbic acid or $400 \mathrm{mg}$ dl- $\alpha$-tocopheryl acetate did not affect the exercise-induced increase in the plasma level of TBARS. Furthermore, Kanter et al. (20) concluded from their study in younger adults (20-29 y) that 6-wk of combined 
ingestion of $\alpha$-tocopherol, ascorbic acid and $\beta$-carotene did not prevent the exerciseinduced increase in oxidative stress.

The only study that examined the effect of antioxidant supplementation on exercise-induced oxidative stress in older adults reported a significantly reduction in urinary output of TBARS after 48-d of $\alpha$-tocopherol supplementation (27). The elderly subjects (55-74 y), however, were supplemented with much higher doses of $\alpha$ tocopherol $\left(800 \mathrm{mg} \cdot \mathrm{d}^{-1}\right)$ when compared to this study. Although subjects in the present study were supplemented for 12-wk with relatively low doses of dl- $\alpha$ tocopheryl acetate $(100 \mathrm{mg})$, ascorbic acid $(200 \mathrm{mg})$, and $\beta$-carotene $(2 \mathrm{mg})$, supplementation significantly increased the plasma levels of $\alpha$-tocopherol $(\Delta$ $\left.14.4 \pm 3.2 \mu \mathrm{mol} \cdot \mathrm{I}^{-1}, \mathrm{P}<0.001\right)$ and $\beta$-carotene $\left(\Delta 0.4 \pm 0.1 \mu \mathrm{mol} \cdot \mathrm{I}^{-1}, \mathrm{P}<0.01\right)$. Ascorbic acid levels in plasma were not measured, but it might be assumed that also those levels were significantly increased after 12 -wk supplementation, because there was a 3-fold increase in ascorbic acid intake (Table 2). It has been shown that the intake of $200 \mathrm{mg}$ ascorbic acid saturates plasma for almost 90\% (21). Therefore, the doses of antioxidant supplementation used in the present study should have been sufficient to increase the antioxidant status and capacity of exercising elderly.

It could be argued, however, that the number of subjects used in the present study was too low to detect any significant change of antioxidant supplementation on exercise-induced oxidative stress $(n=11$, and $n=9$ for the 2 groups). It has to be mentioned, however, that Meydani et al. (27) used only 12 older subjects and showed that 48-d $\alpha$-tocopherol supplementation $(n=6)$ significantly decreased the urinary levels of TBARS after a bout of eccentric exercise. Additionally, Hartmann et al. (14) demonstrated in 8 subjects that vitamin $E$ supplementation prevented exercise-induced DNA damage. Therefore, the number of subjects used in the present study should have been sufficient to observe the potential for a decrease in exercise-induced oxidative stress after 12-wk antioxidant supplementation. Another point that could be raised is that although there were no significant differences between the two groups, large inter-individual differences exist. Since the outcome measures on oxidative stress were independent of factors such as body mass and gender, the results have to be interpreted with some caution.

Although the protective role of $\alpha$-tocopherol during exercise-induced oxidative stress is well established, it has to be mentioned however that the role of ascorbic acid is less clear (18). Ascorbic acid is known to play a role in sparing vitamin $E$, by regenerating $\alpha$-tocopherol from the oxidized tocopheroxyl radical (29, 35). Furthermore, ascorbic acid is effective in preventing the oxidation of the blood glutathione pool during physical exercise (33). So far, only Ashton et al. (1) showed that acute administration of ascorbic acid prevented exercise-induced oxidative stress during a maximal exercise test to exhaustion as measured by electron spin resonance spectroscopy (spin-trap: $\alpha$-phenyl-tert-butylnitrone). They suggested that ascorbic acid could be an effective antioxidant in the prevention of exerciseinduced oxidative stress. It may be that humans only benefit from antioxidant 
supplements if they are deficient or exposed to exceptionally heavy workloads like maximal exercise tests or eccentric exercise protocols.

The exercise protocol used in this study was not exceptionally high, subjects cycled for $45-\mathrm{min}$ at an exercise intensity of $50 \% \mathrm{~W}_{\max }\left(\sim 55 \% \mathrm{VO}_{2 \max }\right)$. However, the older adults in the present study were relatively unfit, and it has been shown that exhaustive exercise results in an increased oxidative stress $(9,19,32)$. Indeed, we observed a significantly increase in the free radical reaction products of antipyrine after exercise $(\mathrm{P}<0.0001)$, similar to findings of a previous study in older adults (25). The exercise-induced increase in the plasma levels of TBARS was also highly significant $(\mathrm{P}<0.0001)$, which indicates that cycling for $45-\mathrm{min}$ at $50 \% \mathrm{~W}_{\max }$ results in a significantly increased oxidative stress. Furthermore, it is known that older adults are more susceptible to oxidative stress when compared to younger adults (24). Additionally, aging is associated with an increased mitochondrial free radical production (34). Therefore, one might intuitively have suspected a decreased exercise-induced oxidative stress after 12-wk antioxidant supplementation.

Moreover, humans may benefit from antioxidant supplements if their antioxidant status is too low. Subjects in this study, however, were not deficient concerning antioxidant intake. Measured vitamin $\mathrm{C}$ intake was higher than the Dutch recommended dietary allowance of $70 \mathrm{mg} \cdot \mathrm{d}^{-1}$ (Table 2). In addition, plasma concentrations of $\alpha$-tocopherol and $\beta$-carotene were similar to findings of previous studies in elderly populations $(11,17,28,30)$. It has been hypothesized that antioxidant supplementation is warranted in older subjects having a high daily physical activity level $(5,31)$. Although the subjects in this study were characterized as sedentary active, further research on this topic is needed.

It could be argued that the method used (antipyrine oxidation) is not sensitive enough to measure the small changes after 12-wk antioxidant supplementation. However, the used method has been validated in vitro as well as in vivo conditions before. It was shown in vitro that exposure of an antipyrine solution in water to ${ }^{60} \mathrm{Co}$ $\gamma$-radiation leads to the formation of three phenolic antipyrine derivatives: parahydroxyantipyrine, ortho-hydroxyantipyrine and meta-hydroxyantipyrine (7). When an antioxidant is added to an antipyrine solution in water, the conversion of antipyrine after exposure to ${ }^{60} \mathrm{Co} \gamma$-radiation can be used as indicator for the free radical scavenging capacity of a potential antioxidant (6). For example, ascorbic acid significantly reduced the conversion of antipyrine, depending on the added concentration of ascorbic acid. The results of the antipyrine method were linearly correlated with the results of the commonly used deoxyribose assay $\left(r^{2}=0.99\right)$. The properties of antipyrine also make it a suitable marker for measuring oxidative stress in vivo. A study in patients with claudicatio intermittens showed that 5-min walking exercise resulted in a significantly increase in the plasma concentration of the free radical reaction products of antipyrine (37). Claudicatio intermittens is characterized by a chronic ischemia-reperfusion injury during physical exercise, which results in an increased oxidative stress. Interestingly, the exercise-induced increase in the ratio oAPOH to antipyrine was similar in claudicants performing 5-min walking exercise $(\Delta$ 
$2.1 \times 10^{-4}$ ) compared to older adults cycling for $45-\mathrm{min}$ at submaximal intensity ( $\Delta$ $\left.2.2 \times 10^{-4}\right)$, which confirms that the increased hydroxyl radical formation in the exercising older subjects could be detected by the antipyrine method.

In conclusion, a 12-wk antioxidant supplementation intervention in an 60-yearold population had no effect on the exercise-induced increase in oxidative stress during 45-min cycling at submaximal intensity as measured by free radical products of antipyrine. 


\section{References}

1. Ashton T, IS Young, JR Peters, E Jones, SK Jackson, B Davies, and CC Rowlands. Electron spin resonance spectroscopy, exercise and oxidative stress: an ascorbic acid intervention study. J. Appl. Physiol. 87: 2032-2036, 1999

2. Bast A, GRMM Haenen, $R$ Van Den Berg, and H Van Den Berg. Antioxidant effects of carotenoids. Int. J. Vit. Nutr. Res. 68: 399-403, 1998

3. Beckman KB, and BN Ames. The free radical theory of aging matures. Physiol. Rev. 78: 547-581, 1998

4. Brigelius-Floh R, and MG Traber. Vitamin E: function and metabolism. FASEB J. 13: $1145-1155,1999$

5. Clarkson PM, and HS Thompson. Antioxidants: what role do they play in physical activity and health? Am. J. Clin. Nutr: 72: 637S-646S, 2000

6. Coolen SAJ. Antipyrine hydroxylates as indicators for oxidative damage. Ph.D. thesis. Eindhoven: Eindhoven University of Technology, 2000

7. Coolen SAJ, FM Everaerts, and FA Huf. Characterization of ${ }^{60} \mathrm{Co} \gamma$-radiation induced radical products of antipyrine by means of high-performance liquid chromatography, mass spectrometry, capillary zone electrophoresis, micellar electrokinetic capillary chromatography and nuclear magnetic resonance spectrometry. J. Chromatogr. A 788: 95-103, 1997

8. Coolen SAJ, M Van Lieshout, JC Reijenga, and FA Huf. Determination of phenolic derivatives of antipyrine in plasma with HPLC-Tandem MS using ESI and Turbo ionspray as interfaces. J. Microcolumn Sep. 11: 701-707, 1999

9. Davies KJ, AT Quintanilha, GA Brooks, and L Packer. Free radicals and tissue damage produced by exercise. Biochem. Biophys. Res. Commun. 107: 1198-205, 1982

10. Forni LG, VO Mora-Arellano, JE Packer, and RL Willson. Aminopyrine and antipyrine free radical-cations: pulse radiolysis studies of one-electron transfer reactions. J. Chem. Soc. Perkin Trans. II : 1579-1584, 1988

11. Fotouhi N, M Meydani, MS Santos, SN Meydani, CH Hennekens, and JM Gaziano. Carotenoid and tocopherol concentrations in plasma, peripheral blood mononuclear cells, and red blood cells after long-term B-carotene supplementation in men. Am. J. Clin. Nutr. 63: $553-558,1996$

12. Goris AHC, and KR Westerterp. Underreporting of habitual food intake is explained by undereating in highly motivated lean women. J. Nutr. 129: 878-882, 1999

13. Hartleb, M. Drugs and the liver. Part II. The role of the antipyrine test in drug metabolism studies. Biopharm. Drug Dispos. 12: 559-70, 1991.

14. Hartmann A, AM Niess, M Grunert Fuchs, B Poch, and G Speit. Vitamin E prevents exercise-induced DNA damage. Mutat. Res. 346: 195-202, 1995

15. Hess D, HE Keller, B Oberlin, R Bonfanti, and W Schuep. Simultaneous determination of retinol, tocopherols, carotenes and lycopene in plasma by means of High-Performance Liquid Chromatography on reversed phase. Int. J. Vit. Nutr. Res. 61: 232-238, 1991

16. Hughes DA. Effects of dietary antioxidants on the immune function of middle-aged adults. Proc. Nutr. Soc. 58: 79-84, 1999

17. Jacques PF, AD Halpner, and JB Blumberg. Influence of combined antioxidant nutrient intakes on their plasma concentrations in an elderly population. Am. J. Clin. Nutr. 62: 1228-1233, 1995

18. Ji LL. Antioxidants and oxidative stress in exercise. Proc. Soc. Exp. Biol. Med. 222: $283-$ 292, 1999 
19. Ji LL, and R Fu. Responses of glutathione system and antioxidant enzymes to exhaustive exercise and hydroperoxide. J. Appl. Physiol. 72: 549-554, 1992

20. Kanter MM, LA Nolte, and JO Holloszy. Effects of an antioxidant vitamin mixture on lipid peroxidation at rest and postexercise. J. Appl. Physiol. 74: 965-9, 1993

21. Levine $M, C$ Conry-Cantilena, Y Wang, RW Welch, PW Washko, KR Dhariwal, JB Park, A Lazarev, JF Graumlich, J King, and LR Cantilena. Vitamin C pharmacokinetics in healthy volunteers: Evidence for a recommended dietary allowance. Proc. Natl. Acad. Sci. USA 93: 3704-3709, 1996

22. Maxwell SR, P Jakeman, H Thomason, C Leguen, and GH Thorpe. Changes in plasma antioxidant status during eccentric exercise and the effect of vitamin supplementation. Free Radic Res Commun 19: 191-202, 1993

23. McCabe DR, TJ Maher, and IA Acworth. Improved method for the estimation of hydroxyl free radical levels in vivo based on liquid chromatography with elecrtochemical detection. J. Chromatogr. B 691: 23-32, 1997

24. Mecocci P, G Fano, S Fulle, U MacGarvey, L Shinobu, MC Polidori, A Cherubini, J Vecchiet, U Senin, and MF Beal. Age-dependent increases in oxidative damage to DNA, lipids, and proteins in human skeletal muscle. Free. Radic. Biol. Med. 26: 303-308, 1999

25. Meijer EP, SAJ Coolen, A Bast and KR Westerterp. Exercise training and oxidative stress in the elderly as measured by antipyrine hydroxylates. Free Radic. Res., in press

26. Meijer EP, KR Westerterp, and FTJ Verstappen. Effect of exercise training on total daily physical activity in elderly humans. Eur. J. Appl. Physiol. 80: 16-21, 1999

27. Meydani M, WJ Evans, G Handelman, L Biddle, RA Fielding, SN Meydani, J Burrill, MA Fiatarone, JB Blumberg, and JG Cannon. Protective effect of vitamin E on exerciseinduced oxidative damage in young and older adults. Am. J. Physiol. 264: R992-998, 1993

28. Meydani SN, M Meydani, LC Rall, F Morrow, and JB Blumberg. Assessment of the safety of high-dose, short-term supplementation with vitamin $\mathrm{E}$ in healthy older adults. $\mathrm{Am}$. $J$. Clin. Nutr. 60: 704-709, 1994

29. Packer JE, TF Slater, and RL Wilson. Direct observation of a free radical interaction between vitamin $E$ and vitamin C. Nature 278: 737-738, 1979.

30. Pallast EG, EG Schouten, FG De Waart, HF Fonk, G Doekes, BM Von Blomberg, and FJ Kok. Effect of 50- and 100-mg vitamin E supplements on cellular immune function in noninstitutionalized elderly persons. Am. J. Clin. Nutr. 69: 1273-1281, 1999

31. Polidori MC, P Mecocci, A Cherubini, and U Senin. Physical activity and oxidative stress during aging. Int. J. Sports Med. 21: 154-157, 2000

32. Powers SK, D Criswell, J Lawler, LL Ji, D Martin, RA Herb, and G Dudley. Influence of exercise and fiber type on antioxidant enzyme activity in rat skeletal muscle. Am. J. Physiol. 266: R375-380, 1994

33. Sastre J, M Asensi, E Gasco, FV Pallardo, JA Ferrero, T Furukawa, and J Vina. Exhaustive physical exercise causes oxidation of glutathione status in blood: prevention by antioxidant administration. Am. J. Physiol. 263: R992-995, 1992

34. Shigenaga MK, TM Hagen, and BN Ames. Oxidative damage and mitochondrial decay in aging. Proc. Natl. Acad. Sci. USA 91: 10771-10778, 1994

35. Sies $\mathrm{H}$, and $\mathrm{W}$ Stahl. Vitamins $\mathrm{E}$ and $\mathrm{C}, \boldsymbol{\beta}$-carotene, and other carotenoids as antioxidants. Am. J. Clin. Nutr. 62: 1315S-1321S, 1995

36. Siri WE. The gross composition of the body. Adv. Biol. Med. Physiol. 4: 239-280, 1956

37. Wijnen MH, SAJ Coolen, HL Vader, JC Reijenga, FA Huf, and RMH Roumen. Antioxidants reduce oxidative stress in claudicants. J. Surg. Res. 96: 183-187, 2001

38. Witt EH, AZ Reznick, CA Viguie, P Starke Reed, and L Packer. Exercise, oxidative damage and effects of antioxidant manipulation. J. Nutr. 122: 766-73, 1992. 
Chapter 8

\title{
Exercise-induced oxidative stress in the elderly as a function of the habitual activity level
}

\author{
Erwin P. Meijer \\ Annelies H.C. Goris \\ Joost L.J. van Dongen \\ Aalt Bast \\ Klaas R. Westerterp
}

Submitted for publication. 


\section{Abstract}

It has been suggested that regular physical activity might maintain and promote the antioxidant defense capacity against oxidative stress. Therefore, we assessed exercise-induced oxidative stress in relation to the habitual physical activity level (PAL) in older adults. PAL was determined as average daily metabolic rate (ADMR) combined with a measurement of basal metabolic rate (BMR): $P A L=A D M R / B M R$. ADMR was measured over two weeks with the doubly labeled water method, preceded by a BMR measurement with a ventilated hood. Antipyrine was used as marker for oxidative stress in vivo. Reaction of antipyrine with hydroxyl radicals results in the formation of para- and ortho-hydroxyantipyrine, where orthohydroxyantipyrine is not formed through alternative oxygenetic pathway. Twenty-six subjects volunteered for the study $\left(n=26 ; 60 \pm 1 \mathrm{y}\right.$; body mass index $27 \pm 1 \mathrm{~kg} \cdot \mathrm{m}^{-2}$ ). PAL was inversely related to the exercise-induced increase in the ratio of orthohydroxyantipyrine to native antipyrine $(r=0.49 ; \mathrm{P}=0.01)$. The relationship between PAL and exercise-induced increase in the ratio of para-hydroxyantipyrine $(r=0.30$; $\mathrm{P}=0.14)$ or thiobarbituric acid reactive species $(\mathrm{r}=-0.31 ; \mathrm{P}=0.13)$ did not reach the level of significance. Therefore, we conclude that physically active older adults have a reduced exercise-induced oxidative stress compared to older adults with a lower level of physical activity. Thus, regular physical activity improves the antioxidant defense capacity. 


\section{Introduction}

Aging is associated with a decline in physical activity. Regular physical activity and exercise are recommended for maintenance of optimal health and prevention or management of chronic diseases (2). It has been shown that low levels of physical fitness are associated with an increased risk of cardiovascular disease mortality $(1,7)$. On the other hand, there is increasing evidence indicating that exercise, especially when performed strenuously, is associated with an increased production of reactive oxygen species (ROS) $(14,25)$. ROS may increase during exercise as a result of a higher mitochondrial $\mathrm{O}_{2}$ consumption and electron transport flux (13). A state of increased levels of intracellular ROS production is referred to as oxidative stress. It has been shown that aging is associated with an increased susceptibility to oxidative stress (17). The relationship between oxidative stress and physical activity, however, is still poorly understood, particularly in advanced age, since there is a substantial lack of data regarding the effects of exercise and training on oxidative stress in the elderly (22).

One of the reasons for the lack of data is the methodological aspect concerning the assessment of oxidative stress and the habitual activity level. In this study, we used antipyrine oxidation (2,3-Dimethyl-1-phenyl-3-pyrazolin-5-one) as a marker for measuring oxidative stress. The properties of antipyrine make it a suitable marker for assessing oxidative stress in vivo. Following oral ingestion antipyrine is completely absorbed and uniformly distributed in the total body water after approximately $1 \mathrm{~h} \mathrm{(27).} \mathrm{Additionally,} \mathrm{antipyrine} \mathrm{is} \mathrm{independent} \mathrm{of} \mathrm{blood} \mathrm{flow} \mathrm{to} \mathrm{the}$ liver, which is an advantage in clinical studies where blood flow is altered e.g. during exercise experiments (11). Moreover, the reaction rate constant of antipyrine with hydroxyl radicals is in the order of $10^{10} 1 \cdot \mathrm{mol}^{-1} \cdot \mathrm{s}^{-1}(8)$. Exposure of an antipyrine solution in water to ${ }^{60} \mathrm{Co} \gamma$-radiation, leads to the formation of three phenolic antipyrine derivatives: para-hydroxyantipyrine, ortho-hydroxyantipyrine and metahydroxyantipyrine. The latter two metabolites are not formed in man through the mono-oxygenase pathway of cytochrome P450 (4). Recently, we showed that in older adults that exercise in a significant increase in the plasma levels of para- and orthohydroxyantiprine could be observed (18). The ratio of the hydroxylated products of antipyrine and the plasma concentration of antipyrine reflects the oxidative stress in vivo.

To assess the physical activity level in an older population we used the doubly labeled water method. This method is generally assumed to be the gold standard for assessing physical activity (23). The doubly labeled water method allows accurate measurement of average daily metabolic rate (ADMR) under unrestricted conditions over 1- to 3-wk intervals. In combination with a measurement of basal metabolic rate (BMR), the physical activity level can be obtained (PAL=ADMR/BMR).

So far, the potential role of oxidative stress during physical activity in old age remains unknown. Therefore, the purpose of this study was to examine the possible 
relationship between the physical activity level and the exercise-induced increase in oxidative stress in older adults.

\section{Methods}

Study design. The study included a 2-wk observation period for the measurement of average daily metabolic rate (ADMR) and physical activity level (PAL). Exerciseinduced oxidative stress was measured during a 45 -min cycling test at submaximal intensity by using free radical reaction products of antipyrine.

Subjects. Twenty-six healthy older men and women aged $\geq 55 \mathrm{y}$, with no known medical illness and receiving no prescription medication, participated in the study. Subjects were recruited from advertisements in the local media. Subject characteristics are shown in Table 1. Detailed information concerning the purpose and methods used in the study was provided before informed consent was obtained. The local Ethical Committee approved the study.

Energy expenditure. ADMR was measured with the doubly labeled water method according to the Maastricht protocol (29). Briefly, subjects were given, on the evening of day $0(22.00-23.00 \mathrm{~h})$ after a background urine sample was collected, a weighed dose of a mixture of 99.9 atom $\%{ }^{2} \mathrm{H}_{2} \mathrm{O}$ in 10.0 atom $\% \mathrm{H}_{2}^{18} \mathrm{O}$, such that baseline levels were increased to $\geq 300 \mathrm{ppm}$ for ${ }^{2} \mathrm{H}$ and $\geq 2300 \mathrm{ppm}$ for ${ }^{18} \mathrm{O}$. Additionally, urine samples were collected on day 1 (from second void) on the evening of day 1, evening of day 7, morning day 8 (from second void), evening of day 14 , and morning of day 15 (from second void). Isotope abundance was measured in urine by using an isotope-ratio mass spectrometer (Optima, Micromass, Manchester, UK). $\mathrm{CO}_{2}$ production was calculated from the isotope disappearance rate from the samples collected on day 1,8 and $15 . \mathrm{CO}_{2}$ production was converted to ADMR with a respiratory exchange ratio equal to the food quotient that was derived from a 1-wk food diary. Mean physical activity level was determined as ADMR combined with a measurement of basal metabolic rate: $\mathrm{PAL}=\mathrm{ADMR} / \mathrm{BMR}$.

Table 1. Subject characteristics

\begin{tabular}{lc} 
& mean $\pm \mathrm{SE}$ \\
\hline women/men & $13 / 13$ \\
Age, $\mathrm{y}$ & $60 \pm 1$ \\
Body mass, $\mathrm{kg}$ & $75.5 \pm 2.2$ \\
$\mathrm{BMI}, \mathrm{kg} \cdot \mathrm{m}^{-2}$ & $27 \pm 1$ \\
$\mathrm{Body}$ fat, $\%$ & $34 \pm 1$ \\
$\mathrm{VO}_{2 \max }, \mathrm{l} \cdot \mathrm{min}^{-1}$ & $1.84 \pm 0.12$ \\
$\mathrm{~W}_{\operatorname{mgx}}, \mathrm{W}$ & $145 \pm 49$ \\
\hline $\mathrm{BMI}=$ body mass index; $\mathrm{VO}_{2 \max }=$ maximal $\mathrm{O}_{2}$ uptake; $\mathrm{W}_{\max }=$ \\
maximal workload capacity. Body fat $(\%)$ was determined by \\
underwater weighing combined with deuterium dilution.
\end{tabular}


Basal metabolic rate. BMR was measured after an overnight fast at $06.45 \mathrm{~h}$. After a period of 15-min under thermoneutral temperature conditions, BMR was measured for at least $15-\mathrm{min} . \mathrm{O}_{2}$ consumption and $\mathrm{CO}_{2}$ production were measured by means of a computerized, open-circuit, ventilated hood system. Gas analyses were performed using a paramagnetic $\mathrm{O}_{2}$ analyzer (Servomex Type 500A, Crowborough Sussex, UK) and an infrared $\mathrm{CO}_{2}$ analyzer (Servomex Type 12-X1). The system was similar to the analysis system for the respiration chambers described before (24) Calculation of BMR was based upon the Weir formula (28).

Exercise-induced oxidative stress. Maximal workload capacity $\left(\mathrm{W}_{\max }\right)$ and maximal $\mathrm{O}_{2}$ uptake $\left(\mathrm{VO}_{2 \max }\right)$ were measured after the BMR measurement. Subjects exercised incrementally on an electronically braked cycle ergometer (Lode Excalibur, Groningen, The Netherlands) until volitional fatigue, as described before (19). One hour thereafter a Teflon catheter (Quick Cath ${ }^{\oplus}$ II, Baxter Healthcare S.A., Swinford, Ireland) was placed into an antecubital vein, and a resting blood sample $(10 \mathrm{ml})$ was drawn. Immediately thereafter subjects orally ingested 10-mg antipyrine (Janssen Chimica, Geel, Belgium) per kg body mass. One hour after ingestion subjects cycled for 45 -min at $50 \% \mathrm{~W}_{\max }$ (determined during the first cycling trial). Blood samples were drawn before and immediately after exercise. Blood was collected into EDTA (1.34 $\mathrm{mM})$ and $\mathrm{GSH}(0.65 \mathrm{mM})$ containing tubes and was centrifuged immediately (3000 $\mathrm{rpm}, 10$-min at $4{ }^{\circ} \mathrm{C}$ ). Aliquots of plasma were frozen in liquid nitrogen and stored at $-20^{\circ} \mathrm{C}$ until further analysis.

Markers of oxidative stress. Antipyrine and thiobarbituric acid-reactive substances (TBARS) were used as indicators for oxidative stress. Antipyrine and its hydroxylates were measured by reversed phase HPLC combined with mass spectrometry (HPLC-MS), as described before (5). Briefly, a reversed-phase Supersphere RP18 Endcapped column (LC-Packings, Amsterdam, The Netherlands), $150 \times 1 \mathrm{~mm}$ I.D., $d_{p}=4 \mu \mathrm{m}$ was attached to a LC system consisting of a LC-10AT pump (Shimadzu Ltd., Kyoto, Japan), and a Triathlon autosampler (Spark Holland, Emmen, The Netherlands). The HPLC was connected to an API-300 LC/MS/MS (Perkin Elmer Sciex Instruments, Thornhill, Canada) which operated in the multiple reaction mode with Turbo ionspray as interface. Sample pre-treatment consisted of $\mathrm{C} 18$ solid phase extraction (Sep-Pak ${ }^{\circledR} \mathrm{C} 18$ Cartridges, Waters, Milford, MA) in order to wash out salts and proteins. Cartridges were conditioned with methanol and $\mathrm{H}_{2} \mathrm{O}$. After that $450 \mu \mathrm{l}$ plasma was inserted in the cartridge, followed by $2 \mathrm{ml}$ ammonium-acetate buffer (10 $\mathrm{mM} ; \mathrm{pH}=5$ ). The cartridge was flushed with $1.5 \mathrm{ml}$ methanol to elute the target components. Samples were evaporated to dryness under nitrogen pressure and dissolved with $450 \mu 1 \mathrm{H}_{2} \mathrm{O}$ after which they stayed 30-min in an ultrasonic waterbath $\left(30^{\circ} \mathrm{C}\right.$ ). Afterwards, samples were filtered by using Spartan 13/20 filters (Schleicher \& Schuell, Dassel, Germany). 
Because, a competitive effect exist between antipyrine and other biomolecules for reaction with hydroxyl radicals, the formation of antipyrine hydroxylates is dependent on the available concentration of antipyrine. Therefore, ratios of phenolic derivatives to native antipyrine are used, similar to the salicylic acid method (16).

TBARS were measured in plasma using a fluorescent thiobarbituric acid (TBA) assay. TBA (Sigma-Aldrich Chemie BV, Zwijndrecht, The Netherlands), 0.375 $\mathrm{g}$, was dissolved in $250 \mathrm{ml}$ demineralized $\mathrm{H}_{2} \mathrm{O}$ and $2.5 \mathrm{ml} 1 \mathrm{M} \mathrm{HCl} .111 \mu \mathrm{l}$ plasma and $1000 \mu \mathrm{l} \mathrm{TBA}$ solution were mixed and vortexed in an Eppendorf cup after which it was placed in a waterbath $\left(95^{\circ} \mathrm{C}\right)$ for $1 \mathrm{~h}$. Samples were cooled down to room temperature and the absorption was measured spectrophotometrically at $532 \mathrm{~nm}$ (Spectronic 1001, Meyvis, Bergen op Zoom, The Netherlands). Results were expressed as micromoles of MDA.

Statistical analysis. Data are presented as means \pm SE. Paired $t$-tests (two-tailed) were used to evaluate differences between pre- and post-exercise conditions. Simple regression was used to examine the relationship between PAL and the indicators of oxidative stress. Correlations are Pearson product-moment correlations. Statistical significance was accepted as $\mathrm{P}<0.05$. The StatView5.0 program (SAS Institute Inc., Cary, NC, USA) was used as the statistical package.

\section{Results}

Exercise significantly increased the ratio of para-hydroxyantipyrine (p-APOH) to native antipyrine from $9.1 \times 10^{-3} \pm 0.9 \times 10^{-3}$ pre-exercise to $11.8 \times 10^{-3} \pm 0.9 \times 10^{-3}$ postexercise $(\mathrm{P}<0.001)$. Additionally, the ratio of ortho-hydroxyantipyrine (o-APOH) to native antipyrine increased from $7.7 \times 10^{-3} \pm 0.9 \times 10^{-3}$ pre-exercise to $11.9 \times 10^{-3} \pm 0.9 \times 10^{-3}$ post-exercise $(\mathrm{P}<0.001)$, whereas the plasma level of TBARS increased from $0.36 \pm 0.02$ $\mu \mathrm{M}$ pre-exercise to $0.43 \pm 0.02 \mu \mathrm{M}$ post-exercise $(\mathrm{P}<0.001)$, respectively. The mean physical activity level (PAL) was 1.64 0.13 (range:1.44-2.00). PAL was inversely related to the exercise-induced increase in the ratio of o-APOH to native antipyrine $(r=0.49, P=0.01)$ (Fig. $1 B$ ). The relationship between PAL and the exercise-induced increase in the ratio of p-APOH to native antipyrine (Fig. 1A), and between PAL and the exercise-induced increase in the plasma level of TBARS (Fig. 1C) did not reach the level of significance $(r=-0.30, P=0.14$ and $r=-0.31, P=0.13$, respectively).

\section{Discussion}

To our knowledge, this is the first study that examined the effect of the daily physical activity level, as measured by the doubly labeled water method, on exercise-induced oxidative stress in older adults. The results of the study suggest that the exerciseinduced oxidative stress, as measured by free radical reaction products of antipyrine, is reduced in physically active older adults compared to inactive older adults, when performing a bout of exercise at the same relative intensity. 

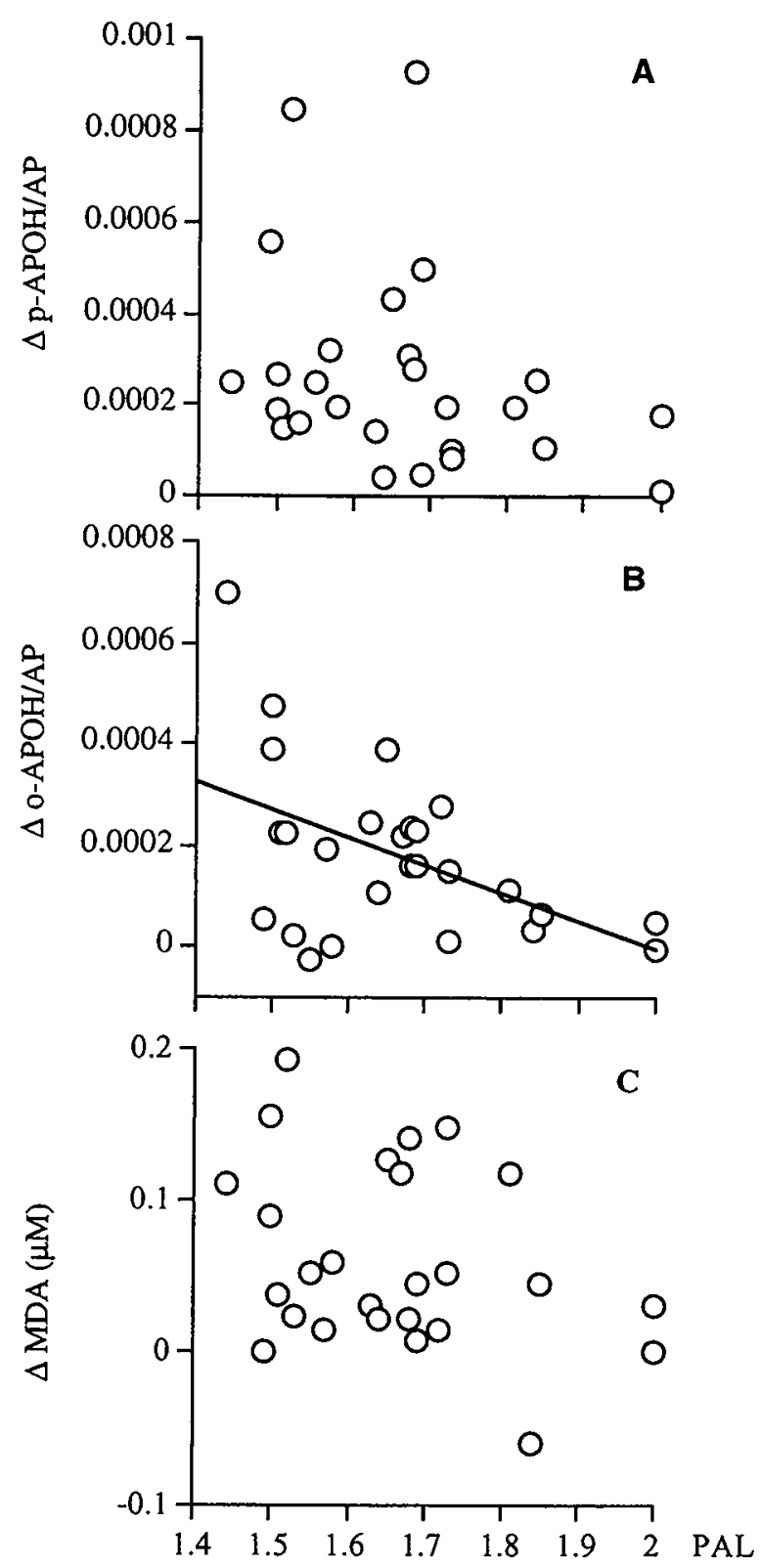

Figure 1. Relationship between physical activity level ( $\mathrm{PAL}=$ average daily metabolic rate/basal metabolic rate) and indicators for exercise-induced oxidative stress. A) PAL and the ratio of parahydroxyantipyrine (p-APOH) to native antipyrine (AP). B) PAL and the ratio of orthohydroxyantipyrine (0-APOH) to native antipyrine. $Y=0.001-0.001 X ; r=-0.49 ; P=0.01$. C) PAL and the plasma level of TBARS.

It has been suggested that regular physical activity might maintain and promote the antioxidant defense capacity against oxidative stress (25). However, physical activity 
in free-living conditions is difficult to measure. Until now only one study attempted to examine the relationship between the physical activity level (PAL) and the antioxidant defense mechanism in the elderly. Kostka et al. (15) showed in aged men (65-84 y) that there was no association between PAL and resting TBARS values, plasma total antioxidant status and levels of red blood cell antioxidants. It has to be mentioned that PAL was measured by using an activity questionnaire. Most activity questionnaires have never been validated against the gold standard for the assessment of physical activity, the doubly labeled water method (21). In the present study, we used the doubly labeled water technique combined with a measurement of BMR to assess PAL in an older population.

The current study showed that the exercise-induced increase in the ratio of ortho-hydroxyantipyrine to antipyrine was significantly lower in physically active older adults when compared to inactive older adults $(\mathrm{r}=0.49, \mathrm{P}=0.01)$. Also after adjusting for the plasma $\alpha$-tocopherol concentration, the increase in orthohydroxyantipyrine after exercise remained significantly related to PAL $(r=0.42$, $\mathrm{P}<0.05$ ). Ortho-hydroxyantipyrine is not known to be formed in man through the mono-oxygenase pathway of cytochrome P450. It is only known as a free radical reaction product of antipyrine (4). The relationship between PAL and the exerciseinduced increase in the ratio of para-hydroxyantipyrine to antipyrine failed to reach significance $(\mathrm{r}=0.30 ; \mathrm{P}=0.14$ ), which might be explained by the fact that parahydroxyantipyrine can also be formed by natural breakdown of antipyrine by hepatic cytochrome P-450 enzymes $(6,11)$. Additionally, the relationship between PAL and the plasma level of TBARS did not reach the level of significance ( $\mathrm{P}=0.31 ; \mathrm{P}=0.13$ ), which could be due to the small number of subjects that participated this study (Fig. 1C). It has to be mentioned, however, that the thiobarbituric acid assay used to measure MDA lacks specificity when applied to human plasma (10). The results suggest that physically active older adults might have an improved intracellular antioxidant defense mechanism.

Recently, Brochu et al. (3) observed that there was a strong positive association between physical fitness $\left(\mathrm{VO}_{2 \max }\right)$ and physical activity associated energy expenditure, as measured by the doubly labeled water method. Here, it was suggested that physically active older subjects had a higher physical fitness level than their physically less active counterparts. In relation to the antioxidant defense system, Jenkins et al. (12) reported in twelve younger adults (17-19 y) that the superoxide dismutase activity in skeletal muscle was significantly related to the physical fitness level $(r=0.70 ; \mathrm{P}<0.05)$. Furthermore, Shern-Brewer et al. (26) showed a decreased in vitro oxidizability of isolated LDL in physically active young adults when compared to sedentary young adults. Although it is difficult to compare the results of these studies with our findings, because they used only moderately to highly trained young adults, it seems that the antioxidant defense capacity is improved in physically active older adults. In addition, several animal studies have observed that training can promote gene expression of muscle antioxidant enzymes, such as superoxide dismutase and glutathione peroxidase $(9,20)$. In man, however, 
we recently observed that a 12-wk exercise training program had no effect on the exercise-induced increase in oxidative stress in older adults (18). In this study, twenty older men and women participated in an exercise training group $(60 \pm 1 \mathrm{y})$ and thirteen men and women in a control group ( $64 \pm 2 \mathrm{y})$, and they performed the same cycling test as used in the present study. Although training significantly improved $\mathrm{VO}_{2 \max }$ and $\mathrm{W}_{\max }$ with approximately $10 \%$, no significant differences were observed after 12-wk training in the exercise-induced increase in TBARS and free radical reaction products of antipyrine (18). Additionally, PAL was not changed after 12-wk training. Because no muscle biopsies were taken in the present study to measure gene expression of antioxidant enzymes, we can only speculate that in older adults, an active lifestyle is a more important factor to improve the antioxidant defense mechanism than following an exercise training program. However, further studies are needed on this topic.

In conclusion, the present study showed that the exercise-induced increase in oxidative stress during a bout of exercise is lower in physically active older human subjects when compared to inactive older human subjects. Thus, regular physical activity improves the antioxidant defense capacity. 


\section{References}

1. Blair SN, HW Kohl III, CE Barlow, RS Paffenberger Jr, LW Gibbons, and CA Macera. Changes in physical fitness and all-cause mortality: a prospective study of healthy and unhealthy men. JAMA 273: 1093-1098, 1995

2. Booth FW, SE Gordon, CJ Carlson, and MT Hamilton. Waging war on modern chronic disease: primary prevention through exercise biology. J. Appl. Physiol. 88: 774-787, 2000

3. Brochu M, RD Starling, PA Ades, and ET Poehlman. Are aerobically fit older individuals more physically active in their free-living time? A doubly labeled water approach. J. Clin. Endocrinol. Metab. 84: 3872-3876, 1999

4. Coolen SAJ, FM Everaerts, and FA Huf. Characterization of ${ }^{60} \mathrm{Co} \gamma$-radiation induced radical products of antipyrine by means of high-performance liquid chromatography, mass spectrometry, capillary zone electrophoresis, micellar electrokinetic capillary chromatography and nuclear magnetic resonance spectrometry. J. Chromatogr. A 788: 95103, 1997

5. Coolen SAJ, M Van Lieshout, JC Reijenga, and FA Huf. Determination of phenolic derivatives of antipyrine in plasma with HPLC-Tandem MS using ESI and Turbo ionspray as interfaces. J. Microcolumn Sep. 11: 701-707, 1999

6. Danhof M, A van Zuilen, JK Boeijings, and DD Breimer. Studies of the different metabolic pathways of antipyrine in man. Oral versus i.v. administration and the influence of urinary collection time. Eur. J. Clin. Pharmacol. 21: 433-441, 1982

7. Erikssen G, K Liestøl, J Bjørnholt, E Thaulow, L Sandvik, and J Erikssen. Changes in physical fitness and changes in mortality. Lancet 352: 759-762, 1998

8. Forni LG, VO Mora-Arellano, JE Packer, and RL Willson. Aminopyrine and antipyrine free radical-cations: pulse radiolysis studies of one-electron transfer reactions. J. Chem. Soc. Perkin Trans. II : 1579-1584, 1988

9. Gore M, R Fiebig, J Hollander, C Leeuwenburgh, H Ohno, and LL Ji. Endurance training alters antioxidant enzyme gene expression in rat skeletal muscle. Can. J. Physiol. Pharmacol. 76: 1139-1145, 1998

10. Hageman JJ, A Bast, and NP Vermeulen. Monitoring of oxidative free radical damage in vivo: analytical aspects. Chem. Biol. Interact. 82: 243-293, 1992

11. Hartleb M. Drugs and the liver. Part II. The role of the antipyrine test in drug metabolism studies. Biopharm. Drug Dispos. 12: 559-570, 1991

12. Jenkins RR, R Friedland, and $H$ Howald. The relationship of oxygen uptake to superoxide dismutase and catalase activity in human skeletal muscle. Int. J. Sports Med. 5: 11-14, 1984

13. Ji LL. Antioxidants and oxidative stress in exercise. Proc. Soc. Exp. Biol. Med. 222: 283292, 1999

14. Ji LL, C Leeuwenburgh, S Leichtweis, M Gore, R Fiebig, J Hollander, and J Bejma. Oxidative stress and aging. Role of exercise and its influences on antioxidant systems. Ann. NY Acad. Sci. 854: 102-117, 1998

15. Kostka T, J Drai, SE Betrhouze, J-R Lacour, and M Bonnefoy. Physical activity, aerobic capacity and selected markers of oxidative stress and the anti-oxidant defense system in healthy active elderly men. Clin. Physiol. 20: 185-190, 2000

16. McCabe DR, TJ Maher, and IA Acworth. Improved method for the estimation of hydroxyl free radical levels in vivo based on liquid chromatography with elecrtochemical detection. $J$. Chromatogr. B 691: 23-32, 1997

17. Mecocci P, G Fano, S Fulle, U MacGarvey, L Shinobu, MC Polidori, A Cherubini, J Vecchiet, U Senin, and MF Beal. Age-dependent increases in oxidative damage to DNA, lipids, and proteins in human skeletal muscle. Free Radic. Biol. Med. 26: 303-308, 1999 
18. Meijer EP, J Senden, SAJ Coolen, and KR Westerterp. Effect of training on exerciseinduced oxidative stress in the elderly as measured by free radical products of antipyrine. $J$. Physiol. 528.P, 2000

19. Meijer EP, KR Westerterp, and FJT Verstappen. Effect of exercise training on total daily physical activity in elderly humans. Eur. J. Appl. Physiol. 80: 16-21, 1999

20. Oh-ishi S, K Toshinai, T Kizaki, S Haga, K Fukuda, N Nagata, and H Ohno. Effects of aging and/or training on antioxidant enzyme system in diaphragm of mice. Respir. Physiol. 105: 195-202, 1996

21. Philippaerts RM, KR Westerterp, and J Lefevre. Doubly labelled water validation of three physical activity questionnaires. Int. J. Sports Med. 20: 284-289, 1999

22. Polidori MC, P Mecocci, A Cherubini, and U Senin. Physical activity and oxidative stress during aging. Int. J. Sports Med. 21: 154-157, 2000

23. Schoeller DA. Recent advances from application of doubly labeled water to measurement of human energy expenditure. J. Nutr. 129: 1765-1768, 1999

24. Schoffelen PF, KR Westerterp, WHM Saris, and F Ten Hoor. A dual-respiration chamber system with automated calibration. J. Appl. Physiol. 83: 2064-72, 1997

25. Sen CK. Oxidants and antioxidants in exercise. J. Appl. Physiol. 79: 675-86, 1995

26. Shern-Brewer R, N Santanam, C Wetzstein, J White-Welkley, and S Parthasarathy. Exercise and cardiovascular disease: a new perspective. Arterioscler. Thromb. Vasc. Biol. 18: 11811187,1998

27. Siri WE. The gross composition of the body. Adv. Biol. Med. Physiol. 4: 239-280, 1956

28. Weir JB. New methods for calculating metabolic rate with special reference to protein metabolism. J. Physiol. 109: 1-9, 1949

29. Westerterp KR, L Wouters, and WD van Marken Lichtenbelt. The Maastricht protocol for the measurement of body composition and energy expenditure with labeled water. Obes. Res. 1: 49-57, 1995. 


\section{Chapter 9}

\section{General discussion}


The research presented in this thesis focussed on the effects of imposed exercise training on physical activity and exercise-induced oxidative stress. Based on the observed compensatory decline in non-training physical activity in the elderly after high-intensity exercise, effects were examined of a 12-wk training program of moderate intensity. Secondly, the determinants of physical inactivity in an elderly population were examined by using tri-axial accelerometers in combination with the doubly labeled water method. Thirdly, since exercise increases the generation of reactive oxygen species (ROS), the subsequent studies were intended to obtain more information on exercise-induced oxidative stress in elderly subjects by using free radical reaction products of antipyrine. Furthermore, the effects of training and antioxidant supplementation on oxidative stress were investigated. Finally, we assessed the relationship between the habitual physical activity level and exerciseinduced oxidative stress.

\section{Energy expenditure and physical activity}

Aging is associated with a decline in physical activity level (PAL). Therefore, exercise programs for the elderly are promoted to improve or maintain physical fitness and health. Goran and Poehlman (10), however, did not observe an enhancement of average daily metabolic rate (ADMR) after an 8-wk training program in elderly subjects as measured with the doubly labeled water method. It was suggested that the intensity of the training program $\left(3 \mathrm{~h} \cdot \mathrm{wk}^{-1}\right.$ at $\left.85 \% \mathrm{VO}_{2 \max }\right)$ was too high, and thus fatigued the subjects during the remainder of the day, which resulted in a decline in non-training physical activity. Therefore, it was examined if a training program of moderate intensity could affect the daily physical activity level. Physical activity was measured with a tri-axial accelerometer, an objective method for movement registration. Subjects trained twice a week, for one hour, on non-consecutive days for 12 -wk. All training sessions were performed at a fitness center and supervised by a fitness instructor. The intensity of the training program was approximately $50 \%$ of heart rate reserve.

The results of Chapter 2 and 3 clearly show that also a training program of moderate intensity did not increase ADMR. On the contrary, after subtracting the physical activity of the session of exercise training, subjects showed a significant decrease in non-training physical activity on training days. Because the exercise training sessions were performed during the late afternoon, the decline in non-training physical activity likely preceded the training sessions. Our results, therefore, suggest that the compensation in physical activity as a consequence of participation in an exercise training program, as suggested by Goran and Poehlman (10), seems to be an anticipatory mechanism, i.e. the elderly participants anticipated the advent of exercise training by lowering their physical activity even before the training sessions. Interestingly, the subjects were not aware of the fact that they compensated for the imposed exercise by a corresponding decrease in non-training physical activity. 
Unfortunately, it is unknown at which time the training sessions were performed in the study of Goran and Poehlman (10). Recently, Hunter et al. (15) reported that a 26-wk resistance training program significantly increased ADMR $\left(963 \mathrm{~kJ} \cdot \mathrm{d}^{-1}\right)$ in elderly subjects $(61-77 \mathrm{y})$. It has to be mentioned, however, that the increase in activity associated energy expenditure (AEE; $\left.503 \mathrm{~kJ} \cdot \mathrm{d}^{-1}\right)$ failed to reach significance $(\mathrm{P}=0.18)$ after adjusting for the estimated energy cost of the resistance training $\left(215 \mathrm{~kJ} \cdot \mathrm{d}^{-1}\right)$. Furthermore, Hunter et al. (15) did not use a non-training control group and it could be questioned whether appropriate statistical analyses were used. Therefore, it can be concluded that exercise training in an elderly population, independent of intensity, frequency or type of training, does not affect the daily physical activity level. Conversely, our results indicate that in elderly humans an exercise intervention reduces non-training physical activity.

The results described in Chapter 4 clearly show that to obtain a higher level of physical activity, elderly should spent relatively less time on low-intensity activities. Spending relatively more time on low-intensity affects the mean PAL negatively, whereas high-intensity activities do not have much impact on PAL. Low-intensity activity, associated with an accelerometer output $\leq 200$ counts $\cdot \mathrm{min}^{-1}$, includes activities such as lying, sitting and standing ( $<3$ METs [work metabolic rate/resting metabolic rate]). Moderate-intensity activity, associated with an accelerometer output between 200-500 counts $\cdot \mathrm{min}^{-1}$, includes activities like walking (3-6 METs), whereas highintensity activity, associated with an accelerometer output $\geq 500$ counts $\mathrm{min}^{-1}$, includes household activities, exercise and sports ( $>6$ METs). Recently, we (36) observed that the decline of $37 \%$ and $35 \%$ in ADMR for women and men, respectively, between the age groups $20-34 \mathrm{y}$ and $75+\mathrm{y}$ was mainly a consequence of a substantial reduction in AEE. In Chapter 4 it is shown that this reduction in AEE could be explained by a shift from spending more time on low-intensity activities instead of moderate- and highintensity activities. Elderly spent approximately $17 \%$ more of their time on lowintensity activities than younger adults. Therefore, elderly wanting to increase their activity level should be recommended to exchange low-intensity activities for moderate-intensity activities. Additionally, it has been shown that regular moderateintensity physical activity provides substantial health benefits (24). Thus, reduction of physical inactivity does not necessarily imply high-intensity sports (exercise training).

Intuitively, one might hypothesize that elderly individuals with a high physical fitness $\left(\mathrm{VO}_{2 \max }\right)$ might be more physically active compared to elderly humans with a lower physical fitness. Recently, Brochu et al. (2) reported a positive association between $\mathrm{VO}_{2 \max }$ and AEE. Additionally, we observed a strong positive relationship between $\mathrm{VO}_{2 \max }$, adjusted for differences in fat-free mass $\left(\mathrm{rVO}_{2 \max }-\mathrm{FFM}\right)$ and the physical activity level, as assessed directly by using tri-axial accelerometers, in elderly females $(r=0.31 ; P=0.014)$ and males $(r=0.41 ; P<0.001$; Fig. 1$)$. Because of the strong association between AEE and $\mathrm{VO}_{2 \max }$, it remains speculative why exercise training does not result in an increased level of free-living physical activity. The imposed 12wk training intervention resulted in a significant increase in $\mathrm{VO}_{2 \max }$ of about $8 \%$ (Chapter 3 and 6). It could be argued that although a strong positive correlation exists 
between these two phenotypes, this relationship is not straightforward. To address this point, Dvorak et al. (6) reported that in an elderly population $(n=117)$, high levels of $\mathrm{VO}_{2 \max }$, independent of physical activity levels, were associated with a more favorable cardiovascular disease risk profile. Additionally, Erikssen et al. (7) showed that even small improvements in $\mathrm{VO}_{2 \max }$ were associated with a lowered risk of death. Whereas, Pate et al. (24) showed that higher levels of PAL were associated with a lower cardiovascular disease profile and overall mortality. These studies support the idea that $\mathrm{VO}_{2 \max }$ and the daily level of physical activity may act in a unique and independent manner to improve cardiovascular and metabolic health in the elderly. Cause and effect, however, remain unclear, $\mathrm{VO}_{2 \max }$ can be modulated by physical activity and $\mathrm{VO}_{2 \max }$ might modulate physical activity.

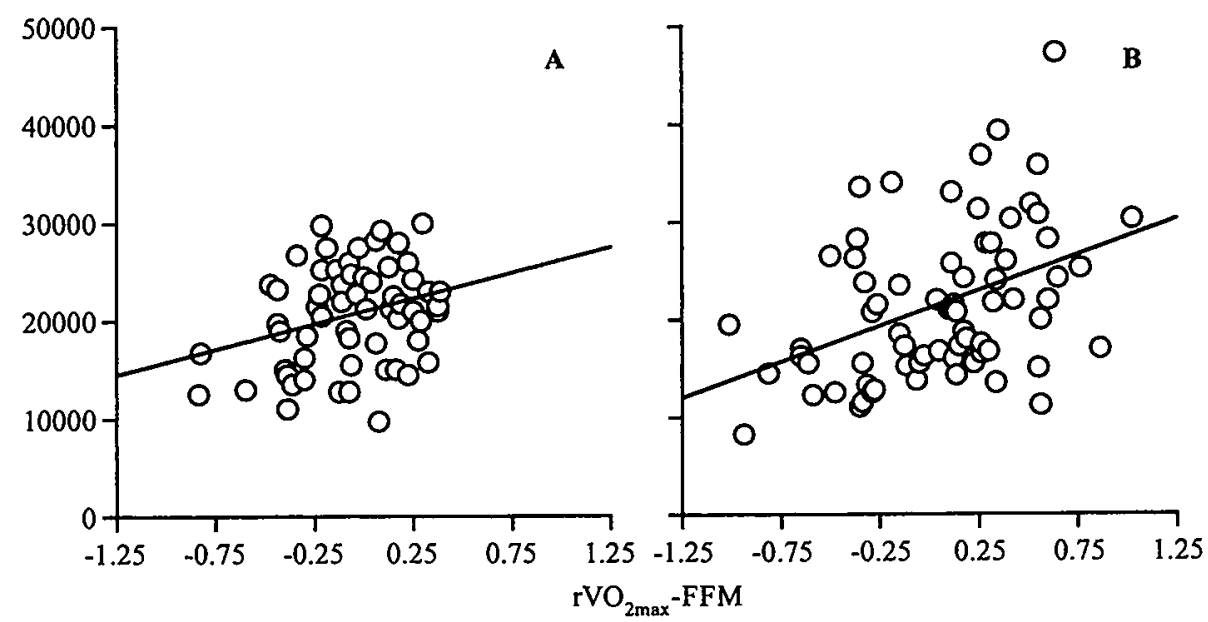

Figure 1. Average accelerometer output for 14-d (counts.day ${ }^{-1}$ ) as a function of $\mathrm{VO}_{2 \max }$, adjusted for fat-free mass $\left(\mathrm{rVO}_{2 \mathrm{max}}-\mathrm{FFM}\right.$, in $\left.1 \cdot \mathrm{min}^{-1}\right)$. A, in elderly females $(\mathrm{n}=62)$. Regression line: accelerometer output $=21107+5532 \times \mathrm{rVO}_{2 \max }-\mathrm{FFM}(\mathrm{r}=0.31 ; \mathrm{P}=0.014)$. $\mathrm{B}$, in elderly males $(\mathrm{n}=71)$. Regression line: accelerometer output $=21116+7263 \times \mathrm{rVO}_{2 \max }-\mathrm{FFM}(\mathrm{r}=0.41 ; \mathrm{P}=0.0004)$.

Aging is associated with an increase in body fat (1). An exercise intervention to increase fat oxidation may be beneficial in reducing obesity in the elderly. In Chapter 3 , it was investigated if a 12-wk training program of moderate intensity could affect substrate utilization in the elderly. To minimize for the residual effects of training on energy expenditure and substrate utilization, subjects were measured $36 \mathrm{~h}$ after the last training session. During sleep or rest, the respiratory exchange ratio (RER) showed a significant decrease after the training period. Assuming an unchanged contribution of protein oxidation, the decline in RER indicates approximately a $7 \%$ increase in the magnitude of the fat oxidation, which is in accordance to findings of previous studies in elderly subjects $(25,33)$. The training-induced increase in resting fat oxidation has been attributed to an increased activity of the sympathetic nervous system $(25,33)$. 
However, not all studies have been so consistent. Sial et al. (31) observed in elderly subjects after 16-wk of endurance training that only fat oxidation was increased during exercise of moderate intensity $\left(50 \% \mathrm{VO}_{2 \max }\right)$ and not during resting conditions.

Additionally, in Chapter 3 it was demonstrated that the change in RER was inversely correlated with the pre-training RER, which is in accordance with findings of a previous training intervention study in younger adults (34). In both studies, training increased relative fat utilization in subjects with a high pre-training RER, whereas subjects with a low pre-training RER decreased their relative fat utilization. It remains, however, unclear what biological mechanism might explain this finding. Although changes in food intake cannot be excluded, a change in eating habit seems not likely since RER may change in both directions. Furthermore, the high correlation between pre-training RER and the change in RER ( $p<0.01)$ makes it less plausible that the change in RER was a consequence of regression to the mean.

\section{Assessment of oxidative stress}

Studies performed in humans have shown that exercise results in an increased oxidative stress. It has to be mentioned, however, that these studies have relied on the use of endogenous markers for assessing oxidative stress. Because, endogenous markers have several methodological disadvantages (12), we attempted to measure exercise-induced oxidative stress in vivo by using a newly developed technique of aromatic hydroxylation. The principle of aromatic hydroxylation is that an aromatic compound undergoes addition reactions with hydroxyl radicals, producing characteristics of hydroxylation (14). Due to its high reactivity, the hydroxyl radical has a very short half-life and is therefore transiently present at extremely low concentrations. Therefore, to assess oxidative stress in vivo, it is at least necessary that 1) the aromatic probe has a sufficient high concentration (in relation to its rate constant for hydroxyl radicals) to be able to compete with other scavenger molecules; 2) the hydroxylated product(s) cannot be further metabolized; 3) the product(s) hydroxylated by hydroxyl radicals is (are) different from possible enzyme-produced hydroxylated metabolites (9). An appropriate candidate for use in man is antipyrine (2,3-dimethyl-1phenyl-3-pyrazolin-5-one). Exposure of an antipyrine solution in water to ${ }^{60} \mathrm{Co} \gamma$ radiation leads to the formation of three phenolic antipyrine derivatives: parahydroxyantipyrine ( $\mathrm{p}-\mathrm{APOH}$ ), ortho-hydroxyantipyrine (o-APOH) and metahydroxyantipyrine (m-APOH). The last two metabolites are not endogenously formed (5). Recently, it was reported that 5-min walking exercise in patients with claudicatio intermittens resulted in a significant increase in the plasma concentration of $\mathrm{p}-\mathrm{APOH}$ and o-APOH (4). Thus, the ratio of the hydroxylated products of antipyrine to the plasma concentration of antipyrine reflects the oxidative stress in vivo.

However, it could be argued that the ingested antipyrine affects the intracellular antioxidant balance. In spite of that, subjects orally ingested only $10 \mathrm{mg}$ antipyrine per $\mathrm{kg}$ body mass. Assuming that a subject has a body mass of $70 \mathrm{~kg}$ and a body fat percentage of $25 \%$ then the amount of FFM is $52.5 \mathrm{~kg}$. Antipyrine is uniformly 
distributed on the total body water (approximately $70 \%$ of FFM). Thus, $700 \mathrm{mg}$ antipyrine is distributed over 36.81 total body water, resulting in a concentration (molecular weight: 188.2) of $100 \mathrm{mmol} \cdot \mathrm{I}^{-1}$. One might expect that this concentration is too low to affect the intracellular antioxidant balance. Additionally, one might argue that the available concentration of antipyrine could be the limiting factor in the formation of the free radical reaction productions during exercise. In Chapter 5, however, it was observed that the concentration of antipyrine was not different between pre- and post-exercise conditions $(158.5 \pm 9.8 \mu \mathrm{M}$ and $155.6 \pm 9.4 \mu \mathrm{M}$, respectively). Therefore, the exercise-induced increase in both ratios was due to an increased concentration of $\mathrm{p}-\mathrm{APOH}$ and $\mathrm{o}-\mathrm{APOH}$ and not to changes in antipyrine concentration. Moreover, the results clearly show that submaximal endurance exercise in elderly subjects significantly increased oxidative stress, which is in accordance with previous studies in elderly humans that have relied on endogenous markers for measuring oxidative stress $(17,19)$.

\section{Exercise training and oxidative stress}

In view of the age related increase in the susceptibility to oxidative stress and because of the significant increase in oxidative stress during exercise one might question if untrained elderly would benefit from following an exercise training program. The results of Chapter 6 clearly show that 12-wk training had no effect on exercise-induced oxidative stress in elderly humans as measured by free radical reaction products of antipyrine. Despite the fact that training in elderly humans improves functional capacity, it appears not to compromise antioxidant defense mechanisms. It could be argued that the intensity of the training program $(\sim 50 \%$ heart rate reserve) was too low to pose a challenge for adaptive responses to the antioxidant defense system. In addition, it may be possible that greater elevations of $\mathrm{VO}_{2 \max }(\sim 9 \%$ increase in this study) or a longer training period may be necessary before any significant changes in oxidative stress during exercise would occur.

Interestingly, the habitual activity level as assessed with the doubly labeled water method was inversely correlated with the exercise-induced increase in oxidative stress (Chapter 8). Additionally, it has been reported in twelve younger adults (17-19 y) that the superoxide dismutase activity in skeletal muscle was significantly related to the physical fitness level $(r=0.70 ; P<0.05)(16)$. Furthermore, Shern-Brewer et al. (30) showed a decreased in vitro oxidizability of isolated LDL in physically active young adults when compared to sedentary young adults. Although it is difficult to compare the results of these studies with our findings, because they used only moderately to highly trained young adults, it seems that the antioxidant defense capacity is improved in physically active older adults. It could be argued whether genetic or environmental factors mediate the antioxidant defense capacity. However, no muscle biopsies were taken in our study to measure gene expression of antioxidant enzymes, thus it can only be speculated that in elderly humans, a physically active lifestyle is a more important 
factor to improve the antioxidant defense capacity than an exercise training program. Therefore, further studies are needed on this topic.

\section{Antioxidant supplementation and oxidative stress}

In elderly subjects, submaximal exercise resulted in a significantly increased oxidative stress (Chapter 5) and training did not affect this increase in oxidative stress (Chapter 6). Because aging is associated with an increased susceptibility to free radical damage, it was hypothesized that supplementation with antioxidants could possibly reduce the exercise-induced oxidative stress in elderly subjects. The results of Chapter 7 , however, show that 12-wk of antioxidant vitamin supplementation (100 $\mathrm{mg} \mathrm{dl- \alpha -}$ tocopheryl-acetate, $200 \mathrm{mg}$ ascorbic acid and $2 \mathrm{mg} \beta$-carotene) had no effect on the exercise-induced oxidative stress in elderly subjects. Although subjects were supplemented for 12-wk with relatively low doses of $\mathrm{dl}$ - $\alpha$-tocopheryl acetate, ascorbic acid, and $\beta$-carotene, supplementation significantly increased the plasma levels of $\alpha$ tocopherol $\left(\Delta 14.4 \pm 3.2 \mu \mathrm{mol} \cdot \mathrm{l}^{-1}, \mathrm{P}<0.001\right)$ and $\beta$-carotene $\left(\Delta 0.4 \pm 0.1 \mu \mathrm{mol} \cdot \mathrm{l}^{-1}\right.$, $\mathrm{P}<0.01$ ). Therefore, the doses of antioxidant supplementation used should have been sufficient to increase the antioxidant status and capacity of exercising elderly. It could be argued, however, that humans only benefit from antioxidant supplements if they are deficient or exposed to exceptionally heavy workloads like maximal exercise tests or eccentric exercise protocols. The subjects, however, were not deficient concerning antioxidant intake. Measured vitamin $C$ intake was higher than the Dutch recommended dietary allowance of $70 \mathrm{mg} \cdot \mathrm{d}^{-1}$. In addition, plasma concentrations of $\alpha$ tocopherol and $\beta$-carotene were similar to findings of previous studies in elderly populations $(20,23)$. It has been hypothesized that antioxidant supplementation is warranted in elderly subjects having a high daily physical activity level $(3,26)$. Although the subjects in this study were characterized as sedentary active, further research on this topic is needed.

It has to be mentioned that during the last decades the emphasis in free radical research has relied on the negative side effects of free radical damage. However, ROS might play an important role in the cellular stress signaling pathway cell, to protect against severe stress and to adapt or resist the stress (8). There is increasing evidence that ROS are used as signal, messenger and trigger molecules. For example, nuclear factor (NF)- $\mathrm{KB}$ signaling system, AP-1 and thioredoxin effect gene expression (21, 29). This might explain why the evidence that dietary antioxidants can cure lifethreatening diseases in humans is still lacking. If ROS are involved in the oxidationreduction (redox) regulation of cell functions, then it is perhaps easier to understand why attempts to advantageously change antioxidant balance in disease and aging experiments have largely failed. Cells normally function in a reducing environment but, as this is changed to a more oxidizing (or less reducing) state, cell functions and gene expressions also change (11). Antioxidants can inhibit the oxidant triggered signaling mechanisms that the cell uses to adapt to a free radical insult. Additionally, most free-radical scavengers act in oxidant-reduction reactions that are reversible, and 
some, such as ascorbate, can act both as antioxidants and pro-oxidants, depending on the conditions (8). Thus, administration of a powerful antioxidant (i.e. powerful reducing agent) after oxidative damage has started could promote damage (13). Moreover, one should realize that the best mechanism for boosting the antioxidant defense system seems to be the oxidative stress itself. In humans, physical activity is believed to have many anti-aging benefits. It is therefore likely that some of its benefits are derived through the imposed oxidative stress on the antioxidant defense system. The fact that the exercise-induced oxidative stress in an elderly population is inversely related to the habitual activity level as shown in Chapter 8, supports this hypothesis.

\section{Directions for future research}

One of the conclusions of this thesis is that in an elderly population the habitual activity level is determined by the fraction of time spent on activities of low intensity such as sitting and standing. High-intensity activities (exercise and sports) do not have much impact on the activity level. It could be discussed whether the same phenomenon exists in younger age groups. Additionally, it could be questioned what the most appropriate approach would be to omit physical inactivity in the general population. Recently, it was postulated that non-exercise activity thermogenesis (NEAT) mediates resistance to weight gain with overfeeding (18). Non-exercise activities were defined as the activities of daily living other than exercise (sports and fitness-related activities) and include sitting, standing, walking and fidgeting. However, more research is needed to measure the effect of non-exercise activities on weight gain and physical inactivity related diseases such as type 2 diabetes and coronary heart disease. Tri-axial accelerometers would be an appropriate tool for measuring these non-exercise activities.

Furthermore, more research is needed to examine if in an elderly population regular physical activity is a more important determinant to improve the antioxidant defense system than exercise training. It would be interesting to know if the habitual activity level is related to the gene expression of antioxidant enzymes such as superoxide dismutases and glutathione peroxidases. Additionally, more research is needed to examine whether the mitochondrial oxidant production is affected by advancing age and if physical activity and exercise can alter it. In that respect it would be interesting to measure the content of uncoupling proteins (UCPs) in skeletal muscle, because it is known that UCPs play an important role in energy metabolism (28). One assumed mechanism to reduce mitochondrial oxidant production is to increase the rate of metabolic uncoupling (32). When $\mathrm{O}_{2}$ consumption is uncoupled from ATP generation, heat is produced. UCPs mediate this thermogenesis. UCPs increase the rate of electron transfer and inhibit superoxide formation by mitochondria (27). Partial uncoupling stimulates $\mathrm{O}_{2}$ consumption, shortens the lifetime of $\mathrm{CoQ}^{-\bullet}$ (which is an excellent one-electron $\mathrm{O}_{2}$ reductant and initiator of ROS formation), and inhibits ROS production (32). Consistent with the hypothesis that metabolic 
uncoupling might regulate ROS release is the recent evidence indicating that an increase in uncoupling reduces mitochondrial ROS production (22), whereas levels of mitochondrial oxidants rise in mice with a targeted deletion of UCP-3 (35). So far, no studies have yet been performed in humans that examined the relationship between oxidative stress and UCP content in skeletal muscle.

\section{Main conclusions}

In summary, the major findings from the research presented in this thesis are:

- In an elderly population, a 12-wk training program of moderate intensity results in a decline of non-training physical activity (Chapter 2).

- $\quad$ Training increased relative fat utilization in low fat oxidizers and vice versa, for elderly displaying a high pre-training fat oxidation (Chapter 3 ).

- In the elderly, spending relatively more time on low-intensity activities negatively affects the mean physical activity level. Despite this, it is not necessary for the elderly to participate in high-intensity, sporting activities in order to increase their physical activity level (Chapter 4).

- In the elderly, oxidative stress occurs during cycling at submaximal intensity as measured with free radical products of antipyrine (Chapter 5).

- $\quad$ 12-wk training had no effect on exercise-induced oxidative stress in elderly humans. Despite the fact that training in the elderly improves functional capacity, it appears not to compromise antioxidant defense mechanisms (Chapter 6).

- In elderly subjects antioxidant supplementation had no effect on the exerciseinduced increase in oxidative stress (Chapter 7).

- Physically active elderly subjects have a reduced exercise-induced oxidative stress compared to elderly with a lower level of physical activity. Thus, regular physical activity improves the antioxidant defense capacity (Chapter 8). 


\section{References}

1. Bemben MG, BH Massey, DA Bemben, RA Boileau, and JE Misner. Age-related patterns in body composition for men aged 20-79 yr. Med. Sci. Sports Exerc. 27: 264-9, 1995

2. Brochu M, RD Starling, PA Ades, and ET Poehlman. Are aerobically fit older individuals more physically active in their free-living time? A doubly labeled water approach. J. Clin. Endocrinol. Metab. 84: 3872-3876, 1999

3. Clarkson PM, and HS Thompson. Antioxidants: what role do they play in physical activity and health? Am. J. Clin. Nutr. 72: 637S-646S, 2000

4. Coolen SAJ. Antipyrine hydroxylates as indicators for oxidative damage. Ph.D. thesis. Eindhoven: Eindhoven University of Technology, 2000

5. Coolen SAJ, FM Everaerts, and FA Huf. Characterization of ${ }^{60} \mathrm{Co} \gamma$-radiation induced radical products of antipyrine by means of high-performance liquid chromatography, mass spectrometry, capillary zone electrophoresis, micellar electrokinetic capillary chromatography and nuclear magnetic resonance spectrometry. J. Chromatogr. A 788: 95-103, 1997

6. Dvorak RV, A Tchernof, RD Starling, PA Ades, L DiPietro, and ET Poehlman. Respiratory fitness, free living physical activity, and cardiovascular disease risk in older individuals: a doubly labeled water study. J. Clin. Endocrinol. Metab. 85: 957-963, 2000

7. Erikssen G, K Liestøl, J Bjørnholt, E Thaulow, L Sandvik, and J Erikssen. Changes in physical fitness and changes in mortality. Lancet 352: 759-762, 1998

8. Finkel T, and NJ Holbrook. Oxidants, oxidative stress and the biology of ageing. Nature 408: 239-247, 2000

9. Ghiselli A, O Laurenti, G De Mattia, G Maiani, A Ferro-Luzzi. Salicylate hydroxylation as an early marker of in vivo oxidative stress in diabetic patients. Free Radic. Biol. Med. 13: 621-626, 1992

10. Goran MI, and ET Poehlman. Endurance training does not enhance total energy expenditure in healthy elderly persons. Am. J. Physiol. 263: E950-7, 1992

11. Gutteridge JMC. Does redox regulation of cell function explain why antioxidants perform so poorly as therapeutic agents? Redox Rep. 4: 129-131, 1999

12. Hageman JJ, A Bast, and NP Vermeulen. Monitoring of oxidative free radical damage in vivo: analytical aspects. Chem. Biol. Interact. 82: 243-93, 1992

13. Halliwell B. The antioxidant paradox. Lancet 355: 1179-1180, 2000

14. Halliwell B, and JMC Gutteridge. Free radicals in biology and medicine. Oxford: Claredon Press, 1989

15. Hunter GR, CJ Wetzstein, DA Fields, A Brown, and MM Bamman. Resistance training increases total energy expenditure and free-living physical activity in older adults. J. Appl. Physiol. 89: 977-984, 2000

16. Jenkins RR, R Friedland, and $H$ Howald. The relationship of oxygen uptake to superoxide dismutase and catalase activity in human skeletal muscle. Int. J. Sports Med. 5: 11-4, 1984

17. Leaf DA, MT Kleinman, M Hamilton, and RW Deitrick. The exercise-induced oxidative stress paradox: the effects of physical exercise training. Am. J. Med. Sci 317: 295-300, 1999

18. Levine JA, NL Eberhardt, and MD Jensen. Role of non-exercise activity thermogenesis in resistance to fat gain in humans. Science 283: 212-214, 1999

19. Meydani M, WJ Evans, G Handelman, L Biddle, RA Fielding, SN Meydani, J Burrill, MA Fiatarone, JB Blumberg, and JG Cannon. Protective effect of vitamin E on exercise-induced oxidative damage in young and older adults. Am. J. Physiol. 264: R992-8, 1993

20. Meydani SN, M Meydani, LC Rall, F Morrow, and JB Blumberg. Assessment of the safety of high-dose, short-term supplementation with vitamin $\mathrm{E}$ in healthy older adults. Am. J. Clin. Nutr. 60: 704-9, 1994 
21. Meyer M, R Schreck, and PA Baeuerle. $\mathrm{H}_{2} \mathrm{O}_{2}$ and antioxidants have opposite effects on activation of NF-kB and AP-1 in intact cells: AP-1 as secondary antioxidant-responsive factor. EMBO J. 12: 2005-2015, 1993

22. Nishikawa T, D Edelstein, XL du, S-I Yamagishi, T Matsumura, Y Kaneda, MA Yorek, D Beebe, PJ Oates, H-P Hammes, I Giardino, and M Brownlee. Normalizing mitochondrial superoxide production blocks three pathways of hyperglycaemic damage. Nature 404: 787-790, 2000

23. Pallast EG, EG Schouten, FG De Waart, HF Fonk, G Doekes, BM Von Blomberg, and FJ Kok. Effect of $50-$ and $100-\mathrm{mg}$ vitamin $\mathrm{E}$ supplements on cellular immune function in noninstitutionalized elderly persons. Am. J. Clin. Nutr. 69: 1273-1281, 1999

24. Pate RR, M Pratt, SN Blair, WL Haskell, CA Macera, C Bouchard, D Buchner, W Ettinger, GW Heath, AC King, A Kriska, AS Leon, BH Marcus, J Morris, RS Paffenberger, K Patrick, ML Pollock, JM Rippe, J Sallis, and JH Wilmore. Physical activity and public health: a recommendation from the CDC and ACSM. JAMA 273: 402-407, 1995

25. Poehlman ET, AW Gardner, PJ Arciero, MI Goran, and J. Calles-Escand n. Effects of endurance training on total fat oxidation in elderly persons. J. Appl. Physiol. 76: 2281-7, 1994

26. Polidori MC, P Mecocci, A Cherubini, and U Senin. Physical activity and oxidative stress during aging. Int. J. Sports Med. 21: 154-157, 2000

27. Ricquier D, and F Bouillaud. The uncoupling protein homologues: UCPI, UCP3, stUCP and atUCP. Biochem. J. 345: 161-179, 2000

28. Schrauwen P, G Schaart, WHM Saris, LJ Slieker, JFC Glatz, H Vidal, and EE Blaak. The effect of weight reduction on skeletal muscle UCP2 and UCP3 mRNA expression and UCP3 protein content in type II diabetic subjects. Diabetologia 43: 1408-1416, 2000

29. Sen CK, and L Packer. Antioxidant and redox regulation of gene transcription. FASEB J. 10 : 709-720, 1996

30. Shern-Brewer R, N Santanam, C Wetzstein, J White-Welkley, and S Parthasarathy. Exercise and cardiovascular disease: a new perspective. Arterioscler. Thromb. Vasc. Biol. 18: 1181-1187, 1998

31. Sial S, AR Coggan, RC Hickner, and S Klein. Training-induced alterations in fat and carbohydrate metabolism during exercise in elderly subjects. Am. J. Physiol. 274: E785-90, 1998

32. Skulachev VP. Why are mitochondria involved in apoptosis? FEBS Lett. 397: 7-10, 1996

33. Treuth MS, GR Hunter, RL Weinsier, and S. H. Kell. Energy expenditure and substrate utilization in older women after strength training: 24-h calorimeter results. J. Appl. Physiol. 78: 2140-6, 1995

34. Van Etten LMLA, KR Westerterp, and FTJ Verstappen. Effect of weight-training on energy expenditure and substrate utilization during sleep. Med. Sci. Sports Exerc. 27: 188-93, 1995

35. Vidal-Puig AJ, D Grujic, C-Y Zhang, T Hagen, O Boss, Y Ido, A Szczepanik, J Wade, V Mootha, R Cortright, DM Muoio, and BB Lowell. Energy metabolism in uncoupling protein 3 gene knockout mice. J. Biol. Chem. 275: 16258-16266, 2000

36. Westerterp KR, and EP Meijer. Changes in physical activity patterns with age: a physiological perspective. J. Gerontol. in press. 


\section{Summary}


Aging is associated with a decline in the daily physical activity level (PAL). Regular physical activity is thought to be an important determinant of health and an active lifestyle might delay the age-associated decline in body function and thus enhance the quality of life of older adults. On the other hand, a high physical activity level might be associated with an increased production of reactive oxygen species (ROS). Increased intracellular ROS production is referred to as oxidative stress. The relationship between oxidative stress and physical activity is, however, poorly understood, particularly in advanced age, which could be attributed to methodological aspects concerning the assessment of oxidative stress and the assessment of the PAL. Therefore, the research presented in this thesis focussed on the effects of exercise training on physical activity and exercise-induced oxidative stress.

The effects of exercise training were examined in healthy elderly subjects (62 women, 71 men; mean age: $60 \pm 1$ y [range: 55-75 y]). Subjects trained twice a week, for one hour on non-consecutive days, for 12 weeks. All training sessions were performed at a fitness center and were supervised by a fitness instructor. The intensity of the training program was around $50 \%$ of heart rate reserve. Before, during and after training, variables comprising body composition, sleeping metabolic rate, basal metabolic rate, fat oxidation (respiratory exchange ratio; RER), daily physical activity, physical fitness (maximal oxygen uptake) and exercise-induced oxidative stress were measured. Physical activity was registered by using a tri-axial accelerometer, an objective tool for movement registration, combined with the doubly labeled water method, over a 14-d interval. Oxidative stress was assessed by a newly developed technique of aromatic hydroxylation, namely antipyrine oxidation, during 45-min cycling at submaximal intensity. Additionally, antioxidant intake and the plasma antioxidant status were determined during an antioxidant intervention study. During this intervention, subjects were either supplemented for 12-wk with one capsule a day containing placebo or with one capsule containing 100-mg dl- $\alpha$-tocopheryl-acetate, 200-mg ascorbic acid and 2mg $\beta$-carotene.

The training program of moderate intensity did not increase the daily physical activity level. On the contrary, subjects showed a significant decrease in non-training physical activity on training days. Interestingly, spending relatively more time on low-intensity activity affected the mean PAL negatively, whereas high-intensity activities, which include exercise and sports activities, did not have much impact on PAL. Furthermore, elderly subjects spent approximately $17 \%$ more of their time on low-intensity activities when compared with younger adults from data previously obtained.

Although the training program decreased non-training physical activity, a significant increase in maximal oxygen uptake of approximately $8 \%$ was observed. In addition, 12 weeks of training significantly reduced heart rate during exercise at submaximal intensity. Furthermore, training increased the relative fat utilization in low 
fat oxidizers and vice versa, for elderly subjects displaying a high pre-training fat oxidation. However, no changes in body mass or body composition were observed.

In elderly subjects, submaximal endurance exercise significantly increased the concentration of free radical mediated metabolites of antipyrine: para- and orthohydroxyantipyrine. Ortho-hydroxyantipyrine is not formed in man through the monooxygenase pathway of cytochrome P450. As the concentration of antipyrine was not different between the pre- and post-exercise condition, it can be concluded that exercise induces oxidative stress in elderly humans. Additionally, 12 weeks of training had no effect on exercise-induced oxidative stress. Furthermore, 12 weeks of supplementation with antioxidant vitamins significantly increased the plasma antioxidant defence capacity, but had no effect on the exercise-induced increase in oxidative stress. Interestingly, the habitual activity level was inversely correlated with the observed exercise-induced increase in oxidative stress.

The results indicate that a training program of moderate intensity improves physical fitness in healthy elderly humans. However, an exercise intervention also reduces nontraining physical activity. Because the exercise training sessions were performed during the late afternoon, the decline in non-training physical activity probably preceded the training sessions. Surprisingly, the subjects were not aware of the fact that they compensated for the imposed exercise by a corresponding decrease in nontraining physical activity. Additionally, it was shown that to obtain a higher level of physical activity, elderly should spend relatively less time on low-intensity activities such as lying, sitting and standing. Therefore, elderly people wanting to increase their activity level should be recommended to exchange low-intensity activities for moderate-intensity activities like walking. Consequently, it can be concluded that reduction of physical inactivity does not necessitate participation in high-intensity activities like sports (exercise training).

To address the importance of a high PAL, it was shown that the habitual activity level was inversely correlated with the observed exercise-induced increase in oxidative stress. It seems that the antioxidant defence capacity is improved in physically active elderly humans. Genetic or environmental factors have the potential to mediate the antioxidant defence capacity. However, no muscle biopsies were taken in this study to measure gene expression of antioxidant enzymes. Thus, it can only be speculated that in elderly humans, a physically active lifestyle is a more important factor to improve the antioxidant defence capacity than an exercise training program. Despite the fact that training in elderly humans improves functional capacity, it does not appear to compromise antioxidant defence mechanisms.

Twelve weeks of antioxidant supplementation had no effect on the exerciseinduced oxidative stress. An explanation might be that humans only benefit from antioxidant supplements if their antioxidant status is (too) low. Subjects in this study were not deficient concerning antioxidant intake. It has been hypothesized that antioxidant supplementation is warranted in elderly subjects having a high daily 
physical activity level. Although the participants were characterized as moderately active, further research on this topic is needed.

In conclusion, the studies described in this thesis demonstrate that 1) a training program of moderate intensity can result in a decline of non-training physical activity; 2) training increases relative fat utilization in low fat oxidizers and vice versa, for elderly displaying a high pre-training fat oxidation; 3) spending relatively more time on low-intensity activities negatively affects the mean physical activity level. Despite this, it is not necessary for elderly to participate in high-intensity, sporting activities in order to increase their physical activity level; 4) oxidative stress occurs during cycling at submaximal intensity as measured by free radical mediated products of antipyrine; 5 ) a training or antioxidant supplementation intervention has no effect on exerciseinduced oxidative stress; 6 ) physically active elderly subjects have a reduced exerciseinduced oxidative stress compared with elderly with a lower level of physical activity. Thus, regular physical activity improves the antioxidant defence capacity. 
Samenvatting 
Veroudering gaat samen met een afname van de dagelijkse lichamelijke activiteit. Regelmatige lichaamsbeweging is een belangrijke factor voor de fysieke gezondheid. Een actieve levensstijl vertraagt wellicht de met veroudering geassocieerde afname in lichamelijk functioneren, resulterend in een verhoogde kwaliteit van leven. Echter, een hoge lichamelijke activiteit gaat samen met een verhoging van de zuurstofopname en kan zo resulteren in een verhoogde productie van reactieve zuurstofradicalen. Een situatie waarbij de intracellulaire reactieve zuurstofradicaalproductie stijgt, wordt oxidatieve stress genoemd. Over de relatie tussen oxidatieve stress en lichamelijke activiteit is nog weinig bekend. Dit hangt samen met methodologische barrieres betreffende het meten van lichamelijke activiteit en het meten van oxidatieve stress in vivo. Dit proefschrift beschrijft de effecten van training op dagelijkse lichamelijke activiteit en inspannings-geïnduceerde oxidatieve stress, waarbij gebruik is gemaakt van nieuwe methodes.

De effecten van training werden onderzocht bij gezonde ouderen (62 vrouwen, 71 mannen; gemiddelde leeftijd: $60 \pm 1 \mathrm{jr}$ [variërend van 55 tot $75 \mathrm{jr}$ ]). De proefpersonen trainden 12 weken twee maal per week, gedurende é́n uur op niet opeenvolgende dagen. De trainingen werden uitgevoerd bij een fitnesscentrum onder leiding van een fitnessinstructeur. Het trainingsprogramma had een middelmatige intensiteit ( $50 \%$ van de hartslagreservecapaciteit). Vo6r, tijdens en na het trainingsprogramma werden de volgende variabelen gemeten: lichaamssamenstelling, energiegebruik in rust en tijdens de slaap (de zgn. ruststofwisseling), vetverbranding (respiratoir quotiënt), dagelijkse lichamelijke activiteit, lichamelijke fitheid (maximale zuurstofopname capaciteit), en inspannings-geïnduceerde oxidatieve stress. Lichamelijke activiteit werd gemeten over een 14 daagse periode met een drie-dimensionale versnellingsopnemer, een objectieve methode voor meting van het activiteitenpatroon, gecombineerd met tweevoudig gemerkt water. Oxidatieve stress werd gemeten tijdens een 45 minuten durende fietstest op submaximale intensiteit met een recent ontwikkelde techniek van aromatische hydroxylering, namelijk antipyrine oxidatie. Tevens werd de antioxidant-inname en antioxidantstatus van het bloedplasma bepaald tijdens een antioxidantsuppletie interventie. De proefpersonen kregen hiervoor gedurende 12 weken één capsule per dag met placebo of één capsule per dag met 100 $\mathrm{mg} \mathrm{dl}$ - $\alpha$-tocoferyl-acetaat, $200 \mathrm{mg}$ ascorbinezuur en $2 \mathrm{mg} \beta$-caroteen.

Het trainingsprogramma resulteerde niet in een stijging van de lichamelijke activiteit. Integendeel, proefpersonen compenseerden de trainingsactiviteit met een significante daling van de niet-training geassocieerde lichamelijke activiteit. Het activiteitsniveau van ouderen werd met name bepaald door de tijd besteed aan activiteiten in de laagste van drie intensiteitscategoriën. Activiteiten met de hoogste intensiteit, zoals sportactiviteiten, hadden weinig invloed op het activiteitsniveau. Tevens bleek dat ouderen ongeveer $17 \%$ meer van hun tijd besteedden aan activiteiten met de laagste intensiteit, zoals liggen, zitten, en staan, in vergelijking met jong volwassenen. Activiteiten met 
een middelmatige intensiteit waren gedefinieerd als activiteiten zoals wandelen en fietsen.

Het trainingsprogramma resulteerde in een verhoging van de maximale zuurstofopname capaciteit van ongeveer $8 \%$. De hartslag tijdens inspanning met een submaximale intensiteit daalde. Bovendien verhoogde het volgen van de training de relatieve vetverbrandingen bij personen met een lage initiële vetverbranding en vice versa bij personen met een hoge initiële vetverbranding. Er werden geen veranderingen in lichaamsgewicht en lichaamssamenstelling geconstateerd als gevolg van training.

De 45 minuten durende inspanningstest leidde tot een significante verhoging van de plasma concentratie van de vrije radicaal gemedieërde producten van antipyrine, ortho- en para-hydroxyantipyrine. Ortho-hydroxyantipyrine wordt niet gevormd via het endogene metabole pad van cytochroom P450. Doordat de plasma concentratie van antipyrine voor en na inspanning niet verschillend was, kan men concluderen dat bij ouderen lichamelijke inspanning oxidatieve stress induceert. Het volgen van een trainingsprogramma had geen effect op de inspannings-geïnduceerde oxidatieve stress. Bovendien verhoogde antioxidantsuppletie weliswaar de plasma antioxidatieve capaciteit, maar dat resulteerde niet na 12 weken in een verlaging van de inspannings-geïnduceerde oxidatieve stress.

Het volgen van een trainingsprogramma verhoogde de lichamelijke fitheid. Echter, zonder een verhoging van het totale activiteitsniveau. Er trad een daling op van de activiteit naast de trainingssessies. Deze daling ging, in een situatie waarbij de training 's avonds plaatsvond, al vooraf aan de training. Verrassend genoeg hadden de proefpersonen geen notie van deze compensatie. Om een verhoging van het gemiddelde activiteitsniveau te bewerkstelligen zouden ouderen minder tijd moeten spenderen aan activiteiten met een lage intensiteit, zoals zitten, staan en liggen. Ouderen die actiever willen worden, zou geadviseerd moeten worden om activiteiten met een lage intensiteit om te wisselen voor activiteiten met een middelmatige intensiteit zoals wandelen. Een verhoging van lichamelijke activiteit impliceert niet noodzakelijkerwijs dat men moet deelnemen aan activiteiten met een hoge intensiteit zoals sport-activiteiten.

Het belang van een actievere levensstijl blijkt uit de waarneming dat het habituele activiteitsniveau samenhing met een verminderde oxidatieve stress tijdens inspanning. Het lijkt er op dat bij lichamelijk actievere ouderen de antioxidatieve capaciteit is verhoogd. Het is echter de vraag in hoeverre genetische dan wel omgevingsfactoren hierbij een regulerende rol vervullen.

Uit het onderzoek beschreven in dit proefschrift kan geconcludeerd worden dat 1) een trainingsprogramma van middelmatige intensiteit resulteert in een daling van de niettraining geassocieerde activiteit; 2) training verhoogt de relatieve vetverbranding bij personen met een lage initiële vetverbranding en vice versa bij personen met een hoge initiële vetverbranding; 3) Het gemiddelde activiteitsniveau wordt negatief beïnvloed 
door de hoeveelheid tijd die men relatief spendeert aan activiteiten met een lage intensiteit. Desondanks wordt het activiteitsniveau bij ouderen niet verhoogd door participatie aan hoog intensitieve activiteiten zoals sport; 4) submaximale inspanning, zoals gemeten met antipyrine oxidatie, induceert oxidatieve stress; 5) Zowel training als antioxidant vitamine suppletie heeft geen invloed op deze inspanningsgeïnduceerde oxidatieve stress; 6) Lichamelijk actieve ouderen hebben een verminderde inspannings-geïnduceerde oxidatieve stress in vergelijking met inactieve ouderen. Regelmatige lichamelijke activiteit verbetert de antioxidatieve capaciteit. 


\section{List of abbreviations}

$\begin{array}{ll}\text { AEE } & \text { activity associated energy expenditure } \\ \text { ADMR } & \text { average daily metabolic rate } \\ \text { ANOVA } & \text { analysis of variance } \\ \text { AP } & \text { antipyrine (2,3-dimethyl-1-phenyl-3-pyrazolin-5-one) } \\ \text { ATP } & \text { adenosine triphosphate } \\ \text { m-APOH } & \text { meta- hydroxyantipyrine } \\ \text { p-APOH } & \text { para-hydroxyantipyrine } \\ \text { o-APOH } & \text { ortho-hydroxyantipyrine } \\ \text { BMI } & \text { body mass index } \\ \text { BMR } & \text { basal metabolic rate } \\ \text { CAT } & \text { catalase } \\ \text { CONT } & \text { control group } \\ \text { DEE } & \text { diet-induced energy expenditure } \\ \text { EDTA } & \text { ethyleen-diamine-tetra-acetate } \\ \text { ESR } & \text { electron spin resonance spectroscopy } \\ \text { EXER } & \text { exercise training group } \\ \text { FFM } & \text { fat-free mass } \\ \text { FM } & \text { fat mass } \\ \text { GPX } & \text { glutathione peroxidase } \\ \text { GSH } & \text { glutathione } \\ \text { h } & \text { hour } \\ { }^{2} \mathrm{H}_{2} \mathrm{O} & \text { deuterium } \\ { }^{2} \mathrm{H}_{2}{ }^{18} \mathrm{O} & \text { doubly labeled water } \\ \mathrm{HPLC} & \text { high-performance liquid chromatography } \\ \mathrm{HR} & \text { heart rate } \\ \mathrm{HRR} & \text { heart rate reserve } \\ \text { kg } & \text { kilogram } \\ \text { kJ } & \text { kilojoule } \\ 1 & \text { liter } \\ \mathrm{MDA} & \text { malondialdehyde } \\ \mathrm{MET} & \text { metabolic equivalent (work metabolic rate/resting metabolic rate) } \\ \mathrm{mg} & \text { milligram } \\ \text { min } & \text { minutes } \\ \mathrm{MJ} & \text { megajoule } \\ \mathrm{ml} & \text { milliliter } \\ \mathrm{MS} & \text { mass spectrometry } \\ \mathrm{OH} & \text { hydroxyl radical } \\ \mathrm{P} & \text { probability value } \\ & \end{array}$




$\begin{array}{ll}\text { PAL } & \text { physical activity level (ADMR/BMR) } \\ \text { ppm } & \text { parts per million } \\ \text { r } & \text { Pearson product moment correlation } \\ \text { RER } & \text { respiratory exchange ratio } \\ \text { RMR } & \text { resting metabolic rate } \\ \text { ROS } & \text { reactive oxygen species } \\ \text { rpm } & \text { revolutions per minute } \\ \text { SD } & \text { standard deviation } \\ \text { sec } & \text { seconds } \\ \text { SEM } & \text { standard error of the mean } \\ \text { SMR } & \text { sleeping metabolic rate } \\ \text { SOD } & \text { superoxide dismutase } \\ \text { TBA } & \text { thiobarbituric acid } \\ \text { TBARS } & \text { thiobarbituric acid reactive species } \\ \text { TBW } & \text { total body water } \\ \text { VO } & \text { oxygen uptake } \\ \text { VO } & \text { maximal oxygen uptake } \\ \text { vs } & \text { versus } \\ \text { W } & \text { watt } \\ \mathrm{W}_{\max } & \text { maximal workload capacity } \\ \text { wk } & \text { week } \\ \text { y } & \text { year }\end{array}$




\section{Dankwoord}

Promoveren doe je uiteindelijk in je éntje. Echter zonder hulp van anderen was het nooit zover gekomen. Net zoals bij bijvoorbeeld voetbal zijn niet alleen de scorende spits of de ouderwetse nummer 10 (uitgezonderd J.C.) verantwoordelijk voor het eindresultaat. Daarom wil ik een aantal personen bedanken die direct of indirect een bijdrage hebben geleverd aan het tot stand komen van dit proefschrift.

Allereerst mijn promotor Klaas Westerterp vanwege de enthousiaste, kritische en efficiënte begeleiding die er toe bijgedragen heeft dat ik de afgelopen vier jaar met plezier aan het onderzoek heb gewerkt. Tevens wil ik mijn co-promotor Aalt Bast bedanken voor de erg prettige discussies over het uitgevoerde onderzoek en over datgene wat hiervan uiteindelijk op papier werd gezet.

Verder wil ik Stefan Coolen bedanken voor de prettige samenwerking met Eindhoven en de leerzame introductie in de wereld van de analytische chemie en de vele discussies over van alles en nog wat. Joost van Dongen wil ik bedanken voor de assistentie bij de vele antipyrine metingen op de LC-MS.

Betreffende de uitgevoerde analyses in Maastricht wil ik graag Joan 'Mickey Rourke' Senden en de immer vrolijke Jos 'Vinnie Jones' Stegen bedanken voor de grote medeen tegenwerking. Zonder jullie hulp hadden de vele plasma samples waarschijnlijk nu nog in de vriezer gelegen (of reeds in de autoclaaf). En Joan, de Glenfiddich smaakte overigens erg lekker en omdat deze fles whisky geen eeuwig leven heeft, moeten we binnenkort maar weer eens een weddenschap afsluiten.

Voor de technische ondersteuning wil ik de whizzkids van Humane Biologie Loek Wouters (tevens voor het bepalen van de vele deuterium monsters) en Paul Schoffelen bedanken. Wanneer o.a. mijn 'Power' Mac weer eens het spoor bijster was, was jullie hulp en kennis van zaken onmisbaar.

Mijn dank gaat ook uit naar de eigenaars en instructeurs van de fitnesscentra Scorp en Topfit te Maastricht voor het ten uitvoer brengen van de trainingsprogramma's. In het kader van de samenwerking met de fitnesscentra en de proefpersoonwerving gaat ook mijn dank uit naar Toet Kirsch van stichting Trajekt en Frans Verstappen. Tevens wil ik de vele proefpersonen bedanken voor de medewerking en voor het braaf blijven uitvoeren van de vele opgelegde en strikte instructies van mijn kant om het onderzoek keurig te laten verlopen.

Additionally, I am thankful to Prof.dr. Harm Kuipers, Prof.dr. Jos Kleinjans, Prof.dr. Johan Koster, Prof.dr. Eric Ravussin and Prof.dr.ir. Wim Saris for their time and effort in critically evaluating this thesis.

Vanwege de vele donderdagavonden in de Pub (my goodness, my Guinness), mountainbike-tochten op de woensdagavond, etentjes (Mega Meijer Mixer), cartavonden, hardloopwedstrijden en duurloopjes, congresbezoek (in binnen- en 
buitenland), steengrillen in Charlemagne, de traditionele carnavals-vrijdagavonden en de zgn. werksfeer etc. gaat uiteraard ook mijn grote dank uit naar mijn collega's van Humane Biologie en overig los lopend wild zoals Luc 'Robbie' van Loon (Beaver Lake was zeker indrukwekkend, maar die lady in wet-suit viel toch wel wat tegen), de buurmannen Freddy 'El Ferro' Troost (wellicht beter bekend als voorzitter van de Orgie $^{\circledast}$ ) en Chris 'the butcher' Hukshorn, Joost 'womenator' Oomen (gelukkig was jij tenminste nog éen van de weinige echte voetballiefhebbers bij HB), Michiel 'collega' van Nieuwenhoven, kindervriend Edgar van Mil, Bert 'The Seattle Mariner' Benthem, Dean 'The Leicester Tiger' Sewell (I really hope for you that Leicester will win the FA cup in the near future), Mark Spigt, Marco Mensink, Jochum Plat, Margriet Kruijshoop, buurvrouw Marieke van Ooijen, Marja van der Hulst, Patrick Schrauwen, Reinout Hesselink, Marleen Kamphuis, Eva Kovacs, Guy Plasqui en natuurlijk ons aller Truus Dickhaut. Overigens wil ik Freddy en Joost ook nog bedanken voor het feit dat ze mijn paranimfen willen zijn. Tenslotte wil ik mijn kamergenoot Annelies Goris bedanken voor de leuke tijd de afgelopen vier jaar en het feit dat ik als paranimf bij jou promotie mocht optreden.

Bedankt allemaal! 


\section{List of publications}

\section{Full papers}

Meijer E.P., K.R. Westerterp, and F.T.J. Verstappen. Effect of exercise training on total daily physical activity in elderly humans. European Journal of Applied Physiology 80(1): 16-21, 1999.

Westerterp K.R., E.P. Meijer, M. Rubbens, P. Robach, and J-P. Richalet. Operation Everest III: energy and water balance. Pflügers Archiv - European Journal of Physiology 439(4): 483-488, 2000.

Meijer E.P., K.R. Westerterp, and F.T.J. Verstappen. Effect of exercise training on physical activity and substrate utilization in the elderly. International Journal of Sports Medicine 21(7): 499-504, 2000.

Goris A.H.C., E.P. Meijer, A. Kester, and K.R. Westerterp. Use of a triaxial accelerometer to validate reported food intakes. American Journal of Clinical Nutrition 73(3): 549-553, 2001.

Goris A.H.C., E.P. Meijer, and K.R. Westerterp. Repeated measurement of habitual food intake increases under-reporting and induces selective under-reporting. British Journal of Nutrition, in press.

Meijer E.P., A.H.C. Goris, L. Wouters, and K.R. Westerterp. Physical inactivity as a determinant of the physical activity level in the elderly. International Journal of Obesity, in press.

Meijer E.P., S.A.J. Coolen, A. Bast, and K.R. Westerterp. Exercise training and oxidative stress in the elderly as measured by antipyrine hydroxylation products. Free Radical Research, in press.

Westerterp K.R., and E.P. Meijer. Changes in physical activity patterns with age: a physiological perspective. Journal of Gerontology $A$, in press.

Meijer E.P., S.A.J. Coolen, A. Bast, and K.R. Westerterp. Exercise-induced oxidative stress in older adults as measured by antipyrine oxidation. Metabolism, accepted for publication.

Meijer E.P., A.H.C. Goris, J. Senden, J.L.J. van Dongen, A. Bast, and K.R. Westerterp. Antioxidant supplementation and exercise-induced oxidative stress in the elderly as measured by antipyrine hydroxylates. British Journal of Nutrition, accepted for publication.

Meijer E.P., A.H.C. Goris, J.L.J. van Dongen, A. Bast, and K.R. Westerterp. Exerciseinduced oxidative stress in older adults as a function of the habitual activity level. Submitted for publication. 


\section{Published abstracts}

Meijer E.P., K.R. Westerterp, and F.T.J. Verstappen. Effect of fitness training on daily physical activity and aerobic power. International Journal of Obesity 23(Suppl 3): S79, 1998.

Meijer E.P., K.R. Westerterp, and F.T.J. Verstappen. The effect of 12-wk exercise training on physical activity and substrate utilization in the elderly. Medicine \& Science in Sports \& Exercise 31(5): S379, 1999.

Meijer E.P., S.A.J. Coolen, K.R. Westerterp, and W.H.M. Saris. Antipyrine as a marker for exercise-induced oxidative stress. Pflügers Archiv - European Journal of Physiology 438(5): $\mathrm{R} 71,1999$.

Coolen S.A.J., E.P. Meijer, M. van Lieshout, W.H.M. Saris, and F.A. Huf. Determination of hydroxylated derivatives of antipyrine in plasma with HPLC-Tandem-Mass Spectrophotometry. Proceedings of the Nutrition Society 58(4): 170A, 1999.

Meijer E.P., S.A.J. Coolen, W.H.M. Saris, and F.A. Huf. Antipyrine as a marker for exerciseinduced oxidative stress in untrained young adults. Proceedings of the Nutrition Society 58(4): 170A, 1999.

Goris A.H.C., E.P. Meijer, A. Kester, and K.R. Westerterp. The use of a triaxial accelerometer for the individual reliability of reported food intake. International Journal of Obesity 24 (Suppl 1): S65, 2000.

Meijer E.P., A.H.C. Goris, L. Wouters, and K.R. Westerterp. Mean physical activity level in the elderly is inversely related to time spent on low activity intensity. International Journal of Obesity 24 (Suppl 1): S181, 2000.

Meijer E.P., J. Senden, S.A.J. Coolen, and K.R. Westerterp. Effect of training on exerciseinduced oxidative stress in the elderly as measured by free radical products of antipyrine. Journal of Physiology 528.P, 2000. 


\section{Curriculum vitae}

Erwin Peke Meijer werd geboren op 29 mei 1974 te Hoorn (Noord-Holland), waarna hij opgroeide in Enkhuizen. In 1992 behaalde hij het VWO diploma aan de Rijksscholen Gemeenschap te Enkhuizen. In datzelfde jaar startte hij met de studie Bewegingswetenschappen aan de Vrije Universiteit te Amsterdam, met als afstudeerrichtingen inspanningsfysiologie en sportpsychologie. In september 1996 behaalde hij zijn doctoraalexamen, na een onderzoeksstage bij de toenmalige capaciteitsgroep spier- en inspanningsfysiologie onder leiding van Prof.dr. Arnold de Haan. In maart 1997 startte hij als assistant in opleiding (AIO) bij de capaciteitsgroep Humane Biologie aan de Universiteit Maastricht onder leiding van Prof.dr. Klaas Westerterp. Dit proefschrift beschrijft het onderzoek wat tijdens de promotieperiode is uitgevoerd. 
Erwin Peke Meijer was born in Hoorn (The Netherlands), on the $29^{\text {th }}$ May 1974 . He completed secondary school (VWO) at the Rijksscholen Gemeenschap Enkhuizen in 1992. After this, he started to study Human Movement Sciences at the Vrije Universiteit Amsterdam. During his degree course he achieved a major in exercise physiology and a minor in sports psychology. After a Honours project at the Department of Muscle and Exercise Physiology under the supervision of Professor Arnold de Haan, he graduated in 1996. After his graduation he became a $\mathrm{PhD}$ student in the Department of Human Biology at Maastricht University under the supervision of Professor Klaas Westerterp. The subject of study was physical activity and oxidative stress in the elderly. The research performed during this 4 year $\mathrm{PhD}$ period is described in this thesis. 